\title{
It's The Same Old Story: Rape Representation in New Zealand Newspapers (1975 - 2015)
}

By

Angela Millo Barton

A thesis submitted to the Victoria University of Wellington in fulfilment of the requirements for the degree of Master of Arts in Criminology

School of Social and Cultural Studies

Victoria University of Wellington 


\begin{abstract}
Newspaper reporting of rape, and in particular, representations of women as rape victims, have historically been presented by the media in a misinformed manner, influenced by myths and misconceptions about the dynamics of sexual violence. Previous research has shown media depictions can promote victim-blaming attitudes which affect society's understanding toward sexual violence, promoting false narratives and rape-supportive beliefs. Victim narratives of sexual victimisation struggle within a 'culture of silencing' that prevents the majority of sexual offending from coming to the attention of authorities, and identifying the silencing of women's experiences of rape has, and continues to be, a key objective for feminist scholars. Newspapers are one medium which has been exclusionary of women's experiences, therefore it is important to look at the role of newspapers on a longitudinal level to investigate whether there have been changes in reporting practices and attitudes. To address this issue, this study draws on feminist perspectives and adopts a quantitative and qualitative methodology utilising newspaper articles as a specific source of inquiry. Articles concerning male-female rape were collected from eight prominent New Zealand newspapers across a 40 year period from 1975 - 2015 with individual years for analysis being 1975, 1985, 1995, 2005 and 2015. Results from this analysis show minimal inclusion of women's words regarding newspaper commentary in articles concerning rape. This study also found that across the four decades of analysis, newspapers consistently reported the rape of women by strangers, and sympathetic justice system responses were achieved if the victim was 'respectable' and adhered to an 'appropriate' version of femininity. The findings from this study illustrate discourses that reflect features of a broader social discourse relating to the responsibility of women to protect themselves from rape. The implications from this research can be utilised to better inform journalists in their reporting practices on sexual violence cases in the New Zealand press, with a hope to challenge the way that newspaper reporters and consumers think about constructing rape, and women as rape victims.
\end{abstract}




\section{List of Abbreviations}

ATL - Alexander Turnbull Library

CA - content analysis

CJS - criminal justice system

DFSA - drug facilitated sexual assault

ECA - ethnographic content analysis

FDA - Foucauldian Discourse Analysis

GMMP - Global Media Monitoring Project

INZ - Index New Zealand

MWA - Ministry of Women's Affairs

NZH - New Zealand Herald

ODT - Otago Daily Times

SST - Sunday Star Times

ST - Southland Times

TDN - Taranaki Daily News

TOAH-NNEST - Te Ohaakii a Hine: National Network Ending Sexual Violence Together 


\section{List of Figures}

Figure 1: Total number of articles concerning rape cases across time.......................................45

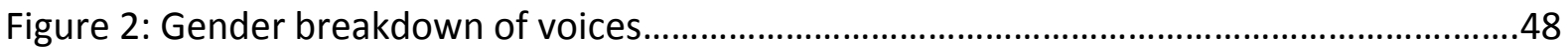

Figure 3: Men's voices measured against the total number of articles......................................49

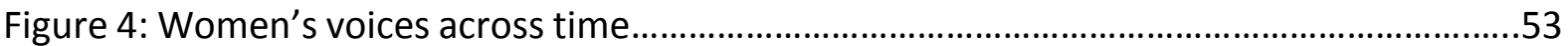




\section{Acknowledgements}

This thesis has been both hugely rewarding and challenging and there are many people I am indebted to for their love and support throughout its completion.

I owe a big thank you to my extensive network of friends that have been there for me in so many ways. To the 'Level 9 Crew' - you know who you are - I have been so lucky to have your support and friendship while writing this thesis. To my partner Kiri who has been there every step of the way, thank you for all your love, support, and late night debriefs when things have been too much. Without you I would not be where I am now. I would also like to thank my family for their unwavering confidence in my ability to achieve anything I set my mind to.

I was lucky enough to have an amazing team of editors who helped make this thesis presentable. Hannah Gibson, Vicki Cowan, Gradon Diprose, Marianne Bevan, Amanda Thomas, Kerry Griffiths, Samantha Keene, and Sophie Beaumont - you are absolute gems!

I would like to extend a big thank you to all the staff on the $9^{\text {th }}$ and $11^{\text {th }}$ floors that have provided me with advice and support throughout. Additionally, the staff at the National Library of New Zealand provided invaluable help and support in my initial phase of data collection and assisting with microfilm requests and technicalities.

To my research assistant Vicki Young - I would not have survived so long at the National Library reading microfilm screens without you! Thank you immensely for all your support along the way and picking me up when I was feeling low (many times).

I owe a huge thank you to the Royal Society of New Zealand Marsden Fund for helping make this research a reality by providing financial support.

Lastly, I am forever indebted to my two amazing supervisors, Associate Professor Jan Jordan and Dr Sarah Wright. It has been a privilege to have your support and guidance over the last year and you both inspire and challenge me in ways I never thought possible. Working with you has encouraged me to push new boundaries, seek 'truth', and fight the patriarchy like never before. I cannot thank you enough for everything you have done and I look forward to working with you in the future. 


\section{Table of Contents}

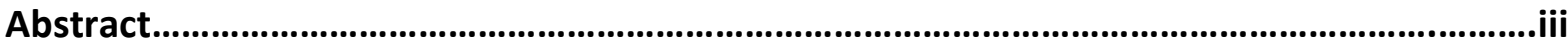

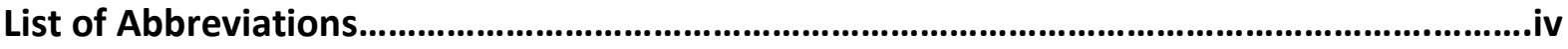

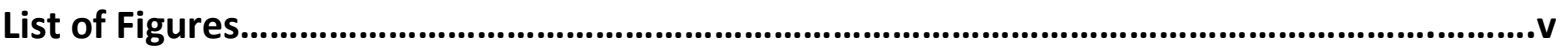

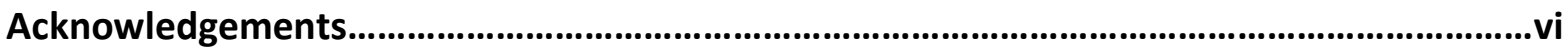

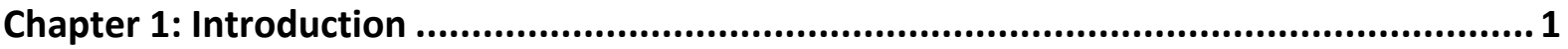

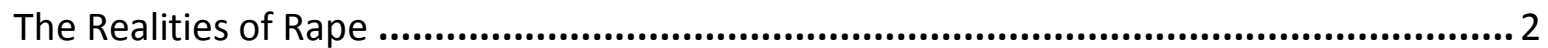

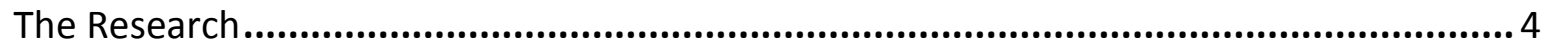

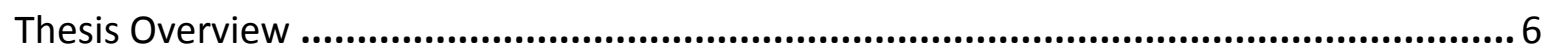

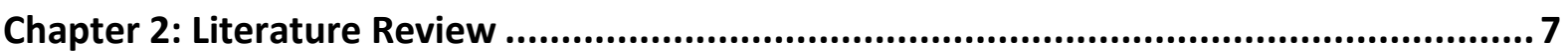

Silencing Women's Words............................................................................. 7

Newspaper Construction: Past and Present ................................................................. 10

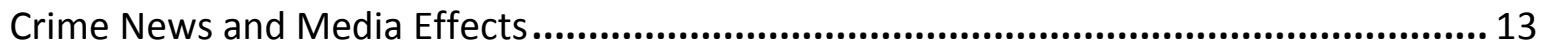

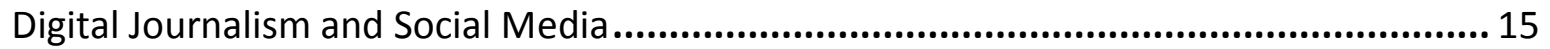

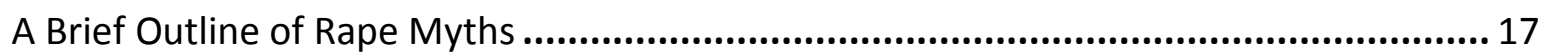

"Roll Up, Roll Up! Read All About It!" International Newspaper Reporting of Rape ......... 19

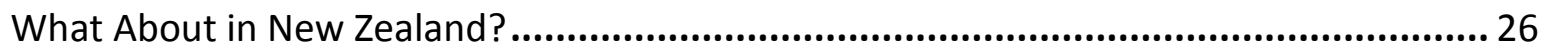

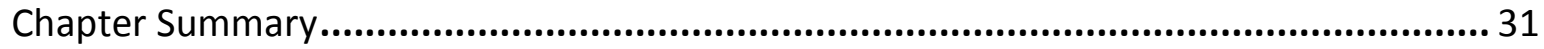

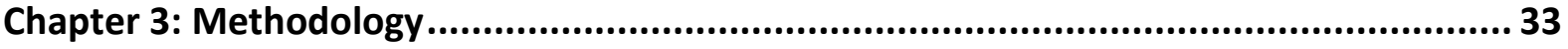

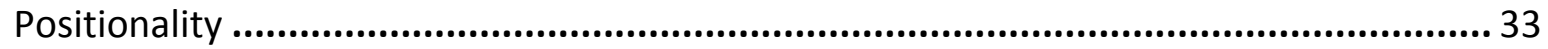

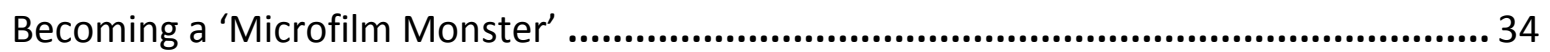

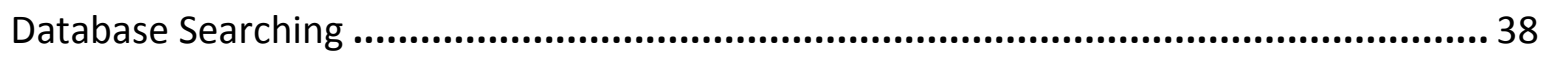

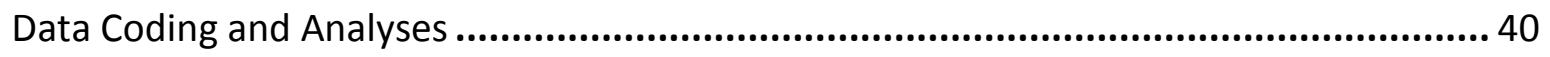

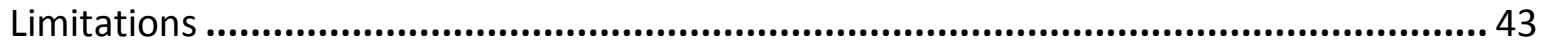

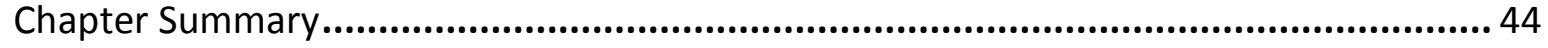

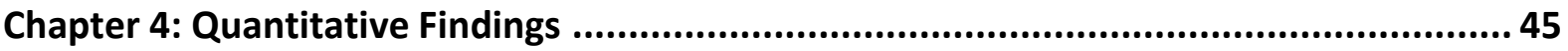

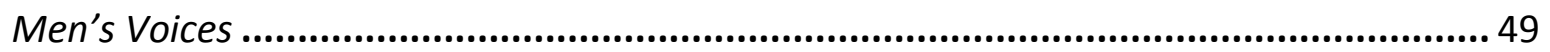

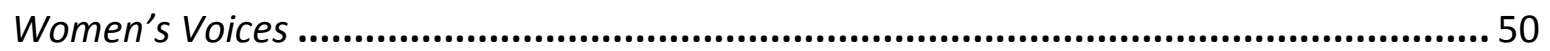

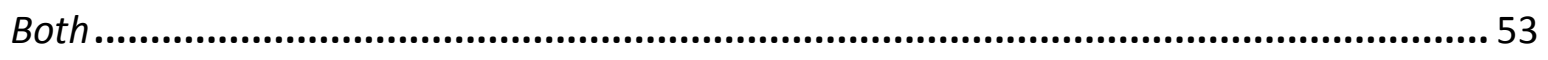

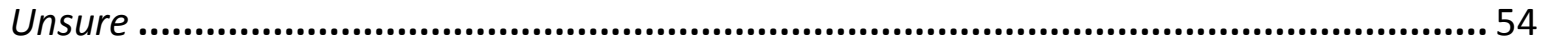

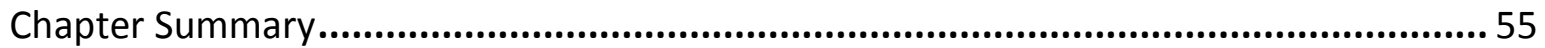

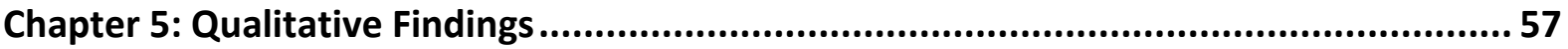




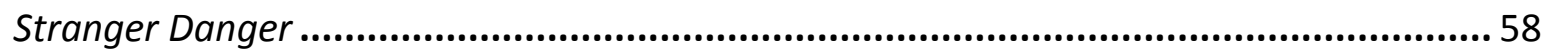

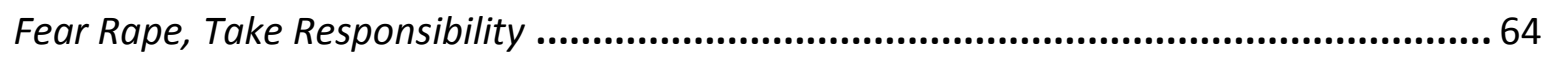

'Real Rape' Only Happens to 'Good Women' ............................................................ 69

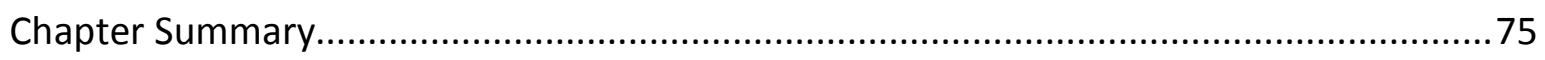

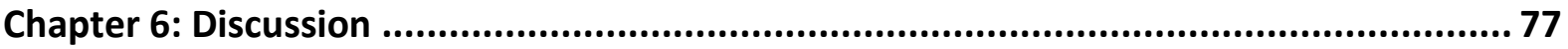

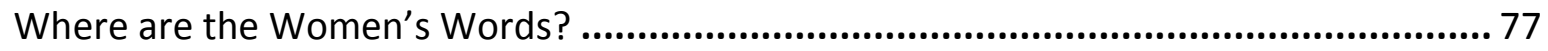

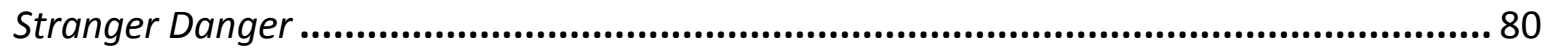

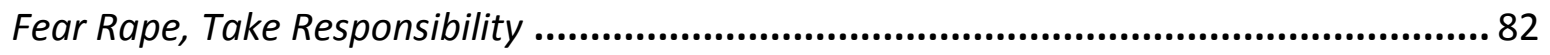

'Real Rape' Only Happens to 'Good Women' ................................................................ 84

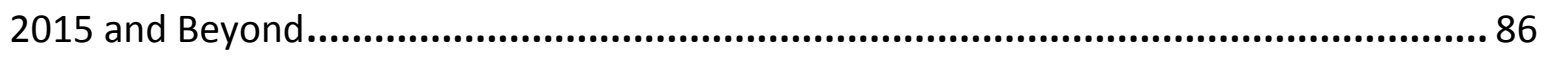

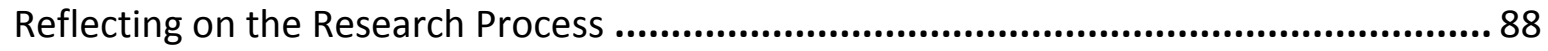

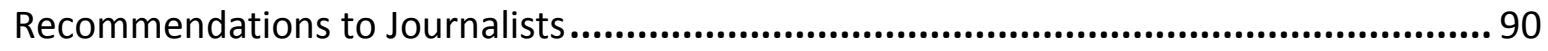

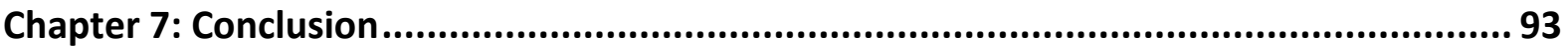

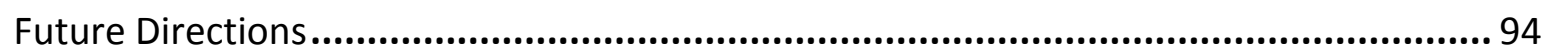

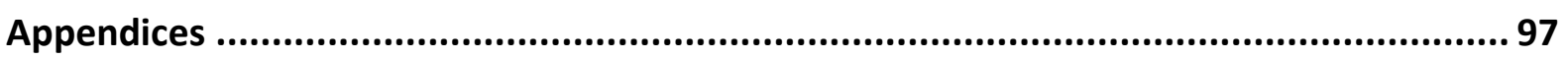

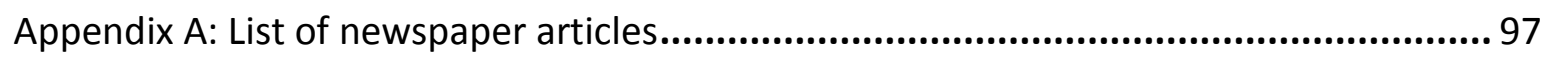

Appendix B: List of newspaper articles with no author ................................................. 98

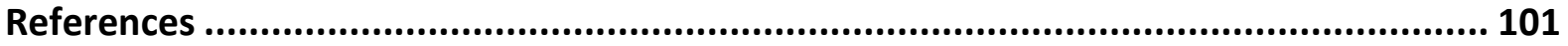




\section{Chapter 1: Introduction}

Rape is one of the most traumatic attacks on women and to say there is no injury

is to perpetuate myths that minimise the effects of rape. Your brutal and

insensitive handling of these stories ignore the very real physical and mental pain suffered by rape survivors (Mussen \& Matthews, 1985).

We know more today about rape's prevalence and the complex dynamics giving rise to its occurrence than ever before. A little over four decades of feminist action and advocacy has improved the many services available for rape victims. As Jordan (2012) has stated: "the reforms of the past 40 years have facilitated an environment within which sexual victimisation research is funded and conducted, inquiries and commissions undertaken, and survivors' narratives published" (Jordan, 2012: 254). However, despite these insights gained and advances made, sociocultural and environmental changes have made little dent in reducing violence against women, rape's occurrence, or the attitudes surrounding it.

Susan Brownmiller (1975) was one of the first second-wave feminists to discuss the long history of myths and misconceptions about sexual assault by challenging patriarchal structures that condoned violence against women. Brownmiller's pioneering work was the first step in unveiling what feminist academics have since termed 'rape culture' ${ }^{1}$. The widespread and normalised nature of rape culture makes it increasingly hard for victims to speak out, as they learn to believe they will not be taken seriously, or are dismissed when they do. One way that dominant social norms are maintained and reinforced is through the objectification and sexualisation of women's bodies within the media. News media remain the major and most influential source of information, ideas and opinion for most people around the world, and newspapers are a primary source of information for many people (Greer, 2013). In New Zealand, this is no different, and newspaper reporting on rape presents some grave concerns in relation to how women as victims, and the very act of rape itself, are represented. Wood and Dickson (2013) have noted that media reporting on sexual violence

\footnotetext{
${ }^{1}$ A rape culture can be broadly defined as an environment in which rape and sexual assault are common. More specifically, it describes a culture in which dominant social norms belittle, dismiss, joke about or even condone rape and sexual assault, perpetuating the idea that sexually objectifying women is simply a way of life (Bates, 2014). Magilsen (2015) adds that a rape culture is underpinned by historical norms that place men in the position of a dominant aggressor while woman are placed in the position of the submissive and inferior party. These prevailing social attitudes have the effect of normalising or trivialising sexual violence.
} 
is often ill-informed and the media are a key agent in creating and perpetuating myths and misconceptions about the dynamics of sexual violence. This misinformation affects society's shared understanding of, and attitudes toward sexual violence, promoting false narratives and rape-supportive beliefs in society (Wood \& Dickson, 2013). It is alarming that there are still significant pockets of victim-blaming and minimising discourses of rape in the influential medium of newspapers. Such misinformation may influence the social structures for preventing rape and responding effectively to women who have been raped, which are still inadequate (see Gavey, 2005).

A substantive body of international research documents how newspapers report on sexual violence with regards to how women are represented and objectified (Boyle, 2005; CaringellaMacDonald, 1998; Carter, 2002; Heath, Gordon, \& LeBailly, 1981; Kitzinger, 2004; Meyers, 1997; Moore, 2009; Soothill \& Walby, 1991), however little New Zealand data exists on the issue. This thesis addresses this literature gap and provides the first longitudinal insight into how a range of New Zealand newspapers report on rape and how women are discussed in regards to this type of crime. It is crucial to critically analyse the discourse surrounding rape against women because it is a gendered crime - it is overwhelmingly and undisputedly men who perpetrate these offences (Ujevic, 2015).

\section{The Realities of Rape}

When attempting to quantify any information regarding rape, there is difficulty creating an exact picture of prevalence and incidence rates both internationally, and in New Zealand. Sexual violence is hard to measure as these crimes go largely unreported, which means that statistics may fail to reflect the problem in full. Attempts have been, and continue to be made, however, to quantify rape incidences which show a high prevalence of sexual violence in our communities (Rape Prevention Education, 2011b). Figures from Te Ohaakii a Hine - National Network Ending Sexual Violence Together ${ }^{2}$ (TOAH-NNEST) state that approximately one in three women will report they experience unwanted and distressing sexual contact over their lifetime (Wood \& Dickson, 2013) and it is estimated that one in five adult women will

\footnotetext{
2 TOAH-NNEST is an umbrella organisation that acts as a 'national voice' for sexual violence service providers in New Zealand.
} 
experience some form of sexual assault as an adult (Fanslow \& Robinson, 2004; Rape Prevention Education, 2011b). Findings from the New Zealand Crime and Safety Survey showed that the lifetime experience of sexual violence was $28.3 \%$ in $2006,24.8 \%$ in 2009 , and 23.8\% in 2014 (New Zealand Family Violence Clearinghouse, 2016).

As mentioned, reporting of sexual violence is extremely low, with an estimated $9 \%$ of incidents ever reported to police (Ministry of Women's Affairs, 2009; Mossman, Jordan, MacGibbon, Kingi, \& Moore, 2009a; New Zealand Family Violence Clearinghouse, 2016; TOAH-NNEST, 2013) and conviction rates are also very low, with approximately only $13 \%$ of cases recorded by the police resulting in conviction (Triggs, Mossman, Jordan, \& Kingi, 2009). Commonly occurring reasons why many sexual offences go unreported include feelings of shame, guilt or embarrassment, disbelief in the criminal justice system, fear of consequences, and concerns about not being believed (McDonald \& Souness, 2011; Mossman, MacGibbon, Kingi, \& Jordan, 2009b). Other deterrents such as family pressure can contribute to underreporting and attrition (Ministry of Women's Affairs, 2009).

It is critical to clarify the definition of rape used in this research. New Zealand's legal age of sexual consent is 16 (Age Of Consent, 2017) and the crime of 'sexual violation' can be committed in one of two ways: either by 'rape' or by 'unlawful sexual connection' (Crimes Act 1961, s.128 NZ; Rape Prevention Education, 2011a). 'Rape' means the penetration of the genitalia by the penis, without consent, although the slightest penetration is enough and is primarily aimed at being between a male and female (although either the offender or victim may have had gender reassignment surgery) (Rape Prevention Education, 2011a; Wood \& Dickson, 2013). 'Unlawful sexual connection' includes a much wider range of offending forcing someone to give or receive anal sex or oral sex, same-sex offending, and offending with an object. It is still a 'sexual connection' no matter how slight the contact with the offender's genitalia or anus, or with the survivor's genitalia or anus - it includes penetration, and it includes touching (Wood \& Dickson, 2013). There are additional specific sexual assault types, such as incest, sexual harassment, and child sexual abuse that, although extremely important points of investigation, will not be pursued in this thesis.

It is also important to clarify the terminology used in this thesis when discussing women's experiences of rape in newspaper media. There is substantive debate about the usage of the terms 'victim' or 'survivor' when discussing women's experiences of sexual violence. This 
debate stems from awareness that the term 'victim' can be a reinforcement of women's passivity, whilst 'survivor' equates with "active resistance and a sense of agency" (Jordan, 2001: 9). I recognise that this journey from victim to survivor can be a difficult one, with both terms likely to be relevant to different aspects of women's experiences at varying times of their lives (Jordan, 2013; Kelly, 1988). This terminology reflects that not all people who are raped assume the victim label, yet at the same time, survival is neither assured nor necessarily immediately apparent: some women may always deem it a 'work in progress' (Mossman et al., 2009a). The term 'victim-survivor' is sometimes used instead. This study, which looks in detail at constructions of the 'victim' category in the press, recognises that the term 'victim' is inherently problematic, and is wary of reproducing harmful stereotypes. I am mindful of this going into my research, yet because newspaper accounts most often use the term 'victim' when discussing rape, the term 'victim' will be used throughout this thesis (see Marhia, 2008; Ujevic, 2015).

\section{The Research}

This thesis forms one component of Associate Professor Jan Jordan's Marsden scholarship titled Rape, silencing and objectification: A socio-cultural analysis of barriers to rape reform. The Marsden project's overall aim is to explore how the ongoing silencing and objectification of women, as evidenced in a range of media forms (newspapers, women's magazines, and pornography) contribute to the sociocultural environment in which rape both occurs and is responded to by the criminal justice system (CJS). The objective of my research is to explore and identify the different ways that male-female rape is discussed within eight prominent New Zealand newspapers and assess the extent in which women have been represented in rape reports over time.

A further research aim is to analyse whether shifts have occurred in relation to the reliance on gender stereotypes and the perpetuation of rape myths. In accordance with the Marsden project's criteria, a 40 year period is examined from 1975 - 2015, with individual years for analysis being 1975, 1985, 1995, 2005 and 2015. These years were selected to give a representative view of each decade's depiction of rape. Informed by feminist theory, my research explores how rape is constructed in articles from New Zealand's five main daily urban newspapers: the New Zealand Herald (NZH), The Dominion and The Evening Post 
(merged as one publication to become The Dominion Post in 2002), The Press, and the Otago Daily Times (ODT). These newspapers were selected because they have the highest circulation figures for daily newspapers in New Zealand and therefore provide a good representation of the way the news, in general, is presented in the New Zealand press (Thakker \& Durrant, 2006). In addition, one national weekly was selected: the Sunday Star Times (SST), and two regional publications: the Southland Times (ST) and the Taranaki Daily News (TDN).

To achieve this, a quantitative content analysis (CA) was adopted to count the total number of articles across each of the five individual years, then a deeper level of analysis involved using an ethnographic content analysis (ECA) methodology to understand the communication of meaning and allow themes to emerge from the data. Following this, two questions were adopted to guide the research process and were inspired by Carla Willig's (2008) interpretation of a Foucauldian Discourse Analysis (FDA):

\section{How is rape being represented and/or constructed in the articles?}

2. What results from representing and/or constructing rape (and women) in this way?

The impetus for this research comes from the Marsden project and my own personal research interests in the area of sexual violence. It also comes from a place of concern about not only the levels of sexual violence in New Zealand, but how newspaper media report on rape and women as victims and the consequences that arise from this. Rape is recognised as being predominantly a crime in which the victim is female and the perpetrator is male. I am aware that sexual violence happens to individuals of all genders and identities, but for the purpose of this research, my focus is on male perpetrators and female victims where the woman is aged 16 or above. This thesis does not cover all sexual crimes - the reporting of sexual assault on children under 16 and incest is not included in this study, nor is indecent assault. This thesis does not represent the reality of rape to actual women who have been raped, or necessarily those women who live in fear of it happening to them. The impact of rape on women's lives is best understood through listening to the experiences of those who have survived, which is quite different from the information I have examined. As Heather Bauchop noted nearly 30 years ago when conducting New Zealand newspaper research on rape representation: "the pain and destruction cannot be found through newspapers, but it always is the reality that stirs beneath the words that I write" (Bauchop, 1990: 6). However, it is important to examine 
rape's representation in newspapers because the language used can reveal underlying assumptions about what was expected or acceptable behaviour from both men and women, and newspapers provide a valuable indicator of these aspects (Bauchop, 1990).

\section{Thesis Overview}

This thesis draws on newspaper articles as a specific unit of inquiry to examine the way that rape and women as victims have been represented over a 40 year period from $1975-2015$. Although this research is largely exploratory in nature, it is hoped that the findings will contribute to a greater awareness of how New Zealand newspapers report on rape and what could be implemented regarding journalistic protocols to better represent women as rape victims. Furthermore, it is hoped that the findings will challenge the assumptions underpinning rape myths which support the crime. Having highlighted the New Zealand context for this research and outlined the research aims, Chapter Two reviews relevant literature on media practices and newspaper representations of rape both internationally and locally, whilst acknowledging the use of digital and social media in today's current climate of journalism. Chapter Three discusses the methodological approach for this research, outlining the research methods used as well as the limitations and personal challenges faced throughout. Chapter Four showcases my findings from the quantitative CA across the four decades and presents a gendered breakdown of 'voices' in the articles analysed. Chapter Five outlines my qualitative findings showcasing three dominant themes that emerged across each of the five individual years: 'stranger danger', 'fear rape, take responsibility', and 'real rape' only happens to 'good women'. Chapter Six discusses my findings in relation to these three themes and explores the way that digital and social media can influence newspaper reporting on rape. Lastly, Chapter Seven concludes this thesis, and looks at future directions for change regarding New Zealand newspaper reporting of women as rape victims. 


\title{
Chapter 2: Literature Review
}

\author{
Hey mainstream media, it's not lewd or vulgar, it's criminal and illegal. It's not \\ groping, it's sexual assault. It's not jock talk, it's rape culture (sign observed \\ outside the Hobart Resistance Centre, Tasmania, November 2016).
}

This chapter provides a review of the literature on newspaper reporting of male-female rape and how women are represented and objectified as victims in regards to this type of crime. The review begins by outlining how women's words and perspectives are typically omitted regarding the reporting of rape in newspaper media before discussing early newspaper construction techniques and how traditional modes of production have developed to form a new 'mediascape'. The chapter then shows how 'crime news' has traditionally been reported in newspapers before illustrating how digital journalism and social media technologies influence news reporting. A brief description of rape myths is then provided as a preface to understanding how rape is represented in newspapers both internationally and in a local context. While there is a strong base of sexual violence research in New Zealand, and previous attempts have been made at analysing newspaper representations of rape and sexual assault (Bauchop, 1990; Lynch, 2015; Magilsen, 2015; Mitchell, 2001; Ruth, 1984; Wood \& Dickson, 2013), a literature gap exists on a longitudinal level with regards to analysing a wide range of newspapers over a long time period, hence the importance of this study. Further, this chapter only investigates studies of heterosexual rape in newspaper media as the objective of this research is to examine reports where the perpetrator is male and the victim is female ${ }^{3}$.

\section{Silencing Women's Words}

Within the context of patriarchy, a long history exists of silencing women's voices. Historically and cross-culturally, the overt use of rape has functioned as a key mechanism for perpetuating patriarchal control (Brownmiller, 1975; Jordan, 2004; Kelly, 1988; Stanko, 1985), particularly in the context of power relations within intimate partnerships (Jordan, 2012). In light of this, a key challenge for feminists has been to challenge traditional understandings of sexual violence and the ways in which these have shaped discourse, representation, language

\footnotetext{
${ }^{3}$ It should be noted that men, women, and other sexual minority groups can be, and are, victims of sexual violence perpetrated by persons of the same or opposite sex. However, these cases are rarely if ever reported in New Zealand's newspaper media, and such an investigation would be worthy of future research.
} 
and identity (Kitzinger, 2004). In the late 1990s, feminist linguist Deborah Cameron illustrated in her book The Feminist Critique of Language, that 'silence' has been a powerful metaphor in feminist discourse, used to figure all the ways in which women are denied the right or opportunity to express themselves freely whether in a written or spoken sense (Cameron, 1998). One of the most concerning findings in the sexual violence literature is the way that women's words have been documented (read omitted) in regards to rape. Taslitz (1999) has noted that "silencing is a hallmark of oppression, and there is an association between the degree to which a society silences its women and the prevalence of rape" (Taslitz, 1999: 20). Taslitz (1999) argues that women who speak up about being raped 'break the rule of silence' in that they risk either being blamed for what happened, or being disbelieved for saying what happened. In other words, the failure to report rape is an interesting play on the silence theme because our cultural narratives teach women that silence is a sex-appropriate behaviour. Women's initial reaction to rape, then, is often fully consistent with cultural expectations: silence (Taslitz, 1999). This occurs in the contexts of rapists' efforts to control victims. One way they maintain their position of privilege is by undermining the voice and the perceptions of those whom they wish to keep powerless. Put simply, to silence rape is to silence women (Jordan, 2012).

The exclusion of women's words in newspapers has been researched internationally and locally, and provides an important focal point for my study in how women's words are silenced regarding rape reports. Linguists at Lancaster University in the United Kingdom studied 18 Australian newspapers with articles published over a twelve month period from August 2015 to July 2016 (Lukin, 2016). The study sought to investigate what the language of news coverage revealed about gender imbalances and provided some interesting findings. Data included all news articles that contained one of the following keywords: Australia, Australian, or Australians, and of nearly 100,000 distinct words used in the collected news articles 'he' was the sixteenth most frequently used. By comparison, the equivalent female pronoun 'she' was the sixty-sixth most frequently used. 'She' turned up 11,765 times while 'he' appeared more than 40,000 times (Lukin, 2016). That makes the ratio of 'he' to 'she' in Australian news reporting 3.4 to 1 and of the articles in the corpus, 'he said' appeared 9,892 times compared to 'she said' at 2,709 - a ratio of roughly 3.6 to 1 (Lukin, 2016). Given our close associations with Australia, this has implications for New Zealand because it says 
something important about whose voices are being heard in Australian news media (overwhelmingly men's), and the evidence is a rich source for understanding how newspapers project stories and voices.

The Global Media Monitoring Project (GMMP) is the world's longest-running (since 1995) and most extensive research on gender in the news media. Occurring at five yearly intervals, the project measures the overall presence of women and men in the news, as news subjects. New Zealand has taken part in every GMMP since 1995 and the most recent analysis from 2015 highlighted some interesting findings. The sample comprised 172 stories across a range of media sources such as newspapers - New Zealand Herald (NZH), The Dominion Post, the Manawatu Standard, and the Otago Daily Times (ODT) - television, radio, and online news sites. The NZH website and Stuff $f^{4}$ were also incorporated as these sites are the main online news providers in New Zealand (Fountaine, 2015). The study indicated that across the traditional media platforms of newspaper, television, and radio, women were just $18 \%$ of news subjects. New Zealand's 2015 results were lower than the global average of women as $24 \%$ of persons heard, read about or seen in the news (the same global average as achieved in the GMMP 2010), which is a marked drop from New Zealand's 2010 findings where women were $23 \%$ of news subjects (Fountaine, 2015). Results from 2005 showed that $26 \%$ of news subjects in New Zealand were women, concluding that women are becoming less visible as news subjects at each subsequent year of analysis. Fountaine (2015) found that overall, $46 \%$ of New Zealand newspaper reporters in 2015 were women, although both female and male reporters were less likely than the global average to write stories which focus centrally on women. Around the world, $14 \%$ of stories were by women reporters and $9 \%$ by male reporters focus on women; in New Zealand, these figures were $11 \%$ and $8 \%$ respectively (Fountaine, 2015). Furthermore, women made up only $19 \%$ of quoted sources in print news stories from 2015 reflecting the challenges of news media sexism and gender bias across time and content delivery platforms. What can be concluded from the GMMP study is that the world reported in the news is therefore, mostly male (Fountaine, 2015).

\footnotetext{
${ }^{4}$ Stuff is a news website that includes national and local content from The Dominion Post, The Waikato Times, Taranaki Daily News, The Marlborough Express, The Nelson Mail, The Press, The Timaru Herald, and the Southland Times.
} 
Similarly, silencing has also been found in New Zealand newspapers on Māori representation. A 2014 study (Rankine, Moewaka Barnes, McCreanor, Nairn, McManus, Abel, Borrell, \& Gregory, 2014) sampled news items from more than 120 local, regional, and national newspapers over a six month period between 1 November 2007 and 30 April 2008, made up of 21 sampling days to make three constructed weeks of reporting. This study was compared with two previous pilot studies in 2004 and early 2007. The authors found in their sample of 858 news items that mass media covered Māori stories at very low rates in New Zealand newspapers - around one story per paper per day - which even in non-daily papers amounted to less than $3 \%$ of total stories (Rankine et al., 2014). Regarding gender, male sources outnumbered female sources by more than 2:1 in all three studies, and Pākehā men made up the biggest group by gender and ethnicity in the 2008 and the 2004 representative samples (Rankine et al., 2014). Male sources were quoted for longer (68\% of total) whereas women spoke only $29 \%$ of total sentences. Furthermore, there was a narrow range of topics covered, and Pākehā sources were prioritised over Māori, even in articles specifically about Māori issues (Rankine et al., 2014). Their findings raise concerns about the role that mass media play in reinforcing dominant norms, but also point to potential for change.

What these two studies illustrate is that women and Māori citizens are vastly underrepresented in newspaper reporting, and are rarely seeing themselves reflected in this medium. The media can be seen then, to privilege some voices - those voices of power. When thinking about and analysing how women as rape victims are represented in New Zealand newspaper media, these issues of silencing will be of salient importance to address in my study. I will now turn to a discussion of newspaper construction, what makes a story 'newsworthy', and how the rise of the digital and social media landscape can affect sexual violence reporting.

\section{Newspaper Construction: Past and Present}

In a functioning democratic society the public need clear and truthful accounts of events, of their background and their causes, a forum for discussion and informed criticism, and a means whereby individuals and groups can express a point of view or advocate a cause (New Zealand Law Commission, 2013). The expectation then, is that the news media perform these core 
democratic functions, and that the principles of objectivity and balance are followed. However, what we see in the news does not always reflect reality.

For more than half a century, gatekeeping theory has helped scholars and journalists alike understand the key decisions involved in selecting, shaping, and presenting words and images inside the newsroom (Schwalbe, Silcock, \& Candello, 2015; White, 1950). Early definitions of the newspaper gatekeeper were pioneered by David White (1950), where he recognised that the decisions of a newspaper gatekeeper were "highly subjective" and "reliant upon valuejudgments based on the gatekeeper's own set of experiences, attitudes, and expectations regarding the communication of 'news'" (White, 1950: 386). Four decades later, the role of the 'gatekeeper' was defined by O'Sullivan and colleagues as "those personnel, such as editors, who occupy strategic decision-making positions within news media organisations" (O'Sullivan, Hartley, Saunders, Montgomery, \& Fiske, 1994: 126). What shapes news production also concerns the assumptions media professionals make about their audience. In a process known as 'agenda setting theory' (Cohen, 1963), media professionals will sift and select news items and prioritise some stories over others, with a view to set the agenda or tell people what they should be thinking about.

News content is generated and filtered primarily through reporters' sense of 'newsworthiness' - what makes a good story that their audience wants to know about. 'News values' work collectively to inform the selection and production of events as news, and core values include immediacy, dramatisation, personalisation, titillation, and novelty (Greer \& Reiner, 2015; Jewkes, 2011). Editors and journalists select, produce, and present news according to a range of professional criteria that are used as benchmarks to determine a story's 'newsworthiness'; if a story does not contain at least some of the characteristics deemed newsworthy, it will not appear on the news agenda (Jewkes, 2011). Bennett (2004) argues that news content is shaped by interactions among the four main news gates: (1) the reporter's news judgment values, (2) organisational newsgathering routines, (3) economic constraints, and (4) information and communication technologies. In light of this, newspaper reporting on rape is therefore shaped and influenced by a variety of factors including the journalists' attitudes and opinions towards female victims of rape and sexual assault. News values, then, are judgments about the public appeal of a story and whether it is in the public interest. A story does not have to conform to all the criteria in order to make the news, 
although events that score highly on the newsworthiness scale are more likely to be reported. Jewkes (2011) notes that 'sex' is one of the most salient news values especially in the tabloid press, but also in broadsheets and other media.

Newspapers also do not present everything that happens, nor everything they know about. As Sally Ruth (1984) noted when writing for Broadsheet ${ }^{5}$ magazine, the selection of what is emphasised, what is ignored, the use of language, and the idea behind the judgement of 'newsworthiness' are all individual and subjective procedures. Both the style and the claims of newspaper journalism suggest a non-judgemental representation of what others have said or done. Therefore, the public often hold a view of media reporting as the truth and construct their own assumptions of reality around those presented by newspapers (Ruth, 1984). The role of the 'media as truth' was later discussed by Marie-Christine Leps (1992) in her study of English and French newspapers in the nineteenth-century. Leps (1992) outlined that the question of whether or not newspapers provided the truth to their readers is thus readily answered: newspaper knowledge was indeed true, in that it actively sustained and participated in the discursive production of knowledge and power, which generated the 'truth' of the time. Textual mechanisms allowed newspaper reports to appear neutral. Reality is a given, truth is absolute and cumulative, and language is transparent - giving the constant message that social order was maintained (Leps, 1992).

Neale (2015) argues that New Zealand's media industry cannot be considered as reliable nowadays due to commercial motivations which result in inconsistent accountability that exist only when there is a 'newsworthy' story. If a strong, independent media is an essential part of any functioning democracy, and the importance of freedom of speech in our society is valued, significant improvements to the functioning of media will not work if their profit driven nature means it will only report what is of interest to a significant proportion of our population. This, argues Neale (2015) is what makes the media an inconsistent form of accountability. The next section briefly discusses the ways that crime news is constructed with regards to sexual violence reporting and how 'media effects' can influence public opinion on these types of crimes.

\footnotetext{
${ }^{5}$ Broadsheet, a monthly feminist magazine produced in Auckland from 1972 to 1997 and sold throughout New Zealand, played an important part in women's activism. Reporting on everything from politics to art to sexuality to crime, the magazine was a forum in which women expressed a broad range of concerns.
} 


\section{Crime News and Media Effects}

Crime narratives and representations are, and have always been, a prominent part of the content of all mass media (Greer \& Reiner, 2015). Very few people have experiences of criminal incidents and issues; hence newspapers are an important medium through which the public learns about crimes and victims, and are a primary source of information for many people (Greer, 2013; Thakker, 2012; Ujevic, 2015). Newspapers also hold the capacity to be an important opinion-former (Pratt, 2007; Ujevic, 2015). Greer (2013) states that the media are key producers and purveyors of 'knowledge' (truth) about crime, disorder and control, yet crime news follows markedly different patterns to both the 'reality' of crime and its representation in official statistics (Jewkes, 2011). Contemporary news coverage is further dominated by 'sensational' stories about violent crimes, which means that a small number of quite extreme cases are what contribute primarily to an individual's concepts of criminals and crimes (Thakker, 2012). Benedict (1993) explains that when the press reports a sex crime, it also reflects the public opinions elicited by that crime. In relation to crime news, 'sex' remains one of the most salient news values today, where newspapers will over-report crimes of a sexual nature, potentially exaggerating fears of violence against women (Clifford \& White, forthcoming; Jewkes, 2011). Yet sexual assaults by someone known or related to the victim are generally regarded as routine and 'pedestrian' and may contain only limited analysis (Cere, Jewkes, \& Ugelvik, 2014).

These effects on our conception of crime and justice linger because they provide knowledge (truth) that becomes permanently incorporated into our socially constructed world models (Surette, 1994, as cited in Thakker, 2012). The volume and nature of crime reporting further enlarges the dimensions of this problem and increases the immediacy of its threat, making it seem one that is acute, requiring drastic and dramatic action (Pratt, 2007). Given the potential influence of the news media on public opinion and public policy, and the often highly distorted image of crime offered by newsmakers, analysis of news coverage is therefore an important endeavour (Thakker \& Durrant, 2006). As Fowler (1991) and Greer (2013) have noted, the news media select events for reporting according to a complex set of criteria of newsworthiness; so news is not simply that which happens, but that which is regarded and presented as 'newsworthy'. One role of the media is to create a 'second-hand reality' for the public by exposing them to events and experiences which are out of the range of their own 
life space. In cases such as rape, where direct experience is not available to the public, the media serve a large role in defining this truth (Heath, Gordon, \& LeBailly, 1981).

Elisabeth Noelle-Neumann's 'spiral of silence' theory, originally developed in 1974, suggests that we respond to media coverage of a major event or issue by seeking to assess public opinion on the topic, and that assessment shapes our actions (Noelle-Neumann, 1993). This theory can be used to help explain the public attitudes to rape victims. In her pioneering work, Noelle-Neumann examined public opinion as a form of social control in which individuals, almost instinctively sensing the opinions of those around them, shape their behaviour to prevailing attitudes about what is acceptable. If we believe our own views are not widely held, we tend to remain silent in order to avoid social isolation (Noelle-Neumann, 1993). By doing so, we contribute to public opinion as others perceive it, resulting in a spiral effect in which seemingly dominant views gain even more ground while alternatives retreat still further. The news media are not only the original source of coverage but are instrumental in shaping impressions about which views are dominant and which are in decline; these impressions then inform our decisions about what we might, and might not, safely say publicly without becoming isolated from our social group (Noelle-Neumann, 1993). These notions are consistent with a Foucauldian notion of discourse in that how we talk about things (e.g. the female rape victim) can limit how we think and act in relation to those things (e.g. the female rape victim). Insights from media criminology have shown that the construction of media narratives are an increasingly important format by which crime news is presented (Clifford, 2016; Wright Monod, forthcoming), thus we should remain critical of the ways sexual violence is portrayed to us as public knowledge about rape has long been dominated by rape myths.

In our post-millennium technological era, news media is undergoing change which in turn, affects the ways in which news is produced and consumed. The rise of digital journalism and social media technologies has dramatically changed the way audiences receive news, with stories available at unprecedented speed and volumes. Journalists now have multiple platforms with which to disseminate content, which raises some key questions about the nature of how these technologies contribute to the way that sexual violence stories are reported. This aspect will be explored in the next section of this review. 


\section{Digital Journalism and Social Media}

News now comes to us via digital, social media, and mobile platforms. Gaffey (2016) argues that digital and social media websites are being extensively used as news sites, providing a new 'type' of media for the public. Where legacy media sources (traditional forms of news media such as newspapers, television, radio) take a day to react to events, reactions in social media communities may occur in hours or even minutes (Wright Monod, forthcoming). Contemporary online journalism is, among other things, immersive, interconnected, individualised, iterative and instantaneous - verifiable news stories are now beginning to be carried first by social media versions of traditional media groups and then followed by indepth reporting in the traditional media (Pfeffer, Zorbach, \& Carley, 2014). It has been debated that the internet and social media have democratised traditional media and given greater voice to ordinary people. The 'citizen journalist' is an example where anyone, it seems, can be a journalist in the new age, and consumers are playing a more active role in searching out information, allowing them to become informers and informants themselves (Edwards, 2016; Gaffey, 2016).

One significant gap in the literature is how the influence of digital journalism and social media operates in today's climate for news production regarding sexual violence cases. The widespread availability of news, the speed and volume with which it is disseminated, and the influences of digital, social, and mobile media are increasingly becoming an important information source for those seeking news. It is important to consider how the arrival of digital, social, and mobile media has changed the way that news is both produced and consumed, and what changes there have been in relation to the intersections between legacy media and social media (Wright Monod, forthcoming).

A report from the US-based Pew Research Centre found that although the American newspaper publishing industry has been struggling for some time, 2015 was perhaps the worst year for newspapers since the global financial crisis and its immediate aftermath. The report stated that $81 \%$ of Americans received their news online, while around $62 \%$ received their news via social media (Mitchell \& Holcomb, 2016). Where newspapers had expected a bounce-back after the 2008 collapse in advertising, it turned out to be a structural change, 
with the economic crisis only masking the rapid impact of digital technology on a slow-moving industry (Smellie, 2016).

In New Zealand, newspaper organisations put a huge amount of resources and effort into developing and promoting their own news websites and use a range of social media platforms to disseminate their news. 'Clickbait journalism' is becoming the norm (Edwards, 2016; Hutchison, 2016) and social media use highlights the ease with which audiences can construct their own truth - people can pull information from a wide variety of sources at any time and build a truth for themselves (Illingworth, 2016). In 2015, the NZH, which until recently had the country's best array of columnists, merged its news with Newstalk ZB radio, cutting various critical commentators and replacing them on the NZH website with the opinions of talkback hosts (Hager, 2016). Hager (2016) argues that we are no longer getting what we expect and need from news as many important subjects do not get discussed and probed which results in the media having less capacity to dig and scrutinise, too few informed commentators and critics, and not enough healthy space for ideas and debate to be heard. Although social media has opened up new opportunities and given people wider access to communications, it also provides no sense of context. Edwards (2016) argues that is why professional journalism remains crucial to making sense of the mass of information thrown at people. Despite this, a huge challenge remains for traditional newspaper media in New Zealand to ensure their stories remain relevant and credible to their readers (Edwards, 2016).

As Barnaby Bennett, publisher and co-founder of Freerange Press, commented to Radio New Zealand on the state of journalism:

It's not so much that journalism is 'falling apart', but that the ecology is shifting. Rather than there being two or three or four 'big players' and these old conventional newspaper and radio models, it's reconfiguring. I think some of the talent's just moving into different vehicles of distribution and production and how that actually settles is yet to be known and it may just keep moving for the next ten or fifteen years (Bennett on Hill, 2016).

Digital journalism by its nature lends itself to allowing stories to evolve and permitting feedback from consumers to become part of the news gathering and editing process. Digital audiences can therefore have a greater effect on news selection because of increased 
interaction between users and journalists (Boczkowski, 2004). As Robinson (2011) has argued, it makes sense then to consider 'journalism as process' - a compelling need to consider news not as a distinct product but as a shared, distributed action with multiple authors engaged in shifting relationships (Robinson, 2011). Through the impact of new information technology, ordinary people are increasingly provided with the opportunity to make, report, and comment on the news themselves, which ensures that establishment elites no longer have exclusive control of knowledge and information (Pratt, 2007). These factors will arguably have an effect on reporting of rape and sexual violence cases and are worth exploring (see Lynch, 2015). Although my research is not investigating the ways in which rape is represented in digital and social media, these developments may impact on reporting practices in 2015, a factor I will consider the implications of in Chapter Seven. Due to the increasing demand for immediate news, there may be fewer checks and balances than in the past due to greater competition and expectation to release stories as they break. For rape reporting, this could indicate a shift in the types of details given about the victim than deemed necessary due to competing media outlets vying over the same story. Before discussing the literature on how newspaper media report on rape both internationally and locally, it is imperative that we understand the contribution of the media, and the press, to perpetuating rape myths and how these influence the female rape victim's construction and representation in newspapers.

\section{A Brief Outline of Rape Myths}

The term 'rape myth' was coined by Susan Brownmiller (1975) and defined a few years later as being "prejudicial, stereotyped, or false beliefs about rape, rape victims and rapists" (Burt, 1980: 217). These beliefs create a climate hostile to rape victims which seeks to exonerate rapists and blame victims of sexual violence. Such attitudes lead to common misconceptions about rape, and public speculation about whether victims' dress or behaviour could be to blame for their own assaults. The cycle is perpetuated as victims are silenced and blamed, the crime normalised, and perpetrators completely ignored.

There are numerous popular rape myths that permeate society, which consequently support and maintain a rape culture. The refusal to acknowledge that stranger rape is rare is a popular myth (Magilsen, 2015; O'Hara, 2012; Shariff \& DeMartini, 2015), or the conflation of rape with sex, which ignores that rape is a physical attack and leads to the mistaken belief that rape 
does not hurt the victim any more than sex does (see Taslitz, 1999). The idea that rape is a sexual rather than an aggressive act encourages people not to take it seriously as a crime (Benedict, 1993; Griffin, 1986) and leads to the false belief that rape is trivial (e.g. 'she was not really hurt') (Franiuk, Seefelt, Cepress, \& Vandello, 2008). Other rape myths include that only 'loose' or 'sluttish' women are victimised (Benedict, 1993), “only bad girls or promiscuous women get raped" and victims "ask for it" (Burt, 1980: 217; Griffin, 1986) by getting drunk, wearing provocative clothing, or even hitchhiking. If a woman deviates from the traditional female sex role of being at home with family or children she therefore 'asks for rape' (Benedict, 1993).

Rape myths further suggest that women provoke rape by enticing their assailants by their looks and sexuality; or that women deserve rape because rapists (like all men), are believed to find women irresistible so women therefore bring on rape by behaving provocatively (Benedict, 1993). There are expectations that a genuine rape victim needs to be physically and emotionally injured after rape because she would have fought back and that the use of threats will accompany acts of rape (Shapcott, 1988). People also hold the false belief that rape is natural (e.g. men have a biological predisposition to get sex through force) (Franiuk et al., 2008), or that men have greater sexual needs and that their sexuality is more urgent than women's (Griffin, 1986) relating to the myth of the uncontrollable male sex drive, of which women are the sexual gatekeepers.

The idea that women like to use accusations of rape as a tactic for revenge, or simply to get attention, is a long-standing rape myth. So too is that rape is a punishment for past deeds. The victim of a rape is accused of having brought on the crime because of her actions at the time of the assault, or because of her lifestyle before it (Benedict, 1993). Lastly, women who claim they were raped are often construed as lying - they 'cry rape', have ulterior motives, or wanted sex at the time but changed their minds afterwards (Franiuk et al., 2008). Although it is possible that for any specific case the above beliefs may not actually be myths (i.e. the 'she is lying' allegation is accurate if a woman has made a false report), they are 'myths' in the sense that data do not generally support these popular beliefs about sexual assault (Franiuk et al., 2008).

These examples show that the use of victim-blaming language, the trivialisation of rape, and the refusal to acknowledge that stranger rape is rare or that sexual violence can cause 
significant harm are just a few examples of rape myths that exist (Magilsen, 2015; O'Hara, 2012; Shariff \& DeMartini, 2015). The acceptance of rape myths is, as Shapcott (1988) argues, set in a complex of attitudes and beliefs which reinforce the patriarchal world view. Moreover, those who believe rape myths tend to be happy with the traditional views of the way a man or woman should conduct themselves and accept aggression and violence as an inevitable aspect of their relationships, especially in intimate relationships with the opposite sex (Shapcott, 1988).

Whereas men may hold rape myth beliefs in order to rationalise their own behavioural tendencies towards sexual violence, women often maintain an illusion of invulnerability to the threat of rape by endorsing a stereotype of the 'typical rape victim' that is sufficiently different from themselves (Bohner, 2001; Burt, 1980). The stereotyped rape survivor is a distraught, pure, defenceless innocent from an impeccable background. If the woman is emotionally controlled, not physically injured and has a 'reputation' then she is less likely to be seen as a genuine rape survivor (Shapcott, 1988) and this process is carried out routinely to varying degrees in the courts and through the media. Some aspects of this were evident in the 2005 trial of New Zealand woman Louise Nicholas, raped by three ex-policemen in Rotorua in the 1980s (Boyes, 2006).

Rape myths, then, allow us to begin to understand the cultural context in which sexual violence and assault is perpetrated which further contributes to the behaviour being normalised and legitimised not only by the public, but also in the media (Franiuk et al., 2008). A misleading representation of rape in newspaper media can affect the sociocultural environment within which rape both occurs and is responded to by members of the criminal justice system (CJS). The facts of rape which are distorted by the press are those which are highly correlated with either not reporting to authorities or having the rape declared 'unfounded' by them (Heath et al., 1981; O'Hara, 2012). The newspaper media's part in the maintenance of a rape culture is discussed in the following section.

“Roll Up, Roll Up! Read All About It!” International Newspaper Reporting of Rape

The media's search for newsworthiness dictates that certain kinds of rape stories are more likely to receive journalists' attention than others, which will remain silenced and invisible. This results in a privileging of rape stories involving extreme forms of violence, stranger 
attacks and serial rape (Jordan, 2012; Kelly, 1988), which virtually guarantees that the press will ignore the most typical and prevalent rapes - those committed against women by their partners, husbands and boyfriends - in favour of the bizarre, sensational or gory (Benedict, 1993; Meyers, 1997). Although the vast majority of sexual assaults never get any publicity (Caringella-MacDonald, 1998; Meyers, 1997), the ones that do serve an important role in shaping and maintaining our perceptions of sexual assault. Indeed, the rendering of the victim in news reports on rape is of great ideological importance, drawing, as it so often does, the parameters of blameful and excusable behaviour in such a way as to obscure the aggressive act and the aggressor's culpability (Moore, 2009).

There is a large body of feminist literature concerning the distorted media representation of rape, and particularly the rape victim (Benedict, 1993; Boyle, 2005; Greer, 2003; Meyers, 1997; Soothill \& Walby, 1991). The idea that there is a culturally prescribed 'ideal victim' (Christie, 1986) is particularly relevant to news reporting on rape: knowing the aggressor, being drunk, and seeming to display sexual availability are factors that have been used to paint the rape victim as somehow complicit in her victimisation (Benedict, 1993; Meyers, 1997; Moore, 2009). Previous research concerning the depiction of rape in the media on an international scale has highlighted the ways in which news reports sensationalise sexual violence by giving a distorted view of its incidence and nature. Studies have noted that media focus disproportionately on stranger rape, gang rape, on unusual or bizarre assaults, and on those perpetrated against young women (Caringella-MacDonald, 1998; Carter, 2002; Heath et al., 1981; Kitzinger, 2004; Soothill \& Walby, 1991). In addition, media accounts of rape and sexual assault tend to trivialise women's experiences of the attack, or report rapes in a manner that is designed to be titillating or arousing to readers, reiterating the significance of newsworthiness and its "mission to entertain" (Jewkes, 2011: 41).

Several studies confirm the pattern of increasing over-representation of sex crimes in British newspaper media, supporting the notion that sex in the media is a key selling point. In Soothill \& Walby's (1991) large scale analysis of six British newspapers between 1951 and 1985, the number of rape trials in Britain increased nearly four times, from 119 to 450. In the same period, the number of rape cases reported in the press increased more than five times, from 28 to 154 . The percentage of rape cases reported jumped from $23.5 \%$ in 1951 to $34.2 \%$ in 1985. The initial focus was on news coverage of rape but this was later expanded to include 
other sexual offences in the 1980s (Soothill \& Walby, 1991: 20-22). In Northern Ireland, press reporting of sex cases tripled during the 1980s and 1990s (Greer, 2003).

A study concerning marital rape in the news (Soothill \& Grover, 1994) followed the year after the recognition of marital rape in Britain (1991), and focused specifically on how the cases were reported on. Although the authors had no specific information on the number of such cases coming before the courts, they found across nine English and Welsh newspapers that only six cases made it to press for the year 1992. Not only was the coverage sparse, but there was no sustained or widespread coverage of the cases. The same study also analysed the Times newspaper for the years 1991 - 1993 to see whether there was evidence that coverage of marital rape stories was changing. Findings included considerable coverage in 1991 (4), less in 1992 (2), and none in 1993. Overall, the authors concluded the treatment of marital rape by the courts had become so routinised that the matter was no longer 'newsworthy' (Soothill \& Grover, 1994).

Throughout the 1980s and 1990s in the British press, Greer (2013) found that changes in sex crime reports were predominantly case-based and omitted discussion around wider issues except for cases involving predatory sex attackers. Compounded by the use of language and the selective reporting of only certain types of sexual offences, the prevalent but deeply misleading notion that strangers pose the greatest threat was consistently reinforced (Greer, 2013). This is misleading as the propensity to publish stories about extraordinary rapes influences public perceptions of what a 'typical' rape is and who it involves (see Franiuk et al., 2008; and Lynch, 2015). Further, this reporting practice (or preference for stranger perpetrated sexual violence) supports the rape myth that 'real rape ${ }^{6 \prime}$ is perpetrated by strangers and suggests, due to underreporting, that acquaintance rape is less serious and less prevalent (Lynch, 2015).

Marhia's (2008) study identified a random sample of 136 news articles about rape and sexual assault appearing in 10 mainstream newspapers and on the $B B C$ Online news site during the calendar year 2006. Five mainstream daily national tabloid newspapers and five mainstream

\footnotetext{
${ }^{6} \mathrm{~A}$ 'real rape' involves a stranger who attacks a woman late at night, threats to kill, physical violence, serious injury, evidence of overt victim resistance, and attack in a public place and not the victims' or assailants' home. In these cases the survivor is expected to report her victimisation immediately and fully cooperate with the police (Estrich, 1987; Kelly, 1988).
} 
daily national broadsheets were selected for sampling based on circulation figures and popularity. Their content was analysed in relation to the offence(s), perpetrator(s), victim(s), and judicial proceedings, and the language used to represent those categories. Marhia (2008) identified a press construction of rape, perpetrators and victims which was contrary to all research and crime statistics. This, she argued, had a damaging effect on public perceptions of sexual offences and in turn, the reporting of, and conviction rates for, sexual offences. In addition, Marhia (2008) noticed an overwhelming number of reports depicted rape as an outdoor crime, at the hands of a stranger who uses extreme violence, where the victim must be 'proven innocent' through press reporting of her actions before, during and after the attack. Marhia's (2008) report explored themes such as: the press failing to link individual cases of rape and sexual assault to a wider continuum of violence against women, the tendency to over-report 'false allegations', and the use of rape cases involving non-British nationals by the press as a vehicle for mobilising xenophobia.

The effects of binge drinking and rape have also been observed in a study concerning articles published in the Daily Mail between 2005 - 2007 (Meyer, 2010). Meyer (2010) noted "the Daily Mail is considered a morally conservative newspaper that is generally censorious about much of women's behaviour and normatively limits the kind of roles and practices women can legitimately engage in" (Meyer, 2010: 20). Incidents of sexual violence where the survivor was intoxicated showed that $20 \%$ of articles presented the main theme as a "false allegation" (p. 26) and "encourage(d) victim-blaming by never quite taking rape involving alcohol seriously" (p. 24). Meyer (2010) concluded that the Daily Mail constructed a specific set of discourses around rape which allowed for the open perpetuation of rape myths, the regendering of rape involving alcohol, and the masquerading of women's risks and responsibilities as rights - namely that women deserve the consequences (vulnerability and rape) for their behaviour.

Moore (2009) explored the narrative construction of drug-facilitated sexual assault (DFSA) in 319 British newspaper articles (collected from the Daily Mail, the Sun, The Times, and the Guardian) from late 1997 (when the first mentions of the crime appear in the British press) to the end of 2007. Moore's (2009) analysis of newspaper discourse on DFSA reported that the female victim's behaviour was the focal point. Specifically, articles recurrently made reference to the potential victim of DFSA and the importance of increased awareness on the 
part of women (e.g. to be 'on their guard' or 'watching their drink'). The focus on the victim and potential victim of DFSA is thus indicative of the role that gender and sexuality play in media depictions of rape. To note that news coverage of DFSA places emphasis on the victim is to recognise something important about how the contours of this crime problem are sketched out in newspaper media. DFSA then, has therefore been described as an 'epidemic' in the British press: the threat is deemed to emanate from an unknown source, everyone is a potential victim, and attempts to contain the threat are regularly thwarted (Moore, 2009). Wright's (2016) research on young women's drinking culture in a New Zealand context draws similar parallels:

Young women's participation in the culture of intoxication and the pursuit of pleasure is overlaid with expectations that they will be risk conscious. They are asked to occupy and perform a drinking femininity that plans for risk, is alert to it, and acts appropriately in the presence of risk. If women do not, they are likely to be interpreted as problematic consumers, as rebellious 'bad girls', careless and unconcerned (Wright, 2016: 643).

Both internationally and locally, the press is filled with stories of female excess and warnings to women. Sexual assault is framed variously in the media as something that has happened, is happening, and will happen, and women need to be alert to this.

Longitudinal research into how sexual abuse against women was represented in the British and American media from the 1970s to 2004 was conducted by Jenny Kitzinger. Between the 1940s and 1960s, violence against women was a hidden crime but increased exponentially during the 1970s and 1980s (Kitzinger, 2004). Regarding rape coverage, prior to developments in the 1970s, the mainstream media paid very little attention to rape; journalists avoided the word, preferring phrases such as 'carnal knowledge.' In 1971, there were 31 reports of rape cases in the British newspapers the Sun, the Daily Mirror, and The Times. However, coverage more than doubled in 1978 and had almost doubled again by 1985 (Kitzinger, 2004; Soothill \& Walby, 1991), and a similar increase in attention to sexual assault was evident in the American press, with a 250\% increase in coverage in the New York Times between 1972 and 1974 (Kitzinger, 2004). Kitzinger (2004) concluded that the rapid expansion in media attention to sexual violence both reflected, and had a dramatic impact upon, changing understandings of everyday life. Newspaper coverage made a crucial contribution to a spiral of recognition 
helping to fundamentally transform private and public thinking and discussion around sexual violence, and media recognition and representation continue to be a vital part of women's processes of naming and making sense of their memories and communication about the experience (Kitzinger, 2004).

A study looking at rape myths in American online newspaper coverage of the Kobe Bryant case $^{7}$ found that $42.3 \%$ of articles endorsed the myth that the victim was lying (Franiuk et al., 2008). Similarly, O'Hara's (2012) study of American and British newspapers covering three rape cases (two in America and one in Scotland) showed the majority of articles endorsed rape myths within the news media's reporting. Large amounts of rape-related content in USbased soap operas and crime dramas have been shown to "independently cultivate perceptions related to rape and sexual assault, with viewers of those genres more likely to accept rape myths and overestimate false accusations" (Kahlor \& Eastin, 2011: 227).

Newspaper reports of a high-profile campus sexual assault at Carleton University in Canada were analysed over the course of a five year period from 2007 - 2012 (Murrizi, 2015). The study's aim was to illustrate how the 'social problem' of campus sexual assault and the responses to it was constructed by 'claim-makers' (police, university officials, and lawyers) in 15 Canadian newspapers. Although the incident was perpetrated by a male known to the female victim, Murrizi (2015) found that the dominant newspaper discourse reproduced the 'real rape' scenario for five years after the assault. This is highly concerning due to the media instilling exaggerated fears among women regarding their likelihood of being victims of such crimes (Jewkes, 2011) and also frames the crime as an act only committed by strangers.

Similarly, Ujevic (2015) set out to understand how three Canadian newspapers (Toronto Star, The Globe and Mail, and The National Post) constructed sexual assault in their articles across the year 2012. Ujevic's (2015) research aimed to identify and challenge rape myths and stereotypes in these newspapers, in addition to identifying what dominant feminist discourses existed in print news media. Her findings indicated that the majority of articles

\footnotetext{
${ }^{7}$ In 2003, a Colorado woman laid a sexual assault complaint against Kobe Bryant, a basketball player for the L.A. Lakers. Bryant denied the allegation with the argument that the sex was consensual. After intense and sensationalised coverage of the case over the course of a year (before the case went to trial), the prosecution dropped the charge, as the woman decided not to testify in court. This decision was prompted by media coverage in which the woman felt given the way she had been represented in the media as a liar, she would not get a fair trial.
} 
contributed to the perpetuation of rape myths and the impact of the sexual assault on the victims were not recognised.

The press then, tends to report not representative but rather, lurid rapes. Lurid rapes are: (1) those that tend to outrage the public because of their extreme violence, (2) those that victimise the particularly vulnerable, such as elderly women, and (3) those whose victims can be painted as 'vamps', (i.e. deserving of their fate). Among the factors that lead the press to paint the victim as a vamp are whether she in any way deviated from the traditional female sex role of being at home with family or children. Reframed, a woman who voices career goals, independence from male expectations, or, worst of all, sexual interest may be depicted as a vamp (Taslitz, 1999).

Another tendency that the press rely on when reporting sexual assaults against women is relating sex and violence, so that the two became virtually indistinguishable (Cere et al., 2014; Jewkes, 2011). The over-reporting of such crimes was so significant that in Strathclyde, Scotland in March 1981, crimes involving sex and violence accounted for only $2.4 \%$ of recorded incidents, yet occupied $45.8 \%$ of newspaper coverage (Ditton \& Duffy, 1983). So interlinked are the themes of sex and violence, and so powerfully do they combine to illustrate the value of 'risk', that the prime example of newsworthiness is arguably the figure of the compulsive male lone hunter, driven by a sexual desire (Jewkes, 2011). The result is that media narratives are driven by sensationalised, individual cases that target a few 'sick' men instead of systemic male power and everyday 'mundane' sexism (Willis, 1994). Media portrayals of rape are in these ways hegemonic, buttressing the patriarchy that undergirds structural inequality and sexism (Caringella-MacDonald, 1998).

Rape articles consistently have fewer details than do articles about murder or assault, which can result in more public confusion about rape than about those other crimes. Readers who are not fully informed about the details of a rape are left to extrapolate from the details that do appear, or to rely on their own versions of the typical rape to fill in the missing details. Either procedure, as Heath and colleagues' argue, can lead to a very frightening and erroneous view of rape (Heath et al., 1981). The fewer numbers of cases covered, the more distant and isolated is the phenomenon of rape (Caringella-MacDonald, 1998), which gives the message that rape is sporadic rather than structurally generated (Stanko, 1985). 
Media reporting of what are believed to be false rape allegations has also become a fashionable area of inquiry and speculation by journalists in recent years, constructing a narrative of the 'new issue' of false rape complaints (Jordan, 2004). Jordan (2012) states that coverage given to rape reports which are believed to be false is extensive, and articles centred round the theme of women lying appear to be positioned with greater prominence and emphasis than stories covering rape charges that end in conviction. If media frequently report false complaints as numerous, the emphasis is thus placed on women's lack of accuracy in ways that continue to obscure and silence the realities of rape resulting in dangerous consequences for women (Jordan, 2012).

What is evident from this body of international literature on newspaper representations of rape is that media reports predominantly sensationalise sexual violence by giving a distorted view of its incidence and nature. Moreover, newspapers portray a victim-blaming rhetoric that minimises and trivialises the crime of rape, so cases of sexual violence which fit the stereotypes are therefore more likely to be reported, more likely to be taken to court, and more likely to result in prosecution (Ruth, 1984). With this in mind, I now turn to a summary of New Zealand research on this topic and look at the comparisons that can be drawn.

\section{What About in New Zealand?}

The previously discussed literature on rape representation in newspaper media identified the perpetuation of rape myths as a tool that seek to blame the victim for being raped and exonerate the perpetrator. I have identified six New Zealand studies conducted on newspaper media's reporting of rape, which I will now outline in chronological order.

From February to November 1982, Sally Ruth collected newspaper clippings about rape from The Press and the Christchurch Star. To analyse them, she talked to raped women, a rape crisis worker, a policeman, a lawyer, two male representatives from the Star and one male reporter from The Press. In The Press's coverage, prominence was given to attacks on children and the elderly. As The Press reporter highlighted:

The public have a particular abhorrence for these assaults, while those cases of women in the middle age bracket $(18-50)$ are not seen as quite as serious. Our court reporters are guided by good taste and hold the view that sexual violence reports should not descend to the salacious or dwell on unduly details (Ruth, 1984: 32). 
In contrast, the Star representative noted that: "sexual violence cases are usually highly penalised, so they are usually reported" (Ruth, 1984: 32). Ruth (1984) concluded that newsworthiness in The Press was therefore determined by who the victim is, and in the Star, selection by newsworthiness was based on the penalty attached to the charge. Further findings indicated that both papers contained an overwhelmingly high number of cases where the victim was attacked by a stranger, in her own home, or alone at night in a public place. Most of the assaults also included some degree of physical violence (Ruth, 1984). Interestingly, reports from both papers included warnings to other women and most had an element of suggestion that the woman brought it on herself and that this should reduce the seriousness of the penalty. Often included in this type of report was the insinuation that some women deserve rape more than others (Ruth, 1984).

Six years after Ruth's study, Heather Bauchop looked at the public image of rape in New Zealand from 1950 - 1970 by analysing the NZH and the New Zealand Truth (Bauchop, 1990). Bauchop sampled eight complete years throughout the two decades taking dates from the beginning of the period (1950 and 1951), a cluster in the middle (1958, 1960 and 1961), and another at the end (1966, 1967 and 1970). For each of these eight individual years, the full twelve months of the two newspapers were read as she found this method was preferable to sampling a few months of the year as it allowed a full picture of cases being reported to the papers to emerge. Bauchop encountered difficulty in comparing the two publications as they offered very different approaches in their writing about rape, but her research aim was to choose two papers that represented markedly different perspectives on rape stories. The NZH was seen as a reasonably staid source with a 'middle of the road' viewpoint, whilst the Truth was a sensationalist 'people's' paper catering more to those who wished to react to the horror or flashiness of the news as it was presented. In addition, the NZH was a daily and the Truth was a weekly. There were a number of interesting findings from her study: 1) there was a change in the reporting of rape in that it became more frequent and more explicit as time went on, 2) the underlying attitudes of stereotyping victims remained relatively constant, 3 ) the language used to describe sexual violation showed that rape was difficult to isolate from supposedly normal heterosexual relationships, and 4) the Truth gave graphic detail about the rape from the defence point of view by using sensationalist language and headlines whereas the NZH focused on court procedure to a large extent (Bauchop, 1990). In other words, the 
Truth hid the reality of rape under gruesome and stereotypical accounts, in contrast to the $\mathrm{NZH}$ which covered reality by giving the smallest amount of information possible which had the effect of mystifying rape by painting a narrow picture of court proceedings. Overall, her analysis found that rape was a crime that was shocking to the public, and one that outraged the readers - whether in support of the victim or the offender (Bauchop, 1990).

Although case specific, Kate Mitchell's study analysed four high-profile rape cases across a variety of New Zealand newspapers to reveal the media's understanding of rape (Mitchell, 2001). Mitchell (2001) analysed a wide variety of publications: the NZH, The Waikato Times, The Evening Standard, the Taranaki Daily News (TDN), The Dominion, The Evening Post, The Press and the Southland Times (ST); and weekly Sunday papers: the Sunday Star Times (SST), the Sunday News and New Zealand Truth. Mitchell (2001) undertook a discourse analysis to analyse the language used in the articles to describe the victims, offenders, and the crime of rape itself. The first case was Hurricanes rugby player Roger Randle, charged with rape while on tour in South Africa in 1997. The second case was the gang rape of a female soldier by eight of her male colleagues at Linton Military Camp near Palmerston North in 1998. The third case was Christchurch doctor Morgan Fahey, accused of rape in 1998 by three former female patients whereby the abuse allegations went back thirty years. The final case was Kāpiti man Kevin Chadwick, who raped a sex worker in 1996 and an elderly female neighbour in 1997. Mitchell's (2001) analysis demonstrated a wide variance in the style of coverage, some able to be broadly labelled 'sympathetic' to the victim (the elderly woman in the Chadwick case), while other coverage was more judgemental about the victim's role in her victimisation (the Hurricanes case). Mitchell's most salient finding was that newspaper media's coverage of a rape case was largely informed by its proximity to the stereotypical 'real' rape scenario involving a passive 'feminine' victim and a violent stranger-rapist (Mitchell, 2001). Furthermore, newspaper representations of rape were informed by ideological assumptions regarding gender appropriate behaviours, and there was a significant disparity between the media's portrayal of rape and women's realities of sexual violence (Mitchell, 2001). Mitchell concluded that "while women experience a culture in which they are raped, the media represent rape as the isolated actions of individuals" (Mitchell, 2001: 124), illustrating that New Zealand newspaper media in the late nineties were supportive of the status quo in which rape was used as a tool in the social control of women. 
A decade later, Te Ohaakii a Hine: National Network Ending Sexual Violence Together (TOAHNNEST) undertook an analysis of 102 newspaper reports generated from the online search engines of the Stuff website and the NZH between April and September of 2012. Wood \& Dickson's (2013) findings illustrated that sexual violence stories seldom included expert commentary from agencies or those working in the sector, but instead, commonly held rape myths featured prominently such as equating sexual violence with sex, violent 'stranger danger', and the over reporting of false allegations. Reporting was largely restricted to events surrounding the investigation and trial of those accused, rather than coverage of sexual violence as a community issue. Crucially, there was confusion between 'sex,' 'sexual violence' and what consent means (Wood \& Dickson, 2013).

Research examining the way the Roast Busters scandal ${ }^{8}$ was reflected in the NZH's editorials and opinion pieces for the month of November 2013 was carried out by Magilsen (2015) for a Victoria University of Wellington Criminology Honour's paper. Magilsen's (2015) aim was to understand whether the $\mathrm{NZH}$ played a role in maintaining and perpetuating a rape culture through the 10 articles analysed. Magilsen (2015) found two articles in the sample that utilised victim-blaming language using words like 'promiscuous' and emphasising that "young women must ensure their safety and to avoid positions where they could be raped" (Magilsen, 2015: 13). Eight articles supported the victim and focused their attention on condemning the actions of the boys involved, yet used language which described the boys as "sexual savages" and "reviled young predators" (Magilsen, 2015: 13). Five articles supported the notion that aspects of the media (the film industry and Radio Live) played a role in perpetuating and maintaining a rape culture. Although only a small study and not representative of general NZH reporting practices, Magilsen (2015) concluded that the NZH recognised that media do play a role in maintaining and perpetuating a rape culture, however the journalists per se did not partake in this practice themselves. Furthermore, the majority of journalists accepted that a rape culture existed in New Zealand and argued that it

\footnotetext{
${ }^{8}$ The Roast Busters were a group of young New Zealand men who were allegedly involved in group sex with underage and intoxicated girls. The case sparked significant social uproar both at the actions of the men involved, as well as the New Zealand Police investigation, which required an inquiry in their handling of the case. On October 29, 2014, Police announced that no charges would be laid due to a lack of evidence (Steward \& Dennett, 2014).
} 
desperately needed to be addressed, reflecting a need for a change in how journalists' report on rape cases (Magilsen, 2015).

The most recent New Zealand study identified in this literature review concerning newspaper representations of sexual violence was conducted by Lynch (2015). The work analysed a sample of 59 articles across a one year period from June 2014 - June 2015 by using keyword search terms on the Newztext ${ }^{9}$ database to cast light on the way journalists report sexual violence. Lynch's (2015) analysis identified a primary area of concern - the conflation between 'rape' and 'sex' in journalists' attitudes and the defence lawyers they quoted. This is a finding consistent with Mitchell's (2001) study of four high-profile cases. Other issues of concern included the lack of recognition of and reference to sexual violence agencies, an overrepresentation of stranger perpetrated sexual violence, evidence of a hierarchy of victimisation in terms of the way women were represented, and an over-representation of cases in court (Lynch, 2015). Despite these issues, Lynch's (2015) study found some evidence of a shift in discourse, with commonly held beliefs about sexual violence and consent beginning to be challenged. This was evident in that no articles mentioned the victim's clothing and very few implied that the survivor was 'promiscuous'. Although only a one year analysis, Lynch's (2015) findings have laid the foundations for future research to be conducted in today's media climate.

These previous New Zealand studies have shown that the female rape victim is represented in a way that distorts the truth and is objectified through the use of sensationalist language in newspaper articles. While these six studies differ from the current work in the time periods covered (four analysed a short time period, one longitudinal), retrieval methods (three utilised solely a database search or the newspaper's website to retrieve articles), and scope (one study analysed specific rape cases and the longitudinal study covered only two publications), they provide a valuable context on how New Zealand's mainstream media write about women as victims regarding rape cases. The approach taken here - to document depictions of rape across a 40 year period drawing from eight publications - provides a new level of research and insight for the New Zealand context. My research will identify current trends in New Zealand newspaper reporting of rape and assess whether there have been

\footnotetext{
${ }^{9}$ Newztext is a searchable database that covers New Zealand newspaper articles in full text. It contains those publications published by Fairfax Media and also contains the New Zealand Herald from 1998 onwards.
} 
changes across time in the way that women as victims have been represented, objectified, and silenced in articles concerning rape. While international research is useful and essential for increasing knowledge regarding sexual violence, findings of international studies cannot be assumed to be directly translatable to a New Zealand context, validating the necessity of this study. This Master's research builds on the foundations established by previous New Zealand research, but seeks to provide a deeper insight, with a view to challenging societal attitudes about sexual violence and how they present as barriers to rape reform in New Zealand.

\section{Chapter Summary}

This review has examined the literature which explores the way women as rape victims are represented regarding newspaper reporting of rape both internationally and in a local context. This chapter began by identifying the way that women's words are often omitted in newspaper media coverage generally, and in regards to commentary on rape. A discussion of newspaper construction and crime reporting showed that news media heavily influences public opinion and in cases such as rape, where direct experience is not available to the public, the media serve a large role in defining this reality. The role of digital journalism and social media was then described, outlining the changes in news production and consumption, and what these changes mean regarding rape reporting. This review then documented factors that lead to newspaper media perpetuating and maintaining a rape culture, identifying that victim-blaming attitudes exist in the coverage of rape stories. Lastly, this chapter explored the literature gaps in New Zealand media research on sexual violence, which this research seeks to address throughout the course of this thesis. 


\section{Chapter 3: Methodology}

The purpose of this research is to explore and identify the different ways that male-female rape is discussed within eight prominent New Zealand newspapers and assess the extent in which women have been represented in rape reports over time. In line with feminist methodological practice, my research utilises a variety of methods which can best answer particular research questions, whether they be quantitative or qualitative in format (Jayaratne \& Stewart, 1991). For the methodology of this study, I drew upon a feminist framework and adopted a hybrid method combining a quantitative content analysis (CA), an ethnographic content analysis (ECA), and a discourse analysis, which guided me in answering my research questions. After outlining positionality, and relating this to my data collection process, this chapter provides an explanation of how the data was retrieved and analysed, and an examination of the study's limitations.

\section{Positionality}

Positionality can be defined as adopting a position in any context with relation to socially significant variables such as gender, race, ethnicity, sexuality, or socio-economic status to name a few (hooks, 1984). Positionality shapes subjectivity and is thus important for evaluating how a researcher approaches research and interprets data (Ujevic, 2015). With this in mind, I believe that acknowledging my own background is central to the research process.

I am a Pākehā ${ }^{10}$, cis-gender, able-bodied, queer woman. I am also a feminist writing about rape. These identifying factors make me aware of my privilege and place in the world, which contribute to my position as a researcher. As Jordan (2004) notes, it is critical that feminist women conducting sexual violence research are aware of the impact of gender and of the significance of living in a society marked by gender differences and inequalities. It is important to remain reflexive with sensitive topics of research, and thus, my analysis is guided by a feminist, reflexive voice that echoes Bauchop's (1990) work on subjective understandings of gendered violence. I want to generate knowledge about the way we think about rape within

\footnotetext{
${ }^{10}$ The Māori Dictionary defines a Pākehā individual as a New Zealander of European descent, originally applied to English-speaking Europeans living in Aotearoa/New Zealand.
} 
our culture in order to improve the lives of people, and in particular, those of women (Ujevic, 2015). Studying newspaper accounts of rape will provide valuable insight into how traditional attitudes are maintained towards women as rape victims throughout the New Zealand press.

In order to do this, I wanted to cast a wide net across New Zealand's newspaper media. As noted at the beginning of my thesis, the sources I chose to look at were the New Zealand Herald (NZH) and the Sunday Star Times (SST) (Auckland), The Dominion and The Evening Post (Wellington - merged as one publication in 2002 to become The Dominion Post), The Press (Christchurch), the Otago Daily Times (ODT) (Dunedin), the Southland Times (ST) (Invercargill), and the Taranaki Daily News (TDN) (New Plymouth). I wanted to include regional newspapers for a contrasting reporting style and decided to select one from the North Island and one from the South Island giving me a total of eight newspapers from different regions throughout the country. A 40 year period was examined from 1975 - 2015 with individual years for analysis being 1975, 1985, 1995, 2005 and 2015. These years were selected to give a representative view of each decade's depiction of rape. For the years 2005 and 2015 my selection dropped to seven newspapers, due to the merging of two publications to become The Dominion Post. The following section describes my research journey and how I collected my data.

\section{Becoming a 'Microfilm Monster'}

I knew that obtaining newspaper data would be easily accessible for the post-millennium years across all of the newspapers I had selected, but 1975 and 1985 posed a problem. I wanted to be completely thorough with gathering all newspaper articles on rape for these two early years, but in order to do this, every article would have to be gathered via microfilm due to online databases and keyword searching being unavailable. This meant that each day for a full twelve months of eight different newspapers would need to be viewed using the microfilm method. I realised my data collection phase was going to be incredibly time consuming, laborious, and would require huge attention to detail - something that I and my supervisors were hesitant about me managing alone. I decided to employ a research assistant to assist me with the microfilming process. Despite the mammoth task that lay ahead, reading Jewkes $(2011 ; 2015)$ work convinced me that the best way to research newspaper content is to get hold of actual newspapers, as the way we engage with their materiality is radically different to the ways in which we use online sources and databases. More specifically, the 
"browsing of 'real' newspapers allows the researcher to have a healthy lack of control" (Jewkes, 2015: 281). Due to online databases being unavailable for 1975 and 1985, the microfilm method was thus the best, and only method possible.

My data collection began at the Victoria University of Wellington library, but I soon relocated to the Alexander Turnbull Library (ATL) situated within the National Library of New Zealand in Thorndon. I did this because their microfilm collection and equipment far exceeded the university's. Every newspaper that I needed was available, and there were many machines and computers to choose from, not to mention the equipment was more intuitive, quieter, and the environment was a lot more comfortable - conducive I thought, to reading newspapers for what would be a long period of time.
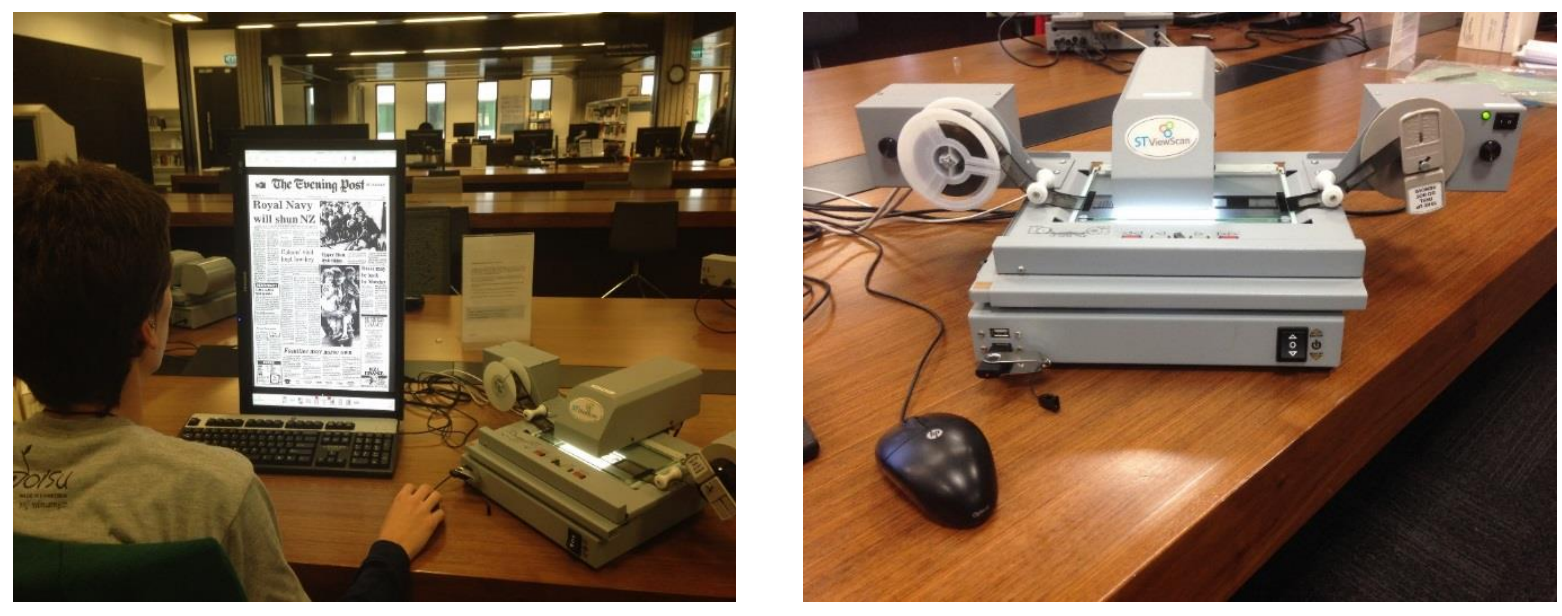

Viewing newspaper microfilm (left), and close up of the viewing machine (right). Alexander Turnbull Library, Thorndon, Wellington.

The most efficient method was to focus on one publication at a time, and read through from the beginning of the calendar year to the end, starting with the large daily papers at 1975 . My goal was to gather every article that mentioned rape, including reports where the word 'rape' was only briefly mentioned in a single sentence. This search process involved scanning the 'news' section for headlines that were relevant to my criteria: all rape cases brought to police attention and those proceeding through court, attempted rapes, and false allegations. All non-news items and social commentary around rape (letters to the editor, opinion pieces, and editorials) were also collected as I believed this would provide an important contrast to court based reporting and give a sense of the public's perception of rape in that year. The 'news' section always appeared at the beginning of the paper, and sometimes consisted of a few pages at the end so the other sections were bypassed as they were not relevant. This 
approach was best as it allowed me to view each publication in its entirety and gain a sense of familiarity with each newspaper's layout and in what order things appear. It also made the cataloguing process systematic and ordered as I needed to store articles on a 'per year > per publication > per month' basis. Furthermore, I wanted to work through each of the five years in chronological order because gaining a sense of New Zealand's social history at each of the 10 year intervals would be important and relevant when it came time to do my analysis. The two regional papers (TDN and ST) and the weekly paper (SST) were left until the end of each year to view as I knew these publications were smaller and would take considerably less time.
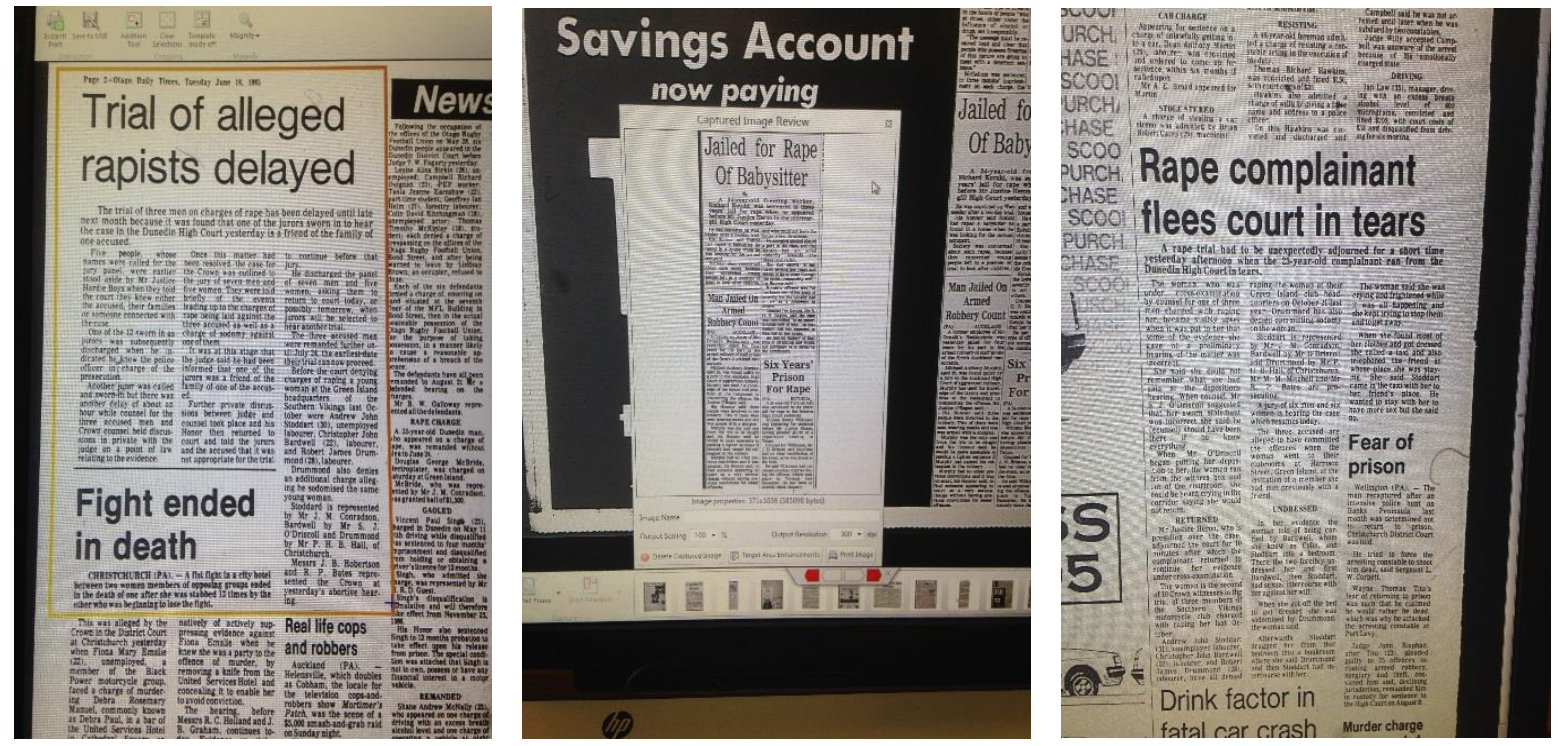

Close ups of rape articles on screen (left and right images). The centre image shows the saved collection of articles at the bottom of screen. Alexander Turnbull Library, Thorndon, Wellington.

Although incredibly time consuming, the advantage of the microfilm method was it provided an accuracy and precision that meant I would not miss any headlines or articles. This method was consistent with Bauchop's (1990) study, and the method that I followed for the present study. Bauchop (1990) argues that sampling means many cases become lost in the court system without revealing changes in newspaper reporting that occurs as the case progresses through the judicial process.

Conducting sole research in a sensitive area such as sexual violence took its toll, however. There were long periods of loneliness, the purchasing of eye drops due to staring at brightly lit text on a screen for hours on end, the mental and physical exhaustion, and nightmares about being attacked alone, at night, by a stranger - this was interesting as I was embodying a rape myth already. I later realised these dreams stemmed from my daily routine of searching 
for rape articles and additionally, on an unconscious level, that the press was publishing many stranger attacks, even though I knew this kind of rape was a minority. I would wake up in the morning dreading another day at the ATL doing the same task, over and over. This period was incredibly challenging and I had no idea when it was going to end $-I$ indeed felt like I was turning into a 'microfilm monster'. Despite these challenges, I was trying to remain positive, and manage myself effectively. My schedule thus far had consisted of four days per week at the ATL, with one mid-week day situated on campus to alleviate the monotonous data collection task of scrolling through thousands of days of newspapers. More importantly, I saw this 'campus day' as a chance to have some much needed human contact, be it with fellow students or debriefs with my supervisors.

After six weeks of fulltime microfilming alone off campus, my research assistant (Vicki) was hired to work with me which came as a welcome relief. Due to the nature of the research, and my entire study centring on the victimisation of women, I needed to feel at ease with whomever I worked with collecting data, and I found a sense of solidarity with Vicki in this. As I discovered, it was hugely beneficial to recruit another female to assist me as there were times when I needed to voice concerns or offload information that in retrospect, I would not have felt comfortable saying to a male. As a feminist researcher, I am attuned to understandings of feminist methodological practices (Alice, 1999; Jayaratne \& Stewart, 1991; Kelly, 1988) and am aware that the majority of research conducted about women is done by women. I was confident then, that having Vicki assist me in this process meant we were embodying feminist values and practices. Working with Vicki sped up my data collection process immensely, and we could sit next to each other while collecting articles; a factor that lent itself to easily conversing about the relevant search criteria and the counting procedures I had put in place. This confirmed to me that the methodological instructions I had created made sense to someone else and were able to be followed and replicated easily. In light of this, my overall mood improved, and over the next few months we were reading through the publications at a fast pace. The microfilm method continued for all eight newspapers for the years 1975, 1985, and three out of eight publications for 1995 (the ODT, the TDN, and the ST). Once all microfilming was completed, Vicki finished her research assistant work with me as the remaining papers for 1995 were available via electronic databases. 

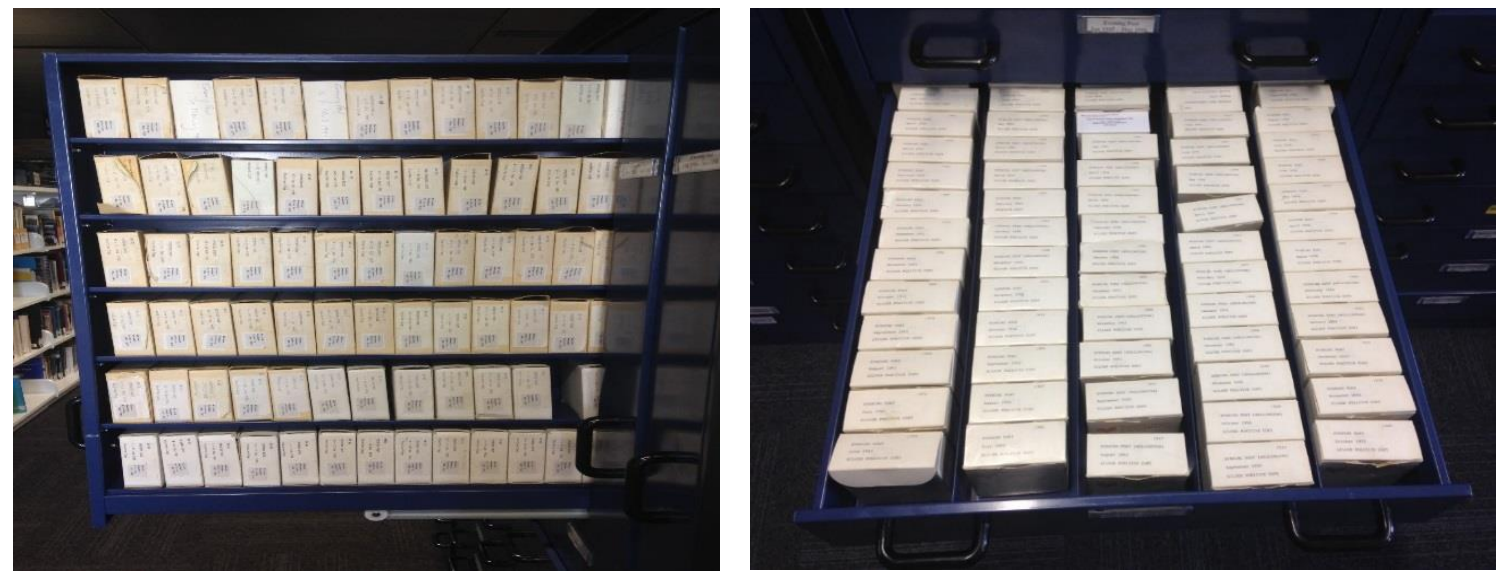

Draws of microfilm reels. Alexander Turnbull Library, Thorndon, Wellington.

Database Searching

The year 1995 saw a mixed-methods approach being adopted as a combination of microfilm and electronic databases were used to gather articles. Although relieved to have finished microfilming full time, I suddenly became wary of using databases, as for so long I had become accustomed to the attention to detail required in scrolling through newspapers on a daily basis. I began with Index New Zealand (INZ) as a first port of call, and the two newspapers available on this database were the NZH and The Press. INZ is a searchable database that contains abstracts and descriptions of articles from New Zealand periodicals and newspapers published from the 1950s to the present day (National Library of New Zealand, 2016). Conversations with ATL staff regarding search terminology on INZ confirmed that articles were indexed according to the discretion of the cataloguer at the time and the search terms they had decided to use. Furthermore, only 'feature articles' (prominent in-depth stories with lots of information present) would be shown, so I risked missing many of the smaller articles about rape for this year, or headlines that did not match my search terms. I began by using the search terms 'rape(d)' and 'rapist(s)' for the period January 1, 1995 to December 31, 1995. As Jewkes (2015) argues, "by exercising control through our choice of searchable keywords when we conduct research, we limit the opportunities to chance upon stories that are of interest and relevance to our research topic, but which did not contain the words we inputted" (Jewkes, 2015: 281). With this in mind, I wanted to make sure I was capturing articles where the offence was categorised specifically as rape in accordance to my criteria of men as perpetrators, and women aged 16 or above as victims. I found that using terms like 'sexual assault', 'indecent assault', or 'sex attack' searched these terms individually and the 
resulting articles were not specific to rape cases. Once my search terms were entered, the database would produce a list of references ordered from the earliest date to the latest that gave the article's title, a short one or two line abstract which I used to determine its relevancy, the name of publication - in this case either the NZH or The Press - the date, and the page number. I then took a note of these latter details, located the appropriate microfilm reel, viewed the article, and saved it.

A secondary database I used to ensure I did not miss any articles that INZ may have failed to catalogue was FindNZarticles ${ }^{11}$. I did find however, this database provided no extra references and reproduced what I had initially found on INZ. Articles from the remaining three newspapers (The Dominion, The Evening Post and the SST) were found using the Newztext database. I used the same search terms 'rape(d)' and 'rapist(s)' for the period January 1, 1995 to December 31, 1995, and once the articles were located I was able to save them for printing at a later date. Although this method was less time consuming, the downside was that I risked missing articles from the newspapers that I had searched via database because they only produced 'feature articles'. Therefore, the year 1995 consisted of much less data than 1975 and 1985 because of using this mixed-methods approach. In total, the microfilming and database searching at the ATL up until the completion of 1995 took five months, even with Vicki's assistance. This took longer than I expected for the scope of the project and I did not expect to be based off campus for so long.

For the year 2005 (January 1 to December 31), all articles for all publications except the ODT were found using the databases Newztext and the Australia and New Zealand Reference Centre $^{12}$ (ANZRC). The ANZRC was used as a secondary source to ensure I had not missed any articles that Newztext may have failed to capture, and for the year 2005, the ANZRC yielded an extra 12 articles for the NZH in addition to the Newztext articles gathered. For 2015 (January 1 to December 31), Newztext was the sole database used. The ODT was not listed on

\footnotetext{
${ }^{11}$ FindNZarticles provides access to material from a range of New Zealand newspapers and journals, enabling users to search a number of national libraries' and institutions' indexes (Christchurch City Libraries, 2016).

12 Designed for libraries in Australia and New Zealand, ANZRC is an Australasian newspaper database that provides articles in full text.
} 
any online databases as this publication remains independently owned from Fairfax Media ${ }^{13}$ and New Zealand Media and Entertainment ${ }^{14}$ who publish the NZH (Smellie, 2016). A one week subscription was therefore purchased which allowed me access to the ODT's searchable archives to gather articles. My search terms continued with the words 'rape(d)' and 'rapist(s)' for the same reasons as previously stated, and I collected all articles concerning rape (completed rapes, attempted rapes, false allegations, and social commentary) relevant to my criteria.

\section{Data Coding and Analyses}

Once I had completed my database searching and had gathered all data, I separated out the rape case articles from the non-news/social commentary articles by using a quantitative CA. A quantitative CA involves the counting and measuring of items, including words and images, and coming up with relevant categories and assigning the data to those categories (Hesmondhalgh, 2006). The focus of a quantitative CA is primarily on categorising and counting occurrences of aspects of content. It is assumed that there is an association between the frequency with which a certain theme appears and its dominance (e.g. significance is synonymous with frequency) (Gill, 2007; Morant, 1999; Noaks \& Wincup, 2004). Adopting this approach, I manually counted the number of articles about rape for each newspaper across the five individual years which produced a total of 1833 reports. I did this initial count because I wanted to gauge the total number of articles I would be working with across all years and all publications. This dataset was extremely large in number, so I needed to be specific and systematic in what my focus would be moving forward. I went through the sample a second time and counted the total number of rape cases across all years and all publications which produced a total of 1053 articles. A third and final level of counting involved reading through

\footnotetext{
13 Fairfax Media is one of the largest media companies in Australia and New Zealand, with investment in newspaper, magazines, radio and internet. Publications under Fairfax NZ include The Dominion Post, The Press, Sunday Star Times, Taranaki Daily News, and the Southland Times. A press release issued on December 82016 stated Fairfax had entered into a binding merger implementation agreement to merge its New Zealand business with New Zealand Media and Entertainment. The transaction is subject to certain conditions including regulatory approval and the parties are going through the approval process with the New Zealand Commerce Commission.

${ }^{14}$ New Zealand Media and Entertainment is an Auckland based media organisation with a portfolio of radio, digital, e-commerce, and print brands, targeting New Zealand audiences.
} 
each of the 1053 articles and counting how many rape cases were instances of 'stranger rapes' - this process almost halved my dataset producing 555 cases. In hindsight, I should have counted the 'stranger rapes' at the same time as counting the number of rape cases but unfortunately this did not occur to me at the time. Overall, my data coding and analysis phase was a lengthy, iterative process of constantly engaging and re-engaging with the data to ensure that I had captured all themes.

As Gill (2007) notes, CA does not distinguish between levels of meaning, and, in fact, only ever addresses the manifest content of representations and their frequency. For my second phase of analysis, I adopted a more in-depth, inductive approach and utilised Altheide's $(1987 ; 1996)$ ECA methodology. Although ECA has been less widely recognised as a distinctive method, several dimensions provide a relevant framework for my study. Altheide $(1987 ; 1996)$ states that throughout the progression from data collection to analysis, a primary concept is to document and understand the communication of meaning. A major difference of ECA compared with traditional quantitative $C A$ is the reflexive and interactive nature of the investigator, concepts, data collection, and analysis. The method's orientation is toward constant comparison and discovery of the data, and involves concepts to consistently emerge during the research process (Altheide, 1987; 1996). In line with Ujevic's (2015) work on Canadian newspaper constructions of sexual assault, remaining open to new concepts and themes emerging from the data while constantly revisiting and revising categories was important whilst remaining reflective throughout the research process (Altheide, 1987; 1996). The ECA method was performed on the 1833 articles in my sample as it was appropriate in order for me to discover emergent patterns and differing emphases among and between the articles by focusing on their narratives (Altheide, 1987; 1996). The narratives I was most interested in concerned whether women's voices were either heard or unheard across my sample because as previously noted in Chapter Two, women's words and perspectives are typically omitted regarding rape reporting. At this point, I decided to conduct a more deductive approach and ask a question of my data: who is speaking professionally across the sample, noting their gender?

The third and final phase of analysis involved reading each article and determining its gendered 'voice'. I categorised them into three areas: 'male', 'female', 'both', or 'unsure'. 
Selecting the 'male' articles only, I made a note of keywords and descriptors that men (as perpetrators or criminal justice system (CJS) professionals) were using to describe female rape victims. This pertains to one of my findings outlined in Chapter Five that 'male voices' are most dominant regarding rape commentary across the four decades I examined. I then constructed a summary sheet for each of the five individual years and wrote out keywords or sentences as they appeared in the text. This technique, adopted by Bogazianos (2011) transforms large amounts of material into a much smaller form, allowing the researcher to actively engage with the data (Bogazianos, 2011). Coding these keywords and phrases was a challenging and lengthy process that involved carefully reading through each article numerous times. In order to see how the 'male' articles/voices constructed rape, I asked a question inspired by Carla Willig's (2008) interpretation of a Foucauldian Discourse Analysis (FDA):

\section{How is rape being represented and/or constructed in the articles?}

This question pertains to my research aim as I am looking to explore and identify the different ways that male-female rape is discussed within New Zealand newspaper articles across time. More specifically, my aim is to assess the way that women (and rape) has been represented and constructed in media reports.

FDA is concerned with how language constructs social life and the role of discourse in wider processes of legitimation and power (Willig, 2008). A Foucauldian view holds that discourses (through the act of constructing) enable and limit what can be said and done in relation to that construction. Discourses make ways of seeing the world both possible and impossible (Willig, 2008). This is a suitable method for my study because a FDA explores the ways discourses have changed over time, and in order to inform further research or refute existing knowledge, qualitative researchers specifically use a FDA to understand how concepts, objects, and subjects are constructed (Willig, 2008). The research question I am asking of my data is important regarding the aims of the research because, as will be explored in Chapters Four to Six, constructing rape in certain ways can limit how women as rape victims can be thought about by the general public or responded to by the CJS. It also enables researchers to make inferences about what practices are made possible. Jewkes $(2011 ; 2015)$ argues that a discourse analysis of newspaper media texts is a particularly useful approach for examining 
the kinds of biases, prejudices and omissions in media reporting. I have chosen this approach because it will enable me to identify general meanings communicated in newspaper discourses that can silence and objectify women's experiences in regards to sexual violence and rape, which will be examined over time and assessed in the context of changes in technology.

Although this project has its groundings in feminist epistemology, gender is not the only aspect of identity which is important to this research. As Duncanson (2008) argues, discourse analyses need to remain alert to the ways in which social divisions are interlaced with each other, and a 'feminist discourse analysis' cannot be attuned to gender as the single underlying factor. In general, feminist research is primarily concerned with the close examination of power relationships and attentive to the ways in which gender intersects with other relations such as race, ethnicity, class, socio-economic status, sexuality, and so forth (Alice, 1999). With this in mind, I was attentive to how these other intersections are represented in my sample of newspaper articles.

\section{Limitations}

As I moved through the research process, I continually thought about issues pertaining to limitations of the study. As the Marsden project's criteria was to sample five individual years each a decade apart, I have no way of knowing how rape was reported on and the language used in the years between. Therefore, the years chosen for this study may not be representative of the usual pattern of offending, if indeed there was one. Using newspapers as the main source, I have only viewed the rapes the public has been presented with; there are a vast number of cases that have not gone through the court system and will remain invisible to the wider public. To be completely thorough, I would have liked to use the microfilm method on all five individual years to capture every article on male-female rape (where the victim is aged 16 and above) for the years 1995, 2005 and 2015 instead of using the database method. Due to time restraints on the project this was not possible, and thus my sample from 1995 onwards may have gaps where I missed articles concerning rape.

Other limitations pertain to my coding of data and interpreting the gendered 'voice' of each article. Being the sole coder meant I did not utilise anyone else to check the reliability of my 
codes, so my coding is arguably subjective - influenced by my personal worldview and particularly relevant to this topic - my experience as a female. Due to time, budget restraints, and the vast quantity of data I collected for this project, I was unable to employ a secondary coder to read through my articles, therefore I was not able to conduct a reliability analysis (the extent to which the results are replicable) (see Stroud \& de Macedo Higgins, 2015). Additionally, the narrow focus on rape determined by my search terms meant that other, intersecting forms of violence against women were excluded from the study. This was necessary however, to narrow the scope of the research.

In line with my research aims, the goal of the study was to compile the most thorough and comprehensive dataset possible in regards to New Zealand newspaper media's articles on rape. What I took away from my intensive research experience was a watertight set of data that to my knowledge, I am confident no other researcher in New Zealand has collected. Despite the limitations I have outlined, writing about rape is a vital part of giving women back their voices, experiences and herstory (Bauchop, 1990). My goal for this project is to challenge societal attitudes about rape presented in mainstream New Zealand newspaper media, and to expose the silencing that women experience as rape victims.

\section{Chapter Summary}

This chapter presented the methodological framework of this thesis. The chapter began outlining positionality and situating myself within a feminist framework. I then described my research journey noting how my data was retrieved and the challenges involved in this. A discussion of the hybrid methodology I adopted for this research then followed, which combined a quantitative CA, an ECA, and a FDA for analysis. Finally, I outlined the limitations of this research. In the following two chapters, I present my results. 


\section{Chapter 4: Quantitative Findings}

...women have not been in charge of the language and like many other activities, there are no words for sexual behaviour which encode the experience from the female perspective. The result of this is that women lack names invested with their meanings and women and men therefore 'doubt' the realities of women's meanings. There is no better example of the silence of females that in the name rape (Spender, 1985: 178).

The results of this research are separated into two chapters. This first chapter presents the quantitative findings from my content analysis (CA) of 1833 newspaper articles gathered from eight publications across the five individual years $(1975,1985,1995,2005$ and 2015). I present and discuss the total number of articles for each year, then move on to show the gender breakdown of 'voices' which are divided into four categories. The graph below shows the total number of articles concerning rape cases at each individual year for eight newspapers (1975 - 1995), and then seven newspapers from 2005 - 2015 ( $n=1833)$. Out of 1833 articles, the total number of cases spanning the five individual years across all newspapers produced the number 1053.

Figure 1: Total number of articles concerning rape cases across time

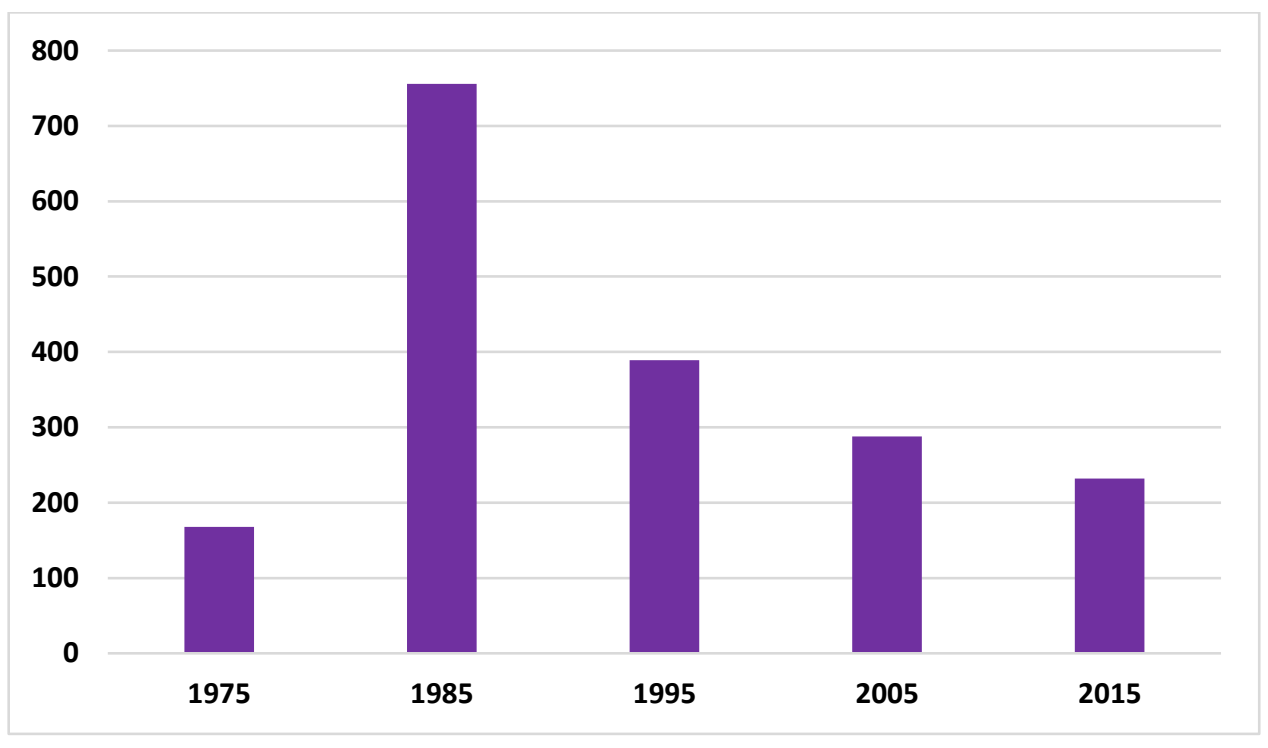

In 1975 , my total article count was 168 . I noticed that articles concerning rape for this year were much shorter, factual court reports, with not much information present about the victim or the perpetrator. The issue of rape in 1975 was likely seen as a taboo subject that was not discussed extensively by New Zealand media, and if it was, sparse information was given. 
Certainly before the 1970s, there was little public discussion of rape and domestic violence, and the extent of this kind of abuse was largely unknown until around 1974, when the Christchurch women's groups first opened rape crisis centres and refuges (Cook, 2011). Although 1975 was the middle of the second-wave feminist movement, and the United Nations declared 1975 as International Women's Year (Ministry for Women, 2016), the hard work of feminist activism to make rape visible (Brownmiller, 1975; Griffin, 1977; Russell, 1975) would not be felt properly until a decade later (Ministry for Women, 2016).

The year 1985 produced 756 articles - far more than any of the other years analysed. I discuss four reasons why I think this year was the largest out of my entire sample. Firstly, the effects of women's liberation and second-wave feminism were being felt by the time New Zealand reached 1985, which not only acknowledged, but brought rape visibility into the spotlight. As Bauchop (1990) has argued, feminists fought to make rape suffering visible and tried to break down the stereotypes of rape that prevented such violence from being recognised. Examples of rape recognition included the social commentary around rape shifting to one of male responsibility which affects all genders, and rape education/prevention workshops being held nationwide by feminist and women's groups which subsequently gained press coverage (McChesney, 1985).

Secondly, the establishment of the Ministry of Women's Affairs (MWA) in 1985 may have also brought rape visibility into the spotlight. MWA's focus was on developing policy highlighting gendered social differences between men and women in New Zealand, and being responsive to women in the community (Ministry for Women, 2016). As Ann Hercus, the then MWA minister said: "the government was committed to providing permanent financial support for rape crisis centres" ("Help For Rape Centres", 1985). A later newspaper report stated that "grants will come from $\$ 150,000$ allocated as part of a commitment to permanent funding of rape crisis centres" ("Cash for Rape Crisis Centres", 1985).

Articles concerning rape amongst the Māori population (once considered a tapu subject) were also being brought to the fore. Māori women have been found to experience sexual violence at up to twice the rate of other women in New Zealand, and a large proportion of Māori women rely on informal support from family, whanau and friends, yet some do not disclose their experiences at all (Ministry of Women's Affairs, 2009). In my analysis, I noticed that 
newspapers rarely noted the victim's ethnicity, however the perpetrator's ethnicity was mentioned if they identified as Māori or Polynesian.

Lastly, cases of spousal rape were gaining press coverage in 1985, although these cases were only considered 'rape' if intercourse was against the wife's will and the parties were living apart in separate residences. The increasingly visible reality was that women were raped and abused by men that knew them, men that they were in relationships with, and men that they were married to (Bauchop, 1990). Increased coverage of cases like these set a precedent for the Rape Law Reform Bill (No. 2) which would come into effect from February $1^{\text {st }} 1986$, and include the introduction of new offences such as inducing sexual connection by coercion, and expanding the definition of sexual assault to make rape one category of a new offence of 'sexual violation' that included both rape and 'unlawful sexual connection' (the latter including all orifices and means of penetration) (Jordan, 2004; 2012; McDonald, 2014). These changes acknowledged that the penis was not the only weapon of sexual assault, nor the vagina the only orifice able to be invaded. Hence, 'sexual violation' offences were redefined to include forced anal and oral sex (using any object able to be used for that purpose), and the concept of 'rape victim' was expanded to apply to both male and female victims of sexual assault (Jordan, 2004; 2012). Furthermore, the Bill meant that a wife's rights were extended to give her sexual autonomy legally, and removed spousal immunity - which traditionally had protected a husband from being charged with raping his wife (Jordan, 2004; 2012; McDonald, 2014). Overall, more incidents of rape were making it to press in 1985 as a result of increased discussion of the issue and changes to New Zealand legislation. An increase in coverage of gang rape cases was visible, in addition to high-profile cases being reported on much more than others. Regarding the latter, articles were being replicated by each newspaper on a nationwide level.

There was a sharp drop in the number of articles after 1985, and the number decreased by almost half, producing 389 articles for the year 1995. The shift in my method from using solely microfilm and adopting the use of databases would perhaps signal this decline in number. Of the 389 articles for 1995, a large proportion concerned a high-profile serial rapist case in Auckland (Joseph Thompson) which all newspapers in my sample covered extensively. This resulted in the introduction of full page spreads, images, maps of offending patterns, and 
timelines of Thompson's offending. After 1995, there was a slow decline in the number of articles concerning rape, with 2005 producing 288 articles, and 2015 further diminishing with 232 articles. My initial thoughts were that rape had disappeared from New Zealand's newspaper landscape as legislation and definitions had changed a decade earlier, and women had gained more social and economic rights as a new 'third-wave' of feminism was arriving through the 1990s. Newspaper outlets creating their own websites (e.g. www.nzherald.co.nz and Stuff) may signify the decline in my article totals post-millennium as newspapers were beginning to use online digital and social media platforms to disseminate information - an avenue fully explored in Chapter Six of this thesis. Internet sites and particularly social networking forums have also revolutionised the ways in which news - including crime news - is produced and consumed (Cere et al., 2014).

The next section is one of my most interesting findings, and looks at the visibility and significance of women's words in rape reports across the four decades. As outlined in Chapter Three, I read through my sample of 1833 articles and determined each one's gendered 'voice' categorising them into four areas: 'male', 'female', 'both', or 'unsure'. The graph below shows this gender breakdown of 'voices' of the 1833 articles.

Figure 2: Gender breakdown of voices

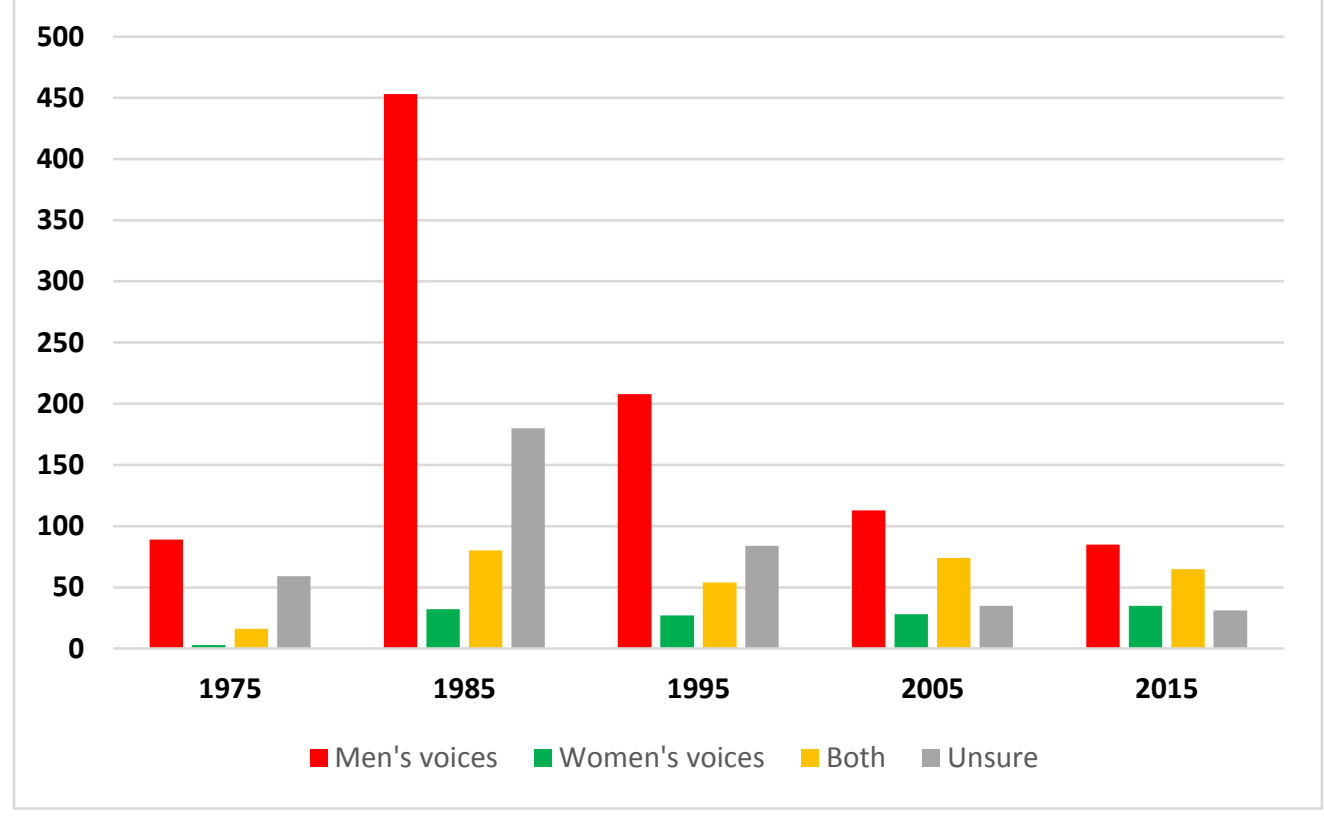




\section{Men's Voices}

In my analysis of articles I found an overwhelming number of them used the male voice (coded in red) as the dominant narrative of the piece. Men's voices appear in many forms, holding positions as professionals in the criminal justice system (CJS) (policemen, lawyers, or judges), or the perpetrator themselves giving testimony in court. This category was coded as men who were providing the commentary or speaking to us as readers of the articles, and there are no female voices present in any of these reports, regardless of the journalist's gender.

In 1975 there are 89 articles that hold the 'men's voices' category (53\% of the total), but in 1985 there are 453 articles (60\% of the total), almost five times the amount of the previous decade. Although the sample was a lot larger for 1985, this is an interesting finding because the difference between men's voices and the other three categories is in stark contrast to the other years by comparison. In 1995, the 'men's voices' category drops by more than half producing 208 articles (again holding 53\% of the total), and for 2005 and 2015, the decrease is less significant: 113 articles (39\%) and 85 articles (37\%) respectively. The 'men's voices' category remains higher than any of the other four categories across each of the five individual years, but significantly more so in the year 1985 . The graph below shows articles featuring men's voices measured against the total amount of articles for each year.

Figure 3: Men's voices measured against the total number of articles

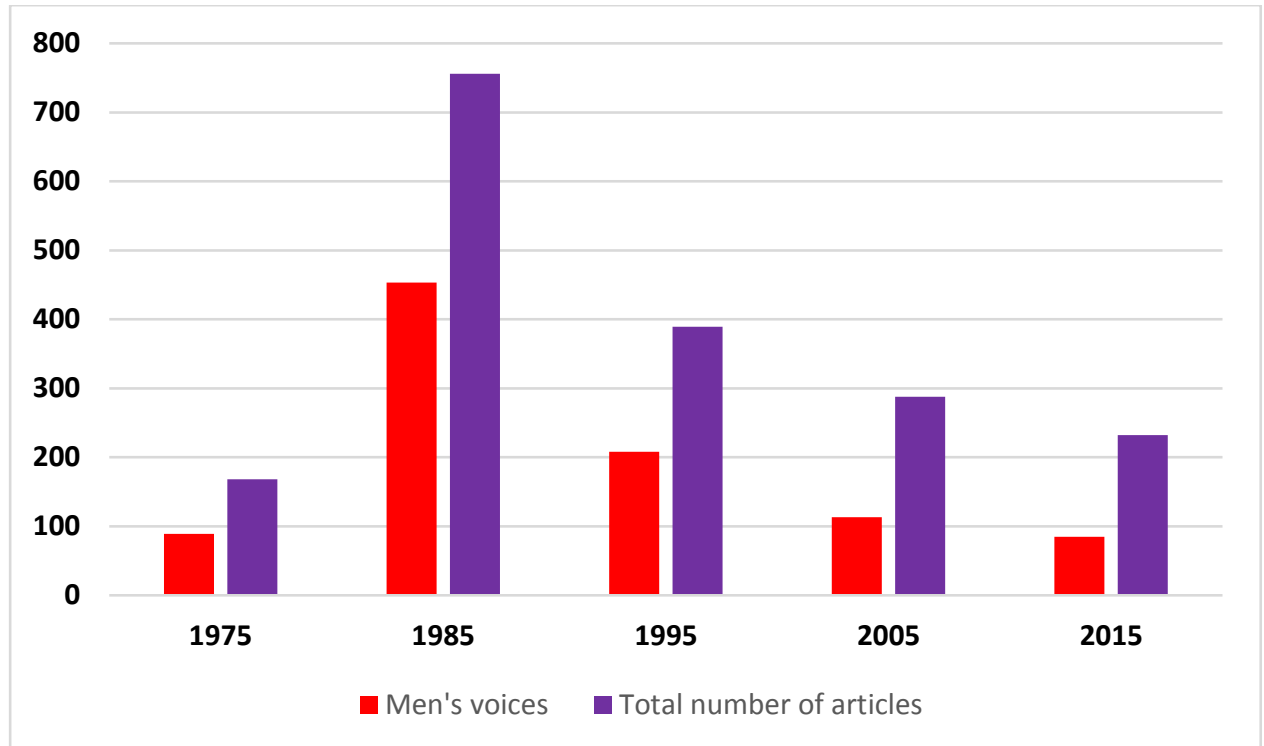


The pictures below illustrate how dominant men's voices are in regards to newspaper commentary about rape across all years using 1985 as an example.

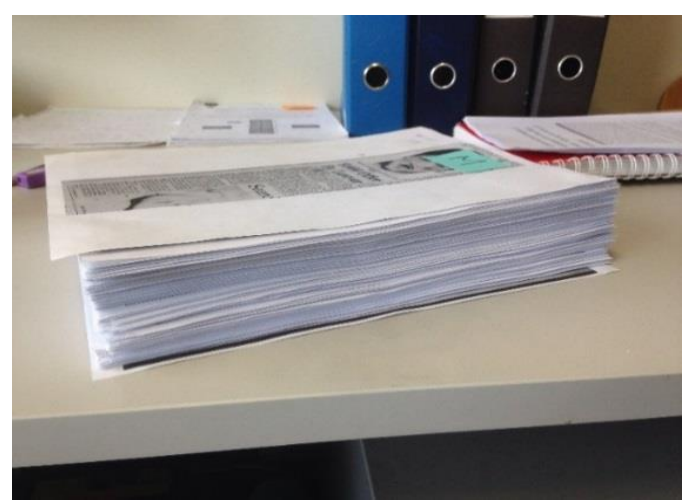

Men's voice articles for the year 1985

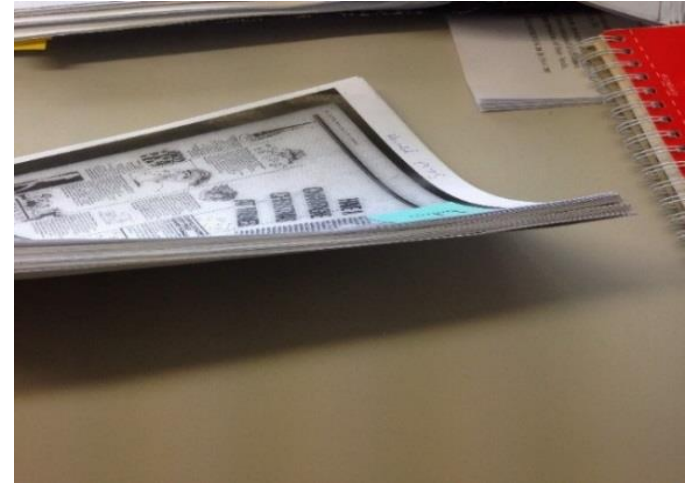

Women's voice articles for all of 1975, all of 1985, the ODT, TDN and the ST for 1995, the ODT for 2005, and the ODT for 2015.

After conducting my analysis of the men's voices category, I was left with the question: why is there is so much male commentary around a crime that happens overwhelmingly to women? The dominant gender that commits rape (men) is also the dominant gender coming through in reporting practices and speaking on behalf of women. Men therefore retain control twice - as the perpetrator and as a commentator - which serves to doubly silence women, by firstly raping her and then retaining the controlling voice through media commentary. Although after 1985 men's voices begin to decline, the overall trend indicates that New Zealand newspaper media prioritise men's voices as dominant in rape reporting, which only serve to remind us how strong patriarchal legacies are and how much more work needs to be done.

\section{Women's Voices}

The 'women's voices' category (coded in green) is the smallest out of all four categories, and this is where women solely provide the commentary in rape articles, with no male voice present. I coded women's voices in the following ways: women as victims, women as CJS professionals, women as relatives or friends of the victim, women working in sexual violence agencies, and women speaking on behalf of the perpetrator. In other words, articles in this category were given the 'women's voice' code regardless of which woman/women were speaking. I recognise that these women who hold positions outside of the 'victim' status 
cannot legitimise or verbalise the experiences of rape that women as victims have gone through, but it is still important because without 'other' women commenting on behalf of rape victims, this category would be virtually non-existent.

In 1975, women's voices are incredibly sparse, a finding which could be expected due to little (if any) involvement from women as CJS professionals. I found only three articles for this year and they are all instances of women as victims giving their testimony in court. In 1985, women's voices increase significantly with a total of 32 articles - although still very small generally compared to men's. Again, they are all instances of women as victims testifying in a court environment. In 1995, the number of articles drops slightly to 27 , and in this year I saw the introduction of women's voices coming through outside of the 'victim' status. There were instances where women who had been victimised would not have a 'voice' per se, but her legal counsel or support network did, a finding that was not visible in 1975 or 1985 . One example from 1995 showed commentary from a female Wellington Sexual Abuse Help counsellor who talked with rape victims. She pointed out that:

Women often fear identification by newspaper media when their case is being reported on as it proceeds through court. Although the court suppresses the name of the victim, often the woman may be identified to people who know her or of her ("Reporting rape cases", 1995).

This finding is also consistent with Bohner's (2001) work, who states that reports from the victim's viewpoint are possible in rape reporting, but the woman may not be willing to reveal her experiences to a newspaper. In 2015, National Rape Crisis spokeswoman Anna-Kristy Munro-Charters commented:

Name suppression may be something that the survivors want or don't want and it should be a choice that is left up to them (Weber, 2015).

In general, the articles I found in the years 1975, 1985 and 1995 did not divulge the victim's details, even if she did have a voice. In 2005, the count of 'women's voice' articles was 28, one article higher than the previous decade. For 2015, it rose slightly producing 35 articles. For both of these years, I noticed an increase in the number of instances where women waived their right to name suppression as the case went through court. I would argue that by waiving name suppression rights, women were acting as role models for other female rape 
victims by breaking the silence and shame that is so often associated with sexual violence crimes. Post-millennium reporting also sees more discussion emerging from women in positions of power such as politicians ${ }^{15}$ or sexual violence advocates such as Louise Nicholas or Tania Billingsley ${ }^{16}$ speaking out about rape and its disclosure. I am not implying that the responsibility for increasing the representation of women's voices lies principally with female victims, but rather that the broader institutional framework of news production and prosecution is male dominated. The fact that CJS personnel are mostly male, that journalists use the police (mostly male) as a primary news source, and that feminist academics/campaigners are routinely neglected in news reporting on sexual violence.

My findings regarding women's voices relate to Caldas-Coulthard's (1995) research, who analysed a sample of 200 British newspaper articles from The Independent, The Guardian and The Times to document the absence of women's words. Caldas-Coulthard's (1995) findings indicated that out of 200 articles, women were given voice 76 times whereas men were given voice 451 times (as cited in Ripcikova, 2008, p. 17) and women constituted only $14 \%$ of people reported in the newspapers implying that women are linguistically underrepresented in the context of news (as cited in Ripcikova, 2008, p. 12). Caldas-Coulthard (1995) concluded that women were being denied the roles of speakers because men are the most powerful and most frequently accessed group. Furthermore, news items were more likely to be written by men than women, men were more often quoted as saying things than women, and men were more often attributed as being the agents of action than women (as cited in Weatherall, 2002, p. 14). Weatherall (2002) has since argued that women are not only ignored by not being the writers in news reports, but are also marginalised by being denied the role of active agents, thus remaining invisible. The absence of women's words is therefore a key finding in this study, and provides an important focal point in the following chapter regarding rape's representation. Although minimal, there is a trend that women's voices across time are steadily rising as the graph below shows.

\footnotetext{
15 Several female Members of Parliament representing New Zealand's Labour and Green parties revealed their history of sexual abuse in parliament as a rebuke to New Zealand's former Prime Minister John Key regarding his comments about the Labour party supporting rapists, murderers and other criminals on the Christmas Island detention centre (Davison, 2015a).

${ }^{16}$ A Wellington woman Tania Billingsley, was sexually assaulted by a Malaysian diplomat in 2015. Her case is an example where waiving the right to name suppression was an important step in speaking out about sexual violence (Davison, 2015b).
} 
Figure 4: Women's voices across time

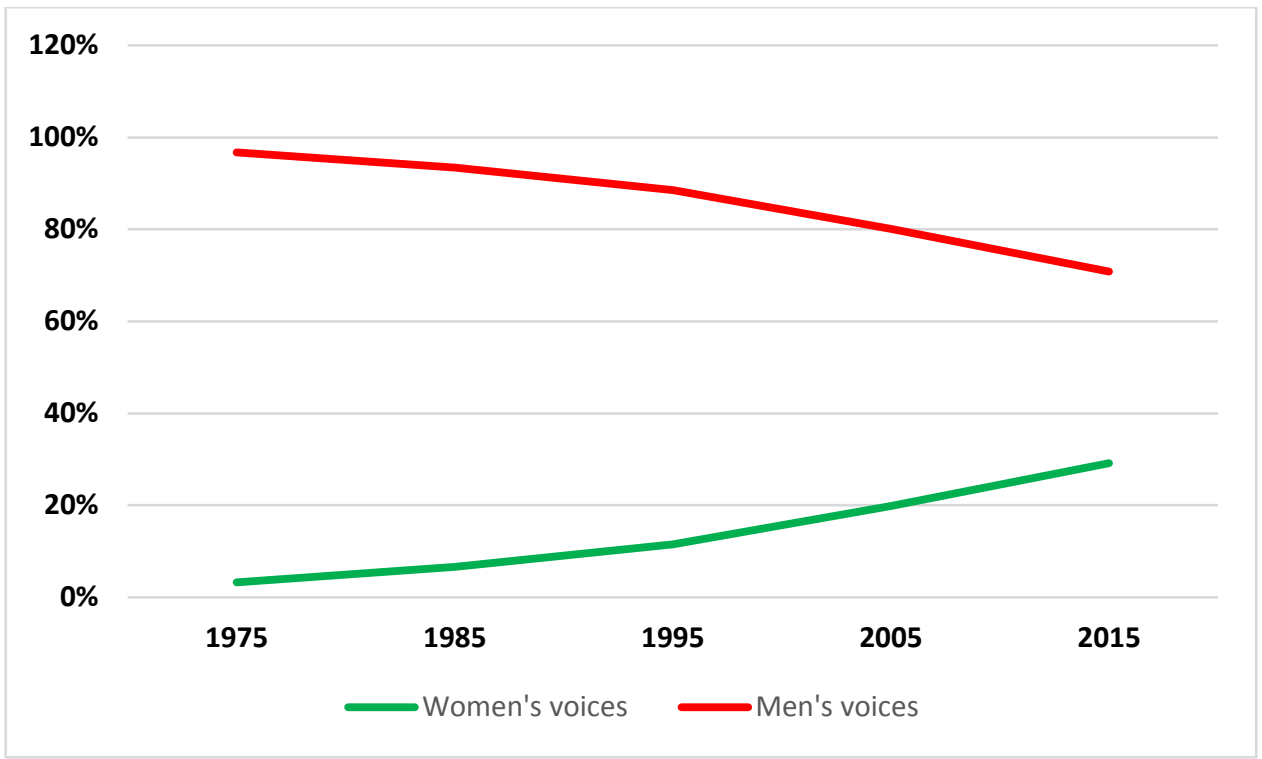

Both

The 'both' category (coded in yellow) shows the number of articles where men's voices and women's voices are present. Again, women's voices in this category do not always carry the 'victim' status as previously explained. This category, although not a large one, exceeds the 'women's voices' category across all five individual years, with the most significant difference being the jump from 16 articles in 1975 to 80 articles in 1985. In 1995 there are 54 articles in the 'both' category (much less than the decade before), and 2005 sees 74 articles. In 2015 there are 65 articles, this total being in the mid-range between 1995 and 2005. Although this could be seen as a positive finding that women's voices are being heard, they are accompanied by men's voices. Therefore, women's voices in the 'both' category (whether as victims, CJS professionals ${ }^{17}$, relatives or friends of the victim, women working in sexual violence agencies, and women speaking on behalf of the perpetrator), are not holding full control of the article's commentary.

\footnotetext{
${ }^{17}$ For the years 1975 and 1985 I found no mention of women as CJS professionals being quoted in the articles. Women became visible in this area for the years 1995, 2005 and 2015.
} 
Unsure

Articles in the 'unsure' category (coded in grey) are where the article's voice is 'genderless'. This means I was unable to tell if it was women or men who were retaining the controlling 'voice' and the gender of the reporter is not given. In 1975, there were 59 articles that occupied this category, 1985 produced 180 articles, and in 1995 there were 84 articles. Articles in this category often had NZPA (New Zealand Press Association), PA (Press Association) or 'staff reporter' as the author, and this was most common in reports from 1975 and 1985. Articles in the 'unsure' category are predominantly short, factual court-based reports with minimal information given about the rape. Below are three examples from the years 1975, 1985 and 1995:

A man will appear in the North Shore Magistrate's court today after an incident in Takapuna yesterday morning in which a young married woman was allegedly bound hand and foot and raped at knifepoint in her home ("Rape Charge", 1975).

A masked man raped a woman at knifepoint in her Otahuhu home early yesterday. Police said the woman woke to find a man wearing a balaclava and armed with a knife in her bedroom. He raped her while her small child and baby lay sleeping in the same room. Her husband was working at the time and her brother was undisturbed in another room of the house ("Woman raped at knifepoint", 1985).

A woman was raped and left unconscious on the floor of a toilet at the Wellington Railway Station for three hours yesterday, Wellington police said ("Second rape reported", 1995).

The 'unsure' category is a particularly interesting finding because from 1975 - 1995, the number of articles exceeds the 'women's voices' and 'both' category, coming second only to 'men's voices'. As Edwards (2016) has observed, newspapers in New Zealand thrived commercially in the 1960s, 1970s, and into the 1980s, with news organisations routinely covering their local courts. As a young journalist, Edwards spent one day per week at the Nelson District Court reporting on every case that came up that day; those stories would then appear in the paper the next day informing readers of what cases had appeared in court. Edwards argues that one of the simplest definitions of journalism is 'being there', and that is journalism practice at its best (Edwards, 2016). I, however, see the practice as transcribing 
notes from the court with no engagement from either the writer or the subject of the story. In the instance of rape cases, perhaps this is why so many of the articles I gathered were placed in the 'unsure' category for the years 1975, 1985 and 1995 as they were rendered 'genderless' and presented as a purely factual report.

Post-millennial reporting for 2005 and 2015 shows that newspapers began to publish the name(s) of the journalists and there is a shift away from ambiguous reporting practices, making it clear whose voice is being expressed in the article. For 2005, this category produced 35 articles (yet remained higher than 'women's voices'), and 2015 produced 31 articles (slightly under the 'women's voices' category). It is important to note the perspective of the writing when reporting on sexual violence in newspaper reporting, and there are three areas that Morant (1999) argues should be considered: 1) who is the subject of the story, 2) from whose perspective the article is written, and 3) whom is the reader intended to identify with? (Morant, 1999). If none of these features are present, then writing in this manner can silence female rape victims because the article remains 'genderless' and the end result is that no-one possesses a voice, least of all, a woman.

\section{Chapter Summary}

This chapter has presented my quantitative results regarding the total number of articles on rape collected across each of the five individual years (1975, 1985, 1995, 2005 and 2015) and

the total number of cases at each of those years. A further layer of analysis involved a gendered breakdown of the articles revealing four strands: 'men's voices', 'women's voices, 'both', and 'unsure'. What can be drawn from this chapter is the significant finding that women's voices, when compared to men's, are barely audible regarding commentary on rape cases in New Zealand newspapers. The next chapter explores my qualitative findings from the research. 


\title{
Chapter 5: Qualitative Findings
}

\author{
Why is it so wrong to hear the truth about the issue of women being raped? \\ Because a woman writes about a woman's perspective on rape, it should not be \\ condemned (Gooch, 1995).
}

This chapter discusses my qualitative findings and showcase three dominant themes that emerged through my reading of the data. As noted in Chapter Three, the amount of data I collected exceeded the scope of this study and there were many other themes and findings that emerged whilst conducting my ethnographic content analysis (ECA). Some of these included a focus on 'false' allegations', promoting selective cultural explanations for rape (see Kitzinger, 2009), differences between metro and regional coverage, the highlighting of a woman's pregnancy during rape, an over-representation of prostitute rape, the focus on alcohol and/or drugs as excusing factors for perpetrators, and the way newspaper headlines changed over the four decades ${ }^{18}$. These are all worthy of investigation but beyond the scope of this thesis. The themes I discuss in this chapter are: 'stranger danger', 'fear rape, take responsibility' and 'real rape' only happens to 'good women'. These themes emerged whilst conducting my ECA and then I investigated them more intensively using a Foucauldian Discourse Analysis (FDA).

To arrive at the three themes, I approached the data guided by the following research question which draws on Carla Willig's (2008) interpretation of a FDA:

\section{How is rape being represented and/or constructed in the articles?}

Chapter Three described how a FDA is concerned with how language constructs social life. A Foucauldian view holds that discourses (through the act of constructing) enable and limit what can be said and done in relation to that construction. Discourses make ways of seeing the world both possible and impossible (see Willig, 2008). This is an important question to ask because the ways rape is constructed limits the way that women as rape victims can be thought about by the general public, responded to by the criminal justice system (CJS), or how women as victims think of themselves. By adopting a FDA methodology, I saw the themes as

\footnotetext{
18 The capitalisation of each headline word particularly from the years 1975 and 1985 is an interesting finding, yet from 1995 - 2015 this trend was less apparent (see Appendix B).
} 
'discourses' or discursive formations. I understand that in making my interpretations, I draw on my own social position as a feminist researcher in the sexual violence field, and acknowledge that my work experience with Wellington Rape Crisis affected the preunderstandings that I brought to my readings of newspaper accounts of rape. Morant (1999) states that it is crucial to remain aware of factors that may impact the construction of research findings, so therefore, my analysis is one possible 'reading' of this material rather than a single, definitive 'truth' or an objective 'final word' on the topic (Morant, 1999). Each of the three themes are explored using examples in chronological order from 1975 - 2015 from my selection of newspapers.

\section{Stranger Danger}

Across the four decades of analysis, the stranger rape theme is dominant. The total amount of rape cases across all five individual years and all publications was 1053, and those classified as 'stranger rapes' was 555 ( $52.7 \%$ of the total). This is significant because more than half of rape cases reported to the press were classified as a stranger rapes. The scenario of intruders breaking into young women's homes was common:

The 24-year old woman awoke to find the intruder, armed with a kitchen knife in her bedroom. The man taped her eyes shut and pricked her throat with the knife to make her submit ("Woman Raped At Knifepoint", 1975).

As were attacks on elderly women:

A 64-year old woman was set upon by a man who jumped through a window he had forced open. The man had punched her to the floor, half throttled her, and attempted to rape her. Leaving her lying on the floor, he stole $\$ 180$ from her purse and ran off. Thirteen hours later she dragged herself to a nearby shop to summon help ("Vicious attack on elderly woman", 1975).

The central city streets were also a place of sexual attacks by strangers:

Pedestrians walked past without offering help or calling police while a 17-year old girl was being indecently assaulted by a young man in Willis Street on Monday evening. They fell to the ground while he was 
trying to get her panties off; she was screaming and crying but no one came to her help ("Girl's Cries To No Avail", 1975).

This report indicated that even with members of the public present, the CBD streets were not a place of safety for women. The headline: Struggle, shout, scream... And know when to stop quoted a male police detective saying:

Of course a woman should struggle, shout, and scream if she is attacked, however, there is a point when an attack has got to a stage where the woman would be in even greater danger should she continue to fight back or make a noise ... it did not always pay for a woman to resist her attacker ("Struggle shout, scream", 1975).

This statement actually prepares women for being attacked by a stranger and gives advice on what to do should you be attacked. I find it interesting that a male police detective should also advise women not to defend themselves against attackers. The consequence of this is that the onus is placed on women to prove their efforts to resist an attack or sexual assault but only up until a point, rather than that responsibility being placed with men and their behaviour. In one case from 1985, the Evening Post reported the story of a woman making her ill-fated walk home after having her keys confiscated by police for drinking and driving. The woman was:

Gagged, a noose tightened around her hands and neck, and dragged along the ground to a grassed area where she was raped ("I was rapist taunt", 1985).

The attack came hours after the screening of a television film which had a scene similar to the one described. Comments like the one below were sent as a letter to The Evening Post by a man claiming to be the rapist:

It is true that some women enjoy being raped. It enlivens their somewhat drab existence ("I was rapist taunt", 1985).

A week later, the man denied any connection with the attack. The letter was thus a hoax and he had told police he was full of remorse. Despite the man's apologies, this comment reinforces misogynistic attitudes towards women as sexual objects, and the nature of female 
sexuality is that all women secretly want to be raped (Benedict, 1993; Griffin, 1986). Furthermore, Griffin argues that the notion that rape is enjoyed by the victim is also convenient for the man who, though he would not commit forcible rape, enjoys the idea of its existence (Griffin, 1986).

The presence of accompanying physical violence and/or a weapon involved is also present in the stranger rape scenario. Types of violence included grievous bodily harm, the use of firearms, knives, sadistic violence, and torture. It was reported by the Otago Daily Times (ODT) that "rape required serious violence" ("Gaoled for four years for rape", 1985) which only serves to perpetuate the myth that rape victims must display physical injuries for the act of rape to be taken seriously, ignoring the very real mental pain suffered by rape survivors (Ruth, 1984; Shapcott, 1988).

Attacks on elderly women were again seen in 1985:

The dead woman was Ellen Dixon, aged 71. The arrested man, aged 34, unemployed, will appear in the District Court today charged with the murder and rape of Mrs Dixon. Mrs Dixon's body, which was naked from the waist down, was found by two young relatives who called at her flat about 9am on Saturday after they saw a door ajar ("Arrest after fatal attack", 1985).

This trend continued in 1995:

A 37-year old man was arrested yesterday and charged in relation to the rape of an elderly woman, aged 82, in Christchurch. The rapist entered the woman's flat through an unsecured window about 4 am. He threatened to kill her if she cried out and repeated his threats while raping her ("Arrest after rape of elderly woman", 1995).

My analysis of The Press from 1985 and 1995 showed that the rape of elderly women by young strange men was common, a finding consistent with Ruth (1984) and Taslitz (1999). Ruth's (1984) study indicated that The Press focused their attention on cases that outraged the public more and so prominence was given to attacks on the elderly because they were seen as more serious than the rape of middle aged women.

Interestingly, the 'noose around a woman's neck' method was again seen in 1995 regarding a stranger attack: 
A woman was dragged into bushes by a cord around her throat, police said. The tightness of the cord caused the woman to black out momentarily. After dragging the woman to some nearby bushes the attacker used the cord to tie the woman's hands. He then put a balaclava over her head and raped her ("Rapist used cord to drag woman", 1995).

A daytime rape of a woman at Victoria University of Wellington by a stranger was reported by The Evening Post:

The woman was allegedly approached from behind, threatened with a knife and raped in the Mount Street cemetery on August $3^{\text {rd }}$ at approximately 10am. While police had been told of the daytime rape, no action could be taken as the woman did not want to lay a complaint. She did however, want the incident made public so other students were aware (MacDonald, 1995).

The high-profile case of serial rapist Joseph Thompson also swamped the press for 1995, with newspapers publishing full page spreads, images, maps, and timelines of Thompson's offending. This case reinforced to the public that 'stranger rape' was a very real phenomenon, and women needed to take steps to ensure their safety. Following this, newspaper media sought commentary from the then Rape Crisis national spokeswoman Toni Allwood who stated that 'stranger rapes' are, in fact, a minority of all rape attacks:

Although there are various strategies that can be employed to deflect a rapist, some work and some do not. You cannot predict what an attacker will do. Although this scenario concerns stranger attacks which are the tip of the iceberg, as most rapes are carried out by a person who knows the victim (Aldridge, 1995).

This example is an anomaly it seems, in the theme of 'stranger danger' presented by the media that most rape was perpetrated by strangers. This comment illustrates that women were commenting on these discourses at the time but the reality of rape by men that women knew, often intimately, did not penetrate into media reporting.

In 2005, we again see stranger attacks on elderly women, this time reported in the Taranaki Daily News (TDN): 
An elderly Taranaki rest home resident was allegedly abducted and raped yesterday by a 15-year-old youth. The sexual assault of the 82year-old grandmother happened in the early evening (Humphreys, 2005a).

And strange men breaking into women's homes:

Invercargill police are looking for a man who raped a woman at knifepoint at the victim's Lithgow St home yesterday morning. The woman, who lived alone, was raped about 2am yesterday after the man called at her house (Smith, 2005).

Police are appealing for public assistance after a 33-year-old Dunedin woman complained she was raped on Saturday. The woman was allegedly raped early in the evening at a McPherson St address by a man who was not known to her (Williams, 2005).

There were also incidences of rapes in bar toilets:

Detective Sergeant Roberts said it appeared a man followed the woman as she walked through the bar of the tavern before the incident occurred. The woman was in the toilet when the man pushed through a door and allegedly sexually assaulted her. The incident happened at a time when the bar was busy, and there were many potential witnesses (Oldham, 2005).

And in hostels:

Al Baiiaty was convicted in March by a jury of raping, assaulting and abducting a 20-year-old woman at a Porirua hostel he was staying. At the time of the attack, Al Baiiaty was on parole following a nine-year sentence for the knifepoint rapes of two Auckland prostitutes and assaulting a third with intent to rape her in late 1997 ("Iraqi refugee loses rape conviction appeal", 2005).

2015 shows the same tendency with the 'stranger rape' scenario visible in reporting practices.

The example below describes a Northland restaurant owner raping an overseas tourist:

The victim was travelling around Northland when she stopped at Riadi's restaurant. Riadi conversed with her and offered her a place to stay. Both smoked cannabis before leaving the restaurant and consumed more at Riadi's home. When she left for one of the bedrooms Riadi followed and raped her ("Rapist appeals conviction, sentence", 2015). 
A large rape and murder case dominated the press in 2015, that of Blessie Gotingco, from the North Shore. She had caught the bus home after finishing work one evening and was then run over and abducted:

The Crown says the 28-year old man charged with Mrs Gotingco's rape and murder was behind the wheel and deliberately drove into her. After the collision, it was alleged he bundled her into the car and took her back to his apartment complex nearby, where he raped her, slit her throat and stabbed her to death (Kidd \& Ryan, 2015).

The New Zealand Herald (NZH) reported the sexual assault of Wellington woman Tania Billingsley by a Malaysian diplomat:

21-year old Billingsley was alone in the bedroom of her home when Rizalman broke in. He took off his pants and underwear before opening the unlocked front door. Inside he took off his jacket and, wearing only a shirt, pushed open the bedroom door, saying 'can I come in?' ("Inside the Rizalman fiasco", 2015).

And the daytime rape of a Lower Hutt woman was reported by The Dominion Post:

Bailey Meredith admitted beating and raping a pregnant woman along the Hutt riverbank at lunchtime on June $11^{\text {th }}$. The 30-year-old professional woman in the early stages of pregnancy was out for her regular walk. Meredith forced her into thick bush, held a knife to her throat and sexually violated her. He kicked her in the head and body, taking off after she fell unconscious ("Riverbank rapist, 17, pleads guilty", 2015).

My analysis shows the 'stranger danger' scenario being reported on from a variety of locations, signalling to women that nowhere is safe from rape. Whether at home, on the city streets, in crowded nightclubs, at university, on public walking tracks, after using public transport, or being a tourist - all of these places are dangerous. The message is thus clear: rape can happen by a strange man to a woman of any age, anywhere and anytime. A 'stranger danger' focus portrayed by newspaper media thus promotes fear in women and limits selfdefinitions and reporting from women raped by men they know, therefore making rape invisible within intimate partner violence contexts. This portrayal of rape is also unrealistic given the vast majority of sexual violence in New Zealand is committed by someone known to the victim (often intimately), occurs mostly indoors and usually does not involve additional physical force (Heath et al., 1981; Kingi, Mossman, \& Jordan, 2010; Lynch, 2015; Wellington 
Rape Crisis, 2014). As Lynch (2015) has previously argued, the stranger rape scenario so often displayed in newspapers has the equally damaging effect of discounting the experience of survivors who are offended against by acquaintances, family members or partners. These portrayals of rape in newspapers distort the true reality and context of sexual violence and underestimate the extent of these crimes, and in doing so render silent the experiences of women and the reality of sexual violence attacks.

\section{Fear Rape, Take Responsibility}

I have never been free of the fear of rape. From a very early age I, like most women, have thought of rape as part of my natural environment - something to be feared and prayed against like fire or lightning. I never asked why men raped; I simply thought it one of the many mysteries of human nature (Griffin, 1986: 1).

My second theme, 'fear rape, take responsibility', is perhaps to be expected given the type of language that newspaper media was presenting to the public, especially in 1975. Police advice from this year was:

Women were not to be out alone after dark, and that women who got off buses at unlit stops were asking for trouble ("Women Run Risk Alone After Dark", 1975; "Rush on real, imagined rape", 1975).

In other words, women were being told by newspaper media they were not allowed to go out at night on their own, let alone use public transportation. It seemed that women even existing meant that they were likely to be the victim of an attack or sexual assault. The advice presented by the press in the above quote, is, I would argue, from a male police officer given the statistics on women's participation in policing at the time. Based on figures from Hyman (2000) and Redshaw (2006), the proportion of female officers who were sworn and in the Central Investigation Branch in the 1970s was very low. In 1970, there were 74 female officers (2.37\%), in 1975 there were 159 (3.86\%), in 1976 there were 190 (4.39\%), and in 1977 there were 169 (3.78\%) (Hyman, 2000; Redshaw, 2006). By 1980 this had slightly risen to 210 (4.23\%) (Hyman, 2000). These percentages did not reflect advanced moves towards equality but did reflect the policy of keeping the number of policewomen in New Zealand at around 
4\%. It was not until 1989 that $308(6.5 \%)$ officers of the total force were women (Redshaw, 2006).

The following quote emphasises women's safety further, mentioning that a safety chain was to be used on doors at all hours of the day to prevent rape:

Women living alone or left alone in houses should be especially careful before they open doors to anyone or at least find out first who is there. It doesn't matter if she is wearing nightwear or not. A safety chain was a great asset - but to be effective they had to be used all the time ("Sex Attacks Warning To Women", 1975).

Women were thus advised not to venture out whether day or night, and to stay in their homes. If they did go out, however, there was a product called 'anti-rape spray' (similar to pepper spray) that could be used ("Anti-rape Sprays 'Illegal'”, 1975). Examples of women using products and carrying items in order to prevent rape draws parallels with advice given from health and safety staff at Massey University Wellington in 2014 after a woman was raped near the campus. The advice from staff strongly suggested that women should take responsibility to prevent an attack by wearing running shoes, and to carry a torch and a whistle while walking at night (Shadwell, 2014).

Comments from 1975 also illustrated that women were expected to 'take responsibility' in managing men's biological urges. The examples below are comments from male judges addressing perpetrators, and they base the act of rape on uncontrollable sexual urges:

You are at a difficult age in your life and were overcome by your own sexual desires ("Rape case", 1975).

Mr Justice Coates said: The fact that your strong sexual urges are a danger to women in our community and you are afflicted with heightened sexuality (“Prisoner Termed 'Danger To Women'”, 1975).

This calls into question an age old sexual script that women are 'sexual gatekeepers' who must manage men's biological urges and are responsible for protecting themselves against rape (Franiuk et al., 2008; Griffin, 1986), which results in many women internalising a sense of responsibility for men's sexual pleasure (Kelly, 1988). The consequence of this is that men are excused, and women are blamed for the act of rape. 
In 1985, the ODT reported that a male police detective advised the public to:

Lock all doors and keep all windows shut at night, as attacks on people in their homes, especially young women, had shown a sharp increase this year ("Attack prompts police warning", 1985).

Ruth's (1984) study had similar findings where rape articles from The Press in 1982 reported implicit warnings to women about taking responsibility for their safety. Similarly, in the sentencing of a man accused of rape in Auckland, a male judge quoted that:

It was somewhat a sad commentary that Auckland was a dangerous city. Any young woman who associated with people such as Harris without finding out anything about their background was running a grave risk (“Attack Was Savage, Brutal Says Judge”, 1985).

In this case, the woman had been in a man's car going to a social event when without warning, he attacked her. It was thus a woman's responsibility to manage who they associated with and it was women who needed to manage 'risky' situations. After a 1985 gang rape, the 'fear of rape' had, according to the then Tauranga mayor, Noel Pope, escalated to a level where nowhere in New Zealand was considered safe:

This horrifying attack brings very quickly to everybody's senses that no area in the country can escape this kind of thing happening ("Search still on for gang rape site", 1985).

A letter to the paper in 1995 showed that women themselves were internalising that New Zealand was not safe from attacks, perhaps due to the amount of male commentary in newspapers reinforcing the 'fear rape' theme:

How many men actually think twice about walking to the dairy after dark? I think it's about time we started talking about curfews for men. From where I am standing, this society is no place for women to be safe (Gravett, 1995).

The following example below showed there were grave consequences for women should they not take responsibility in protecting themselves from rape. The headline Raped woman thought city was safe reads: 
A young woman raped at knifepoint in a central Hamilton carpark had stopped carrying a personal alarm because she thought it was a safe city. The man raped the woman in daylight as she walked home from work at about 6pm. The attacker, armed with a knife, threw her into a flower bed and raped her ("Raped woman thought city was safe", 1995).

A headline regarding the Joseph Thompson case from 1995: Curiosity turns to fear for serial rapist's victim details a woman's fear of seeing Thompson in court for the first time. She explained:

I wanted to see his face in court so I could no longer have to fear that any man walking past me on the street was a rapist and I wanted to end the trauma endured since the rape. I used to walk down the street thinking "it could have been you, it could have been you" ("Curiosity turns to fear for serial rapist's victim", 1995).

2005 also emphasises the 'take responsibility' theme in reporting practices. The following headline from the TDN Warning for women after nights gone wrong amplifies the fear of a rape attack after two sexual assault incidents in New Plymouth. Police advice warned women to be 'on their guard'. Detective Ross Lilley said he was:

Shocked to see at least six young women walking along the streets alone. As a result we are issuing a general warning to young females that when they are out drinking to be on their guard and watch out for themselves (Humphreys, 2005b).

In the same year, Dunedin police stated that:

People need to think of their safety when walking alone (Rae, 2005).

Women were to not only 'fear rape', but also fear men who might kidnap or abduct them:

A man who kidnapped and sexually assaulted a woman at Tiwai last year had a 30-year history of sexual offending. Athol Waters was also sentenced for kidnapping and indecent assault ("Sex attack brings jail", 2005).

Police advice in Invercargill advised women to stay indoors and lock themselves in: 
City folk needed to remain vigilant and aware of the dangers offenders such as Maxwell Franklin presented, two Invercargill detectives noted this week. Detective Sergeant Mark McCloy said "people need to know there is still a street rapist out there. It was disappointing to see how many females were walking home after the incident when police had appealed for street safety. When out at night, stick with a group of friends and use a taxi to get home or walk with a group. Make sure all windows, doors and garages are shut before you go to bed. In a flatting situation, bedroom door locks can add personal security" ("How cops netted city sex fiend", 2005).

The comment above mirrors police advice three decades earlier in 1975 , where preventing rape is solely a woman's responsibility anywhere and anytime. In 2015, there are similar trends. One headline reads 50 years of feminism hasn't stripped away women's fear of men ("Fifty years of feminism", 2015). This is a powerful headline, but not in a positive way. The article illustrates that 'stranger danger' is specific and contextual, and uses the one night stand as an example - the man is a stranger and our attitude to this stranger reflects our attitude to all strange men, or men in everyday life that women encounter. Further, the article shows that in 2015, responsibility is still being placed on women to protect themselves from rape or sexual assault. Women are taught that rape is avoidable and so, when it happens, it is partly their fault (Taslitz, 1999).

A letter to the NZH from a woman titled 'rape responsibility' reads:

We would all like to be able to go anywhere at any time and not get assaulted or raped. The reality is, you cannot. Being in the city at $2 a m$ is risky in itself, but if a woman is also drunk, alone and showing a lot of flesh, her chances of getting pestered only increase. Yes, women should be able to go anywhere freely. But responsibility? The victim, or her parents are partly responsible ("Letter to the editor", 2015).

Although the hard work done by feminist activists from the early 1970 s onwards is credited for the shifts in societal understandings of rape today (Gavey, 2005), it is apparent that newspaper reporting across the time period I examined warns women of their vulnerability which can promote fear. Ideas about women's safety portrayed in newspaper accounts construct women as needing to manage their own vulnerability and in need of protection, rather than identifying male behaviour as the issue that needs to be addressed. 


\section{'Real Rape' Only Happens to 'Good Women'}

A woman is ordinarily expected to be mute, yet she is expected to and must speak promptly and loudly, and in anguish, if there is a 'real' rape. She will be judged by the cultural themes of silence and voice, not by the natural psychological reactions to rape or an informed understanding of its causes and circumstances (Taslitz, 1999: 24).

The last of my themes, 'real rape' only happens to 'good women', was discovered through analysing the language that men (as CJS professionals or perpetrators) were using to describe female rape victims. This theme is solely based on the 'men's voices' category as this was the largest of all four categories that I coded, comprising 948 articles out of the total sample of 1833. Across each of the five individual years, if the rape case did not fit the 'real rape' stereotype, then a woman's character and credibility was heavily questioned. Factors that affected this were prior alcohol consumption, a woman's sexual history, or the absence of injury. In 1975, there are conservative views regarding women's behaviour and the language that men use heavily implies that rape is a woman's fault because she 'led on' her attacker, was an 'easy girl', or 'got what she was looking for'. The following quote from Mr HughesJohnson (a defence lawyer) highlights examples of this:

It was not a bad case of rape. There could not be much sympathy for the woman because the company she kept made it almost inevitable that she would be raped. She was grossly intoxicated when the offence was committed ("Three-year prison term imposed for rape", 1975).

This statement is problematic for a few reasons. Firstly, it brings into question the ability for the act of rape to be classified as having levels of harmfulness, or suggesting that some rapes are not as bad as others. Alternate rewordings from 1975 were "not the most serious kind" or "not a bad one", implying that only those rapes classified as 'serious' warrant further investigation and anything less will be dismissed. Alternatively, rape cases were described as "very serious", "particularly nasty", or as this example below shows, "one of the worst":

Detectives said yesterday that the rape was one of the worst of its kind in recent times ("Assault and Rape Victims", 1975). 
A critical feminist view would argue there is no such thing as a 'bad case of rape' or a 'serious kind of rape' - all rape is serious and women's experiences of sexual assault cannot be compared. The consequence of using such language diminishes a woman's experience as a rape victim and fails to capture the levels of harm that women experience regarding sexual violence. Secondly, the comment alludes to rape being committed due to the woman's character being called into question. By highlighting the company that the woman was in at the time and the people she associated with, these become the reasons for being raped. The woman is constructed as someone who does not deserve compassion, a risk taker who 'got what they were looking for' and who has a problem with alcohol. This is a frame commonly employed against rape victims; demonstrating that the complainant is the type of girl to consume alcohol, it helps to construct her as 'unrapable' (see Childress, 2016). 'Rapable' victims are young, innocent females who do not engage in such 'unbecoming' behaviours as wearing risqué clothing or drinking (Childress, 2016). Recent research on young women and alcohol consumption in the New Zealand press identified that the media constructed a "bad girl' discourse - a woman who is "overtly intoxicated and aggressive" (Wright, 2016: 640). This subject position does not adhere to appropriate feminine behaviour and so any woman occupying it is likely to be looked upon negatively; behaving in such ways still incurs moral judgements about appropriate femininity (Wright, 2016).

Engaging in sex prior to being raped also deemed the female rape victim to be unworthy of sympathy:

The complainant had suffered no harm because she was no stranger to sex ("News from the Supreme Court", 1975).

Below is an example of a 'good woman' from 1975. She was abducted at knifepoint while walking alone at night and taken to the Auckland Domain where she was raped. While the woman is represented as 'good', the perpetrator is not, playing into the 'real rape' stereotype (see Shapcott, 1988):

Mr Ryan said it was fortunate the complainant was a sophisticated lady who was able to deal with the situation and who emerged relatively unscarred. What caused an otherwise normal Polynesian to embark on the incident might indicate the need for psychiatric treatment (“Man gaoled for rape", 1975). 
The idea of a 'good woman' was not, in the eyes of the press, a sex worker. Prostitutes were constructed as 'bad', foolish, and stupid. Mr. Kohn, a defence lawyer quoted:

Intercourse would have been the least distasteful aspect of the incident for her as she was not a stranger to prostitution. If she had any sense she would not have accompanied four strangers in a van (“Four Jailed For 'Vicious' Assault And Rape", 1975).

Polarised media representations of women reflect the paradoxes and contradictions in how femininity is socially represented. Women are either presented as innocent and pure, or as the opposite - sexually experienced and seductive. These examples of the 'good' or 'bad' woman in newspapers are anchored with historically established ways of representing women - in this case the virgin and the whore (Benedict, 1993; Morant, 1999).

The following passage takes a different approach:

I have never heard any witness's evidence so liberally studded with: "I don't knows, I can't remembers' and I'm not sures" as this girl's was. She failed to supply the detail necessary to prove rape or attempted rape ("Jury finds youth not guilty of rape", 1975).

This statement constructs the woman as one who is to be disbelieved that the act of rape occurred. The defence lawyer is suggesting that a crime did not occur, which only serves to minimise the offence and excuse the perpetrator. The woman is categorised as having memory loss, being vague, and unable to prove that a sexual assault took place; omitting that these might be very real symptoms that a woman would experience in the wake of a sexual assault, especially if intoxicated and the perpetrator exploited her vulnerability. As Taslitz (1999) has argued, defence counsels often draw on themes of silence to craft a courtroom story of the lying woman, thus by definition revising the rape narrative to one of consensual sex. Since the passing of the Evidence Amendment Act 1977, a rape complainant's past sexual history has become inadmissible as evidence (Cook, 2011a) sometimes referred to as the "rape shield" provision (McDonald, 2014: 490). Prior to this, a woman's sexual history was allowed to be discussed in front of a jury. Cook (2011b) argues that juries would have been predominantly male in 1975 which may have led to the female rape victim being on trial for her sexual mores thus removing focus from the accused. 
Examples from 1985 also demonstrate that a woman's character and credibility is questioned regarding rape in a number of ways. The quote below serves to equate rape as 'sex' after a man was found guilty of raping a pregnant woman in her car after she stopped on the roadside to help him:

The defence was asking the jury to believe that she turned into a sexual temptress wanting to have sex with a tattily dressed and heavily tattooed man and that she egged him on ("Man Found Guilty Of Raping Woman in Car", 1985).

The headline Defence says rape 'victim' prostitute alludes to the woman not really being a victim, therefore rape did not occur because she was not seen as 'good':

Mr Harder said the complainant was a 'hooker' working in $K^{\prime} R d$ to pay for a drug habit ("Defence says rape 'victim' prostitute", 1985).

The next example refers to the woman being 'immoral' and 'improper', stepping outside the bounds of femininity and therefore being at fault:

John Causer had made allegations during his trial that the girl had acted in an immoral and improper way and was guilty of wholesale perjury ("Rapist jailed 5 1 12 years", 1985).

Comments from Mr Justice Hardie Boys emphasised a woman's immorality further:

Because a girl worked in a massage parlour it did not necessarily follow that she would be satisfied with the concrete floor of a parking building as a place to have sex ("Man convicted on rape charge", 1985).

Although the male judge is trying to sympathise with the victim, his statement is concerning as the unintended conflation of rape as 'sex' dismisses the crime by referring to the woman's profession and the rape in the same context. He further indicates that the sexual acts could be linked which reduces the woman's worth to her profession, and her voice and authenticity are subsequently placed on trial.

Another interesting aspect from the previous two examples is the use of the term 'girl' when describing women as rape victims. Lesley Stirling's examination of the linguistic treatment of 
women in Australian newspapers in the year 1979 found that women were either excluded or defined narrowly and negatively through a range of inappropriate and derogatory expressions and techniques. Stirling's analysis found that newspapers used descriptors such as "girls" (p. 111), "pretty girls" (p. 115), "pets" (p. 111), "beauties", "blondes", or "brunettes" (p. 112) (Stirling, 1987). Although not directly related to rape representation, Stirling's study provides insights into how women were talked about in Australian newspaper media in the 1970s and her findings align with the current study.

The trend of conflating rape as 'sex' continues into 1995:

One businessman called her 'dangerous' and said he always had the impression he could have had an affair with her if he had wanted to. He was quoted as saying that "one probably wouldn't have to revert to rape to have a relationship with her" ("Sorry tale of small-town 'injustice'”, 1995).

If there were no physical injuries present after rape, it implied that a woman's complaint was less serious:

Pointing out there was no evidence of a struggle or resistance by the woman, Mr Atkinson suggested the offence was at the lower end of the scale and had been in circumstances "close to consensual" ("Name suppression application denied", 1995).

In the statement below, the judge actually asks the jury to "put aside their feelings", implying that have preconceived notions about a woman's character and credibility would already exist:

Justice Hansen, in his summing up, told the jury that the trial turned on credibility, especially that of the woman. He said they must put aside any feelings they had of sympathy or disgust ("Jury fails to find verdict in sex trial", 1995).

Female rape victims were described by men as "foolish" and responsible for their own predicament. In this example, the woman is constructed as a "sexual plaything":

While the victim was foolish to go with the men to the Coastal Riders Club rooms, "our law protects the foolish and weak as well as it protects the wise and the strong" said the judge. The woman became 
their sexual plaything for about two hours ("Coastal pair jailed for sex attack", 1995).

Reports in 2005 display women's character and credibility in regards to lying about rape. Women who had engaged in 'sex play' were labelled as promiscuous, and the conflating of rape as 'sex' was seen in a Mount Maunganui gang rape case where multiple men were perpetrators. The Dominion Post stated the rape was:

Some kind of porno fantasy, portraying the woman as a slut who welcomed sex with men in sleazy circumstances ("Victim of rape or haunted by memories?" 2005).

Three decades ago, Susan Griffin noted that:

The whole issue of rape seemed to revolve around whether or not one could trust a woman's word; and behind this questioning of our word, whether one could trust a woman's being, whether we could trust our own being (Griffin, 1986: 26).

Griffin's words align with the Mount Maunganui case, and examples of women's words being disbelieved was noted by the perpetrators who commented to The Dominion Post:

The issue is one of credibility, she had lied. She was very passionate and forward and was a hottie who sought out sex ("Rape claimant 'a hottie who sought out sex'”, 2005).

The following day, the ODT quoted the perpetrators again and discusses the woman's 'lies':

We thought it was best to meet in person so we could discuss her lies and our innocence. We were under pressure. We needed each other's support ("Man accused of rape and abduction", 2005).

Women's words in rape trials have historically been disbelieved or treated with suspicion, as they are regarded as too subjective or unreliable as a basis for determining guilt or innocence on such a serious criminal charge (Edwards \& Heenan, 1994; Taslitz, 1999). Even if women were believed, they were just as likely to be blamed for the whole event (Gavey, 2005). 
Evidence of this goes back to 1970s California, where juries were given the following instructions:

A charge such as that made against the defendant in this case is one which is easily made and, once made, difficult to defend against, even if the person accused is innocent. Therefore, the law requires that you examine the testimony of the female person named in the information with caution" (LeGrand, 1973: 932).

In a study of six rape trials in Australia, Edwards and Heenan (1994) noted that even when there was a consistent and credible story from the complainant and no motive for lying, unless there was clear evidence of violence, defendants were not convicted. This demonstrates that the CJS still operates, in some cases at least, with a degree of inherent suspicion and distrust of the female rape victim. The concern then, is to protect the male accused from the perceived injustice of a conviction based solely on the word of a woman (Edwards \& Heenan, 1994). The focus on a woman's character and credibility is prominent in 2015 , as is the conflation of rape as 'sex'. Defence lawyer Keith Jefferies commented to a female victim after a rape attack in central Wellington:

She should have closed her legs, it's as simple as that. Why didn't she do that? Because the sex was consensual, as easy as that (Shadwell, 2015).

This example from The Press alludes to the act of rape being consensual:

A drunken 16-year-old girl was raped by a group of men at a beach, but the defence says it was a case of willing sexual activity regretted afterwards. The men charged told police that the girl was a willing participant in the sand dune sex. The jury would have to decide whether the complainant was a 'flirting seductress' or whether she had been taken advantage of (Clarkson, 2015).

\section{Chapter Summary}

This chapter has outlined my qualitative findings across four decades of New Zealand newspaper reporting, and focused on three dominant themes identified from my sample of newspaper articles - 'stranger danger', 'fear rape, take responsibility' and 'real rape' happens to 'good women'. What can be drawn from Chapters Four and Five, is the tendency for the 
press to over-represent stranger rapes which paints a false picture of rape to the public, given that the most typical and prevalent rapes that occur - those committed against women by partners, husbands, acquaintances, or family members - are the least likely to receive media attention (Lynch, 2015; Meyers, 1997). A significant finding is that police advice from 1975 mirrors advice given today about women's safety and suggests that it is a woman's responsibility to prevent rape's occurrence. This chapter also explored a woman's character and credibility in regards to rape, where comments were taken from the 'men's voices category. What is evident from my last theme is a strong victim-blaming rhetoric, conservative views about women's behaviour, and disbelief in a woman's testimony - all serving to represent and construct women rape victims as responsible for their own demise, unable to control their sexuality, and as liars. These factors place the sole blame onto the woman for her own demise and the seriousness of the offence is therefore discounted. 


\section{Chapter 6: Discussion}

\section{Women's voices and women's words still struggle to be heard; if heard, to be believed; and if believed, to be understood (Jordan, 2004).}

This discussion begins by exploring the worthiness of women's words in regards to New Zealand newspaper commentary on rape. Answered simply, women's words are worth little across the five individual years I have analysed, but I believe women are worth more than that, especially women as rape victims. These women deserve more than a simple explanation, and their voices need to be heard. I want to use this chapter to explore and identify some of the reasons why women's words, as Jordan (2004) so aptly notes, struggle to be heard, and are thus left silenced. I then move on to discuss the three themes I identified - 'stranger danger', 'fear rape, take responsibility', and 'real rape' only happens to 'good women' - before briefly covering challenges for newspaper reporting in the present day. I conclude with reflections from my research journey, and a list of recommendations to journalists for how to appropriately report on sexual violence cases.

\section{Where are the Women's Words?}

In 2005, The Dominion Post ran the following headline How could jury believe a woman? The article's comment is from the perpetrator:

I find it difficult to accept that the spoken word of a woman could be the basis for my conviction ("How could jury believe a woman asks Iraqi", 2005).

This example shows that a woman's spoken word is untrustworthy and worthless in a court of law when it comes to rape. More importantly, the woman is silenced (by a man) in regards to her experience. The common law requirement that juries be warned about the dangers of convicting on uncorroborated evidence has been gradually overturned in most Western jurisdictions based on English common law (Gavey, 2005; Mack, 1998). Nevertheless, judges have retained authority to comment on such issues in giving their instructions to juries, and it is still common in some places for judges to inform juries that it is dangerous to convict on the basis of the woman's evidence (Edwards \& Heenan, 1994; Mack, 1998; Myers \& LaFree, 1982). In other words, a general distrust existed among those making and administering the 
law of women's capacity or willingness to be truthful about evidence in a rape trial (Edwards \& Heenan, 1994). My findings show that judges and defence lawyers still blame women for making themselves vulnerable to rape by taking ordinary freedoms, and the gruelling crossexaminations women face in court still continue. Research from the Ministry of Women's Affairs (MWA) highlighted to the New Zealand public about the trauma of being involved in a rape trial through media reporting (Ministry of Women's Affairs, 2009). At the time of writing, the rape trial of Black Caps cricketer Scott Kuggeleijn was heavily focused on the denigration of the female victim's character and credibility by a male defence lawyer which thus enabled the jury to excuse the crime leading to his acquittal (Biddle, 2017; "Scott Kuggeleijn rape trial", 2017).

Wright (2016) has argued that those who speak about women (concerned citizens or journalists) have delimited categories with which to interpret the actions of women. Regarding female rape victims, a 'put yourself in their shoes' stance is not enough, unless the victim's testimony or account is presented word-for-word verbatim in a news report. In my analysis, I found that newspapers rely heavily, and sometimes exclusively, on those connected to law enforcement and the criminal justice system (CJS) as their main source of information, a finding consistent with an Australian meta-analysis of 48 studies on news coverage of violence against women (Sutherland, McCormack, Easteal, Holland, \& Pirkis, 2016). This reliance on police and court sources is evident in both New Zealand (Thakker \& Durrant, 2006) and international studies (Clifford \& White, forthcoming). Thakker and Durrant (2006) found that individuals within the legal system - police, lawyers, judges - are the most common source for news articles on sexual offending, with little input from mental health professionals or academics.

Writers of articles about sexual violence often use linguistic features that are functional in obscuring the perpetrator's responsibility. However, the assumption that the use of these features stems from a motive to exonerate the perpetrators and to condemn the victims though not implausible - cannot be supported with concrete evidence (Bohner, 2001). Similarly, early investigative work in a North American context showed that writers of journals (Lamb, 1991), and newspapers (Lamb \& Keon, 1995) when writing about men battering women, wrote in a way that avoided assigning responsibility to men as perpetrators, and this kind of writing was more common among male authors and female authors who wrote with 
other men. One area of concern in my analysis of the early years $(1975,1985$ and 1995) was the uncertainty of who was reporting on the crime. In other words, I could not tell whether it was a female or male journalist writing the article - consistent with my large amount of articles in the 'unsure' category. In 2008, Daniela Ripcikova analysed gender representation in the same British newspapers that Caldas-Coulthard (1995) examined (The Independent, The Guardian and The Times) and found out of 120 articles, men were quoted 248 times while women were quoted 68 times (Ripcikova, 2008). Ripcikova (2008) argues that women constitute a small number of news sources due to journalists' interest in the statements of powerful and authoritative individuals, and predominantly people in those positions would be men. Thirteen years after Caldas-Coulthard's (1995) research, it is apparent that British newspaper discourse is still dominated by men, and women remain underrepresented as speakers (Ripcikova, 2008). Regarding my study, it is possible that crime reporters were predominantly men in the early years, and changes to gender representation in New Zealand journalism balanced out as the millennium approached.

To remind readers of the 1985 case where a woman had a noose tied around her neck and dragged into the bushes where she was raped, I believe men still have a 'noose around women's necks' so to speak, when it comes to reporting and providing commentary on rape cases in New Zealand's newspaper media. Certainly the finding that women's words are not included contributes to the silence - but would an inclusion of their words break it, entirely? The inclusion of women's words for the sake of 'including women' in newspaper commentary on rape may not necessarily signal a positive change if the discourses women adhere to represent rape in terms of my three themes ('stranger danger', 'fear rape, take responsibility', and 'real rape' only happens to 'good women'). Regarding gender, women may have a very different experience of crime in the media from men (Schlesinger, Dobash, Dobash, \& Weaver, 1992), and different women may have different experiences from one another based on their personal histories, variables such as class and ethnicity (Doyle, 2006), and their previous experiences of victimisation.

Doyle (2006) argues the way forward for explorations of media effects or influences has been to move away from the construct of the imagined homogenous audience and instead, look directly at repercussions of representations of crime in the media. In Chapter Three, I asked 
a question inspired by Carla Willig's (2008) interpretation of a Foucauldian Discourse Analysis (FDA):

\section{How is rape being represented and/or constructed in the articles?}

As previously stated, a FDA considers how discourses enable and limit what can be said and done in relation to the construction of concepts, objects and subjects. I was interested in exploring the consequences of how rape (and women) were being represented/constructed in New Zealand newspapers across time. To do this, I asked a second question:

\section{What results from representing and/or constructing rape (and women) in this way?}

This question is important regarding the aims of the research as the construction of rape in certain ways by newspapers can affect the sociocultural environment within which rape occurs, limit how women as rape victims are thought about by the general public, responded to by the criminal justice system (CJS), or how women can think of themselves. Doyle's (2006) argument is consistent with a discourse analysis and significant for my study because the representation of rape is framed in the following three ways: the overrepresentation of stranger attacks, the warning to women to 'fear rape' anywhere and anytime, and the questioning of a woman's character and credibility that she somehow brought on the rape herself. The repercussions of each of these three themes is now discussed.

\section{Stranger Danger}

Of 1053 rape cases, 555 (52.7\%) were classified as 'stranger rapes' indicating that the dominant picture of rape presented through New Zealand newspapers was the 'stranger danger' scenario. Consistent across the five individual years, this picture of rape involved a man with a weapon, who is a stranger to the woman, attacking her alone, at night; a scenario vastly different from the reality of rape in New Zealand. Findings from the New Zealand Crime and Safety Survey showed that stranger perpetrated sexual offences accounted for only $2.1 \%$, 2\% and 1.2\% in 2005, 2008 and 2013 respectively (New Zealand Family Violence Clearinghouse, 2016). In other words, the majority of rapes are committed by men who are known to female victims as date rapes, acquaintance rapes or marital/partner rapes. However newspapers infrequently reported on these cases, perhaps due to them not being 
'newsworthy' which could subsequently diminish reader attention on these types (or categories) of rape. There is a lack of recognition by newspapers that much sexual violence involves repeated assaults by the same perpetrators, with a significant overlap between victims who have experienced both rape and domestic violence (Mossman et al., 2009a).

In a study relating to sexual offending across New Zealand, Thakker \& Durrant (2006) examined 377 articles in three newspapers (the New Zealand Herald (NZH), The Dominion Post and The Press) in the year 2003. There were a number of interesting findings from their study, and most importantly, issues pertaining to law and order and public safety were the themes explored most frequently in the articles. Rehabilitation was covered very infrequently, and a small number of high-profile (more serious) cases were over-represented (Thakker \& Durrant, 2006). These findings align with my theme of 'stranger danger' most notably in 1995, where the Joseph Thompson case illustrated similar traits. One of the implications in to providing extended coverage of rapes involving multiple victims is that it suggests to the public that stranger rape is widespread when the majority of sexual violence in New Zealand is committed by someone known to the victim (Kingi, Jordan, MoekeMaxwell, \& Fairbairn-Dunlop, 2009; Lynch, 2015). Overall, Thakker \& Durrant's (2006) findings suggested that newspapers tend to present specific aspects of information which means that in terms of print media, the public may not necessarily receive balanced coverage of sexual assaults.

A 2009 study by Triggs and colleagues assessed attrition rates in relation to reported adult sexual violation cases, and showed that sexual violation by a stranger accounted for only $16 \%$ of the cases, while in a further $15 \%$ of the cases, the victim had just met the offender (in the last 24 hours). This means that the majority of offenders (69\%) were previously known to the victims, either intimately or otherwise (Triggs et al., 2009). Despite the majority of rapes in New Zealand being committed by someone who is known to the victim, the newspapers and the time period I have studied present an image that is markedly different from this. Moreover, cases appearing in newspapers represent only the tip of the iceberg of national sex offences and are not representative of sexual violence experiences in general. Irrespective of the fact that the majority of sexual assaults are committed by people known to the victim, newspapers persist in presenting a picture of rape that is random and unpredictable (Clifford \& White, forthcoming). Therefore, perceived vulnerability is emphasised over actual 
victimisation (Jewkes, 2011). The reporting of stranger perpetrated rape by New Zealand newspapers across the 40 year period supports the myth that 'real rape' is only perpetrated by strangers and suggests, due to underreporting by the media, that acquaintance rape is less serious and less prevalent (Lynch, 2015). The impact of this construction is that women who are victims of rape by men they know can fail to recognise their experience as rape because of newspaper accounts reinforcing the 'stranger danger' scenario. Press coverage of rape has been found to contribute to women's silence in speaking up about their victimisation (see Taslitz, 1999), and this is one possible reason why women's voices have remained silenced as is evident in my gendered breakdown of articles across the five individual years.

\section{Fear Rape, Take Responsibility}

'Fear rape' as a warning to women continues to haunt us. My analysis of the theme 'fear rape, take responsibility' found that newspapers publicise police commentary on rape in a way which perpetually reinforces the notion that to be safe women were to be sheltered at home, and if they ventured out, they were to be accompanied by a man, or carry necessary tools in case of attack if they were alone. Police were predominantly providing this advice to women, but so too were concerned members of the public writing letters to the newspapers.

Overall, my findings indicated that fearing rape and assigning responsibility to women was portrayed through subtle gendered messages in how articles were structured, the language used, and the order in which incidents were described. This included information that could shift blame from perpetrators to victims by informing women about strategies to avoid becoming a victim. This inadvertently works to construct rape avoidance as a woman's responsibility as opposed to perpetrators and can perpetuate victim-blaming attitudes (Sutherland et al., 2016). This message then transposes elsewhere as seen in the recent strategy from the Wellington City Council and New Zealand Police titled 'Check Yourself' (Wellington City Council, 2017). At the time of writing, the 'Check Yourself' campaign was launched in response to Orientation Week celebrations at Victoria University of Wellington and was designed to encourage people aged $18-25$ to be safe and responsible in the city. The campaign features a video depicting a young, drunk woman at a house party about to head into town for a night out. Her friends urge her not to be 'that girl', and to think of those around her (such as elderly neighbours) whom she might be disturbing. The video ends with 
her friends successfully changing the woman's mind to stay indoors and not go out (Tombs, 2017). Previous research on alcohol harm-reduction campaigns that target women have been found to replicate neoliberal discourses of individualisation, control, and responsibility, and tend to be informed by notions of respectable femininity (Hutton, Wright, \& Saunders, 2013). The complexity of these debates is intensified as young women internalise the individualised risk discourses and focus on sexual assault as one of the risks of drinking (Hutton et al., 2013). The 'Check Yourself' campaign is a recent example showing that women need to 'take responsibility' for their actions rather than focus on eliminating a perpetrator's harmful behaviour. The neoliberal emphasis on 'risk' dictates that women have to manage their own vulnerability against potential harm, exasperates the social pressure they may face, and results in women internalising rape as being their fault. One discourse I found in my analysis was constructed in a way where women who drink alcohol deserve the consequences (of rape) because they failed to take necessary precautions and should have been 'more responsible'; a finding consistent with Meyer's (2010) study of Britain's Daily Mail newspaper.

Another tendency that New Zealand newspapers promoted to its readers especially in 1975 and 1985 was the construction of the home as a 'safe space' for women, in accordance to articles that quoted police advice. Suggesting that women "lock all doors and windows", "use a safety chain", and "take precautions when answering the door (even when in nightwear)" ("Sex Attacks Warning To Women", 1975) fails to recognise the reality that the home is a place of danger for many women and discounts their experiences of rape by boyfriends, partners, or husbands. Kingi and colleagues' 2009 research for the MWA revealed that out of 58 female sexual violence victims interviewed and surveyed, almost all (92\%) of the women knew or could identify the perpetrator(s), and over half (59\%) knew the offender intimately (e.g. family or whānau, current partner or ex-partner) (Kingi et al., 2009). Whilst not a representative sample of sexual violence victims individually or geographically, the study revealed that a significant proportion (76\%) of the assaults took place in an environment familiar to victims: their home (64\%), the perpetrator's home (7\%), or the home of a friend or family/whānau member (4\%) (Kingi et al., 2009).

There is the added responsibility that extends to women wearing the burden of, and being responsible for, managing men's biological urges. This adheres to the sexual script that men's sexuality is more urgent and must be prioritised over women's, resulting in the false belief 
that rape is a natural part of everyday life (Franiuk et al., 2008). In the late 1970s, Carol Smart noted "the 'moral' code restricted a woman's sexuality while encouraging a man to be sexually active" (Smart, 1976: 78). This restriction placed on women was something I noticed in reporting practices particularly for 2005 and 2015.

In sum, the 'fear rape, take responsibility' theme is prominent across the 40 year period I have examined. The implication of rape (and women) being represented this way severely limits women's movements and is a constant reminder that women need to be 'alert', 'on their guard', and ensure their safety by avoiding positions where they could be raped as they go about their everyday lives. Moreover, there was a significant emphasis on the future, hypothetical incident, to the extent that entire articles were directed towards warning women that they might become victims. This 'warning' or 'threat' depicted in the newspapers I analysed, constructed rape as external to the individual and failed to recognise the wider context in which sexual assault happens. The impact of this construction on women to 'manage' themselves is deeply suggestive of the gender dynamics that underscore the cultural construction of rape, whereby women are held at least partially responsible for their own sexual victimisation (see Moore, 2009).

\section{'Real Rape' Only Happens to 'Good Women'}

This final theme, as noted in Chapter Five, was drawn from the language that men were using to describe women as rape victims. Articles under this theme highlighted the way New Zealand newspapers reported on stories that attributed blame to the woman for being raped. This is not surprising because as noted, rape was viewed as a woman's responsibility. A woman provoked rape through her behaviour or dress, or by stepping outside the bounds of acceptable or appropriate 'feminine behaviour'. Constructing women (and rape) in this way has dangerous consequences, as the press insinuates that 'real rape' did not occur. Not all victims are treated as equal within media reporting (Clifford \& White, forthcoming), a notion explored three decades ago by Nils Christie (1986), where he described the 'ideal victim' as "a person who, when hit by a crime most readily are given the complete and legitimate status of being a victim" (Christie, 1986: 18). A 'good woman' fits the 'ideal victim' status, while the woman who is drunk - a 'bad girl', or a sex worker - are seen as 'undeserving victims' and therefore at fault for bringing on the rape attack. The suggestion that women in some way 
brought on the attack themselves and that some women deserved rape more than others (Benedict, 1993; Ruth, 1984) was a finding I noticed in my analysis. In other words, it was not the rapist who 'caused' the rape, it was the woman who failed to prevent herself from enticing him.

A woman's reputation went some way towards explaining how her behaviour could have led to an attack. There seemed to be a picture of a stereotypical rape 'victim' who had little in common with other 'normal', 'respectable' women because of the belief that rape only occurs to certain 'types' of women - those that step outside the bounds of traditional 'feminine' behaviour. If a woman was raped then there was some reason why she, in particular, was the victim. Sexual promiscuity, provocative dress, intoxication, and being single all contributed to the way that the New Zealand newspapers constructed the 'bad woman'. Smart (1976) has stated that the female rape victim redefines herself in terms of her knowledge of women who are raped, namely that she is largely responsible for her own demise. The victim is often thought to have little in common with ordinary women, it being assumed that only a foolish or reckless woman would be found in circumstances where a rape may take place, or that only a sexually promiscuous woman would dress or act in a manner likely to arouse uncontrollable sexual desire. Women who were raped were thus isolated from the body of other women, because rape was viewed as a distant and isolated act (Bauchop, 1990). When reading into men's accounts of the female rape victim, I found this suggestion aligned with Ruth's (1984) study of The Press and Christchurch Star. Furthermore, the rationale for specifying a woman's marital status in The Press was, according to the male representative Ruth interviewed, "to cater for the public who really do think it's worse if she's married because although it's a gross physical and mental intrusion on the woman, it's worse if it intrudes on the whole family as well" (Ruth, 1984: 32). A deviation away from the traditional female sex role of being at home with family or children (and in this instance, married) propagates the rape myth that women thus 'ask for rape' (Benedict, 1993).

Returning to the 'Check Yourself' campaign, the message is one that negatively portrays young women and adds to our culture of victim-blaming in relation to incidents of alcoholrelated harm. As my findings have shown, female rape victims in the press are heavily criticised for being intoxicated at the time of the attack, with alcohol playing a significant part as a victim-blaming tool, casting the woman as a "bad girl" that deserved "anything she got" 
(Smart, 1976: 94) if she was raped. Young women's drinking practices have been noted as inherently newsworthy in that they meet salient news values (Wright, 2016) - they are novel in that they deviate from past practices, there are particular risks that can be drawn from them, and they might be seen as 'fall from grace' situations insofar as they mark a departure from traditional (conservative) understandings of femininity (see Jewkes, 2011; 2015). Hutton and colleagues' (2013) research highlights the need for a move away from campaigns that base themselves on conservative ideals of femininity and 'respectability' (Hutton et al., 2013) and instead toward an approach that can engage and attribute responsibility for rape to men. In my analysis, it was clear that for a woman to have been drinking, flirting, or at a party, meant that she had stepped beyond what was acceptable, with Bauchop's (1990) study echoing these findings.

In summary, judgement on a woman's character was harsh across each of the five individual years. The division into appropriate and inappropriate behaviour was crucial to the understanding of the way that rape was viewed throughout the 40 year period I examined. The press's construction of women (and rape) in this way insinuates that 'real rape' did not occur and the idea of a 'good' and 'bad' woman has defined the way that women who have taken rape cases to court have been treated by the system. The implication of these constructions of women is that, unless she fits into a 'good' woman stereotype, the female victim will ultimately be treated as responsible for the rape.

\section{5 and Beyond}

How will changes in the media affect these themes? Internet sites and particularly social networking forums have revolutionised the ways in which news - including crime news - is produced and consumed (Cere et al., 2014). The reporting of rape stories from the year 2015 and beyond begs questions around journalists' use of and attitudes toward social media as a tool to disseminate information. Some of these include how do journalists' see user contributions affecting what happens? And how do these contributions challenge journalists' ethical practices and normative constructs?

The interplay between traditional news producers/editors and the active audience (e.g. news sharing citizens, or bloggers posting) in the swirl of real-time feedback via social media prompted Bruns $(2008 ; 2011)$ to argue that we live in the era of 'gatewatching'. This has 
involved a rethinking of whether the digital world, where users can be their own gatekeepers, threatens the hegemony of media gatekeepers (Bruns, 2011). Similarly, Hermida (2010) observed that "social media technologies like Twitter are part of a range of Internet technologies enabling the disintermediation of news and undermining the gatekeeping function of journalists" (Hermida, 2010: 300). This involves what Singer (2016) points out as a move away from seeing journalists as gatekeepers and toward seeing them as participants in an unbounded, ongoing communicative endeavour with journalism ultimately becoming more collaborative (Smellie, 2016). Hutchison (2016) argues that journalists should not fear people pointing out their mistakes but use the opportunity to improve their work and to engage with the people who care enough to give feedback. Furthermore, Hutchison (2016) believes that journalism has always been good and bad, and this will continue, but the future challenge is to do more of the good with new digital storytelling forms, and get the audience to care (Hutchison, 2016). Digital journalism has therefore opened up a wealth of new storytelling tools, and more are being developed all the time. The intertwined relationship between consumers/users and journalists, can allow journalists and reporters to build trust and improve their work.

Edwards notes that there has been a significant rise in opinionated journalism in New Zealand and in many cases, if the journalist's opinion was removed there would be no story (Edwards, 2016), yet no reporter is an empty vessel and every one brings a set of opinions, peeves, and prejudices to his or her work, and these can often leak into news reports (Benedict, 1993). The ability to distance your own self, values and views while writing and to present a supposedly unbiased or 'true' account of what happened is that of 'objectivity'. Journalists thus choose aspects of social phenomena for a re-presentation in their news reports and construct a social reality in accordance with that selection, which may or may not reflect the actual reality initially observed (Ruth, 1984). At each stage of the process individual biases may occur (i.e. to be sympathetic or not towards female rape victims), and aside from the characters and beliefs of particular reporters, sub-editors and editors, the process behind the presentation of news stories can therefore, negate any possibility of objectivity.

Overall, the news media's bias toward focusing on events rather than issues implicitly presents sexual violence as a taken-for-granted fact of life, with the emphasis placed on intervention and judgement in particular accusations rather than broader social solutions. 
The fact that sexual violence often fits within a traditional crime beat and that much reporting relies on individual court cases also prioritises the CJS as the primary avenue of intervention (Kitzinger, 2004). Through these stereotypes, through reporting rape predominantly on a case by case basis, and through the failure to explore the wider structural and social context in which these crimes are embedded, the press succeeds in individualising sexual violence and obscuring the continuum of violence against women (Marhia, 2008). Indeed, it continues to propagate harmful myths which feed back into the CIS perpetuating a vicious cycle of underreporting, attrition and low conviction rates.

A complex and multifaceted relationship therefore exists between newspapers and rape in New Zealand. While positive changes have occurred in regards to an increase in the discussion of New Zealand's rape culture, the reporting and representation practices over the 40 year period I have analysed still play a part in what the media focus on. These include stranger attacks, the objectifying of victims, reflecting court-based discourse which can excuse perpetrators and perpetuate stereotypes about victims and victimisation, or an incidentspecific focus that fails to engage in wider critiques of the societal attitudes that support and perpetuate rape (Jordan, 2012; Kitzinger, 2009; Meyers, 1997). New Zealand newspapers still predominantly report rape as titillating, arousing, and sensationalist to readers throughout the four decades from 1975 - 2015 and the question remains whether 'new media' platforms are likely to change themes positively (by challenging them) or negatively (by advancing them).

Reflecting on the Research Process

\begin{abstract}
Whether we like it or not, researchers remain human beings complete with all the usual assembly of feelings, failings, and moods. And all of those things influence how we feel and understand what is going on. Our consciousness is always the medium through which the research occurs; there is no method or technique of doing research other than through the medium of the researcher (Stanley \& Wise, 1993: 157).
\end{abstract}

I acknowledge that I have a particular perspective on rape and women's existence, and I believe it is necessary to show what a woman's reality in the world is. In writing from a feminist criminological perspective I have had certain goals in the actual process of writing: rape is a subject that should not be mystified - rape is already surrounded by a cloud of 
assumptions about the way that women and men should act, about what the crime actually is, about sexuality, and heterosexual intercourse (Bauchop, 1990). I made attempts to be aware throughout my research journey of the assumptions, social knowledge, and preconceptions that I may have brought to my analysis. During this process, I actively attempted to minimise potential biases by reminding myself of my position as a feminist researcher while embracing a post-structural mode of feminism which seeks to identify many intersections outside of gender such as race, ethnicity, class, and sexuality, to name a few.

It is only through the tremendous efforts by feminist women and activists from the 1960s onwards that someone like me has been able to write about rape. Feminist geographer Kim England stated a little over two decades ago that "research is a process, not just a product. Part of this process involves reflecting on, and learning from past research experiences, and being able to re-evaluate our research critically" (England, 1994: 244). Reflecting back on my research experience and wellbeing while conducting this thesis, I was constantly looking for ways to self-care. One of the biggest challenges was acknowledging the impact that researching sexual violence had on me as a researcher. I studied sexual violence during my undergraduate and Honours years and I had not felt affected by it previously (see Keene, 2015). However, the intensity of Masters level research on sexual violence meant that I faced difficulties, especially during my data collection phase where I was enduring long periods of isolation. This triggered a set of emotional and physical impacts such as violent dreams, a heightened risk-awareness state when walking alone at night, and anxiety. Being a selfdirected project on a sensitive topic meant that I was living and breathing this each day. These impacts stemmed from early self-doubts about the credibility of the project, and whether I could do the research 'justice'. An easy answer to these problems would be to say "if the research is so traumatising then stop doing it", a phrase my supervisor was once told in the course of her early academic career. Yet adopting this position does not sit well with me because to not engage in this type of research is a silencing technique in itself, and I am wholeheartedly committed to breaking the silence of women's words regarding sexual violence and dismantling the discourses that surround New Zealand's culture of victimblaming.

Research then, is an ongoing process, and does not stop once we disseminate the findings. For research to be valuable from the perspective of process over product, the value must lie 
beyond a sense of completion. Research continues as we reflect: on the development of an idea, on data collection, on findings, and, on implications. Despite the challenging nature of the research, I am confident I am contributing to an important project and I hope this study will make a significant contribution to the New Zealand sexual violence literature and be used as a platform for other researchers to proceed. While I hope that the scholarship that emerges from this thesis makes a contribution to my field, the greater lessons that have emerged thus far pertain to the research experience itself. The final section of this chapter concludes with a list of recommendations to journalists and reporters when writing about sexual violence and rape. I included this because it is of the utmost importance that we as a society continue to work towards dismantling patriarchal attitudes that underpin rape culture and strive for women's sexual equality both in and out of the academic sphere.

\section{Recommendations to Journalists}

Newspaper media should be aware of how their presentation of news can affect society, such as in the perpetuation of rape culture. The following recommendations should be directed towards journalists to promote 'good practice' when reporting on sexual violence and rape. The results from the line of inquiry I pursued can be utilised to inform media outlets of the best way to present the issue of rape in order to bring about the most positive change in this arena. These guidelines would aid journalists in telling an accurate story, in combination with the most up-to-date New Zealand statistics, and a list of experts in sexual violence who are willing to provide media commentary. These guidelines are based on, and influenced by, previous research regarding recommendations to journalists reporting on sexual violence cases (Lynch, 2015; Marhia, 2008; Wood, \& Dickson, 2013). Ideally, New Zealand newspaper reporters would:

- Address the appropriate use of language and terminology (e.g. not referring to rape as 'sex') and describe sexual violence accurately by avoiding euphemisms and common misconceptions

- Provide accurate information about the severity of sexual violence and the impacts on survivors

- Highlight sexual violence as a broad and prevalent social problem

- Challenge common myths and stereotypes 
- Provide the contact details of local services and helpful resources about sexual violence

- Undertake training for journalists delivered by those individuals working in the sexual violence arena

- Incorporate a wider range of voices in news reporting

- Respect and support victims/survivors of sexual violence by encouraging them to seek help and report the crime

This 'toolkit' would aid journalists in challenging rape culture and provide them with a better awareness of how to report on sexual violence issues appropriately, although such changes may not be universally adopted given differences between journalists, the extent to which they have internalised rape myths, plus editorial directives. These guidelines could however, be distributed to the newspapers I have examined and to tertiary institutions that offer journalism courses throughout New Zealand. This would give journalists a greater understanding of sexual violence realities and equip them with resources to improve their reporting. 


\section{Chapter 7: Conclusion}

This final chapter brings together the key findings discussed in the previous three chapters. It addresses the implications that these findings have in relation to the way that New Zealand newspaper media report on rape, and how women are represented when this crime occurs. Longitudinal research on rape representation in a wide range of New Zealand newspapers has not previously been conducted. Whilst this study is largely exploratory in nature, this research contributes to this literature gap and emerges at a time when momentum is building around addressing New Zealand's pervasive rape culture, especially amongst secondary school students (see Towle, 2017).

This thesis has examined how rape and women as rape victims have been represented in the New Zealand press over four decades from 1975 - 2015. Newspaper articles $(n=1833)$ were collected from eight prominent publications from both the North and South Island between the years 1975 - 2015, and form the basis of this study. Individual years included in this analysis were 1975, 1985, 1995, 2005 and 2015. These years were selected to give a representative view of each decade's depiction of rape, and provides both quantitative and qualitative evidence that newspaper media contributes to rape culture. This thesis argues that the press frame stories about rape in ways that perpetuate rape myths and highlights the urgent need for changes to journalism practices in how the reporting of rape and female rape victims are presented to the public.

Key findings in this study included a disproportionate level of coverage of cases involving stranger rape, even though the majority of women are known to their rapist. As Meyers (1997) and Mitchell (2001) have previously found, the way the press reports rape cases function as warnings for women about risky places and people. Such warnings are both explicit (from police) and implicit, and tend to advise women about self-care in public settings indicating the greatest risk to be from strangers. The highlighting by newspapers that women need to 'take responsibility' for protecting themselves and preventing rape's occurrence obscures where the greatest risks to women are located - such as in the home - and ultimately leaves women responsible for rape rather than men. In addition, newspaper accounts position female rape victims according to culturally constructed notions of what the 'real' rape victim looks like. Implicit in this idea is a focus on what the woman has said, done, 
or worn, as she is held central to analyses of what happened and why. If the representation by newspapers that only a certain 'type' of woman will be raped - that is, the 'good' 'respectable' woman - other women that do not fit this stereotype are judged harshly and their experiences of sexual victimisation are rendered unworthy, and worse, silenced. The private reality of sexual violence against women is less dramatic but far more insidious and widespread than the imagined social reality that is presented by newspapers (Ruth, 1984). Not only is the reality of sexual violence in our society distorted by being largely hidden (unreported) but further bias is introduced in newspaper accounts of actual cases. New Zealand's news media is therefore at least partially responsible for contributing to a cultural narrative that positions women as targets of stranger rape, yet responsible for their apparent victimisation, in their pursuit of 'objectivity' and 'newsworthiness'. I close this chapter by looking at some options for change.

\section{Future Directions}

At the time of writing, a protest was held in Wellington challenging New Zealand's rape culture (March 13, 2017), spurred by comments from a group of Wellington College boys joking about taking advantage of drunk girls on a private Facebook page (see Dooney, 2017). Such comments exemplify prevailing attitudes that young men have around sexual violence, and demonstrate the visibility of rape culture today. As Jordan (2017) noted on the day of the protest:

It is profoundly disturbing that boys in 2017 might consider rape to be a joke. How do we explain the fact that boys whose entire lives have been lived in what some would term a post-feminist era come to not only hold such views but seek peer esteem through sharing them? (Jordan, 2017).

There is an ongoing and pressing need for cultural and societal change through preventative education, challenging and changing the beliefs within and outside the criminal justice system (CJS), positive male role modelling around issues of consent, leadership, and better resourcing. McDonald (2014) has argued that by challenging societal attitudes and debunking rape mythology will most likely result in real change. 
My study provides a limited picture of the realities of rape in New Zealand between 1975 and 2015, because rape was, and still is, a vastly underreported offence. My analysis of four decades of newspaper coverage has shown that societal attitudes to rape and women who are victims of it, has continually been structured around victim-blaming rhetoric and favouring the voices of men, which continues in the present day. So long as men retain the controlling voice in speaking out, about, or for women, it is difficult to see how a rape culture might shift even though there is an increase in its discussion.

This study has only scraped the surface of the many different ways one could analyse how newspapers discuss rape. Other avenues might investigate how individual rape cases were reported on and the contrast between publications, analysing rape headlines and how these have changed over the decades, the amount of coverage given to 'false' allegations, or further still, a focus on article placement of rape stories and in which section they appear in newspapers. This thesis thus provides a rich platform for future research in this area. We live in a world where there is a pervasive rape culture, but we also live in a world where there is an emerging intolerance to it (as seen by the rape culture protest already outlined). It is through continuing to challenge rape culture and the insidious myths and misinformation that accompany it, that real change will occur (Lynch, 2015). In light of the findings discussed, this study invites other researchers to hold the media accountable for their misrepresentation of rape cases, and to demand change.

Finally, although the education of journalists is important, fundamental change involves deconstructing all parts of our culture that work to constrain women's agency. The media could lead this process by accepting the way rape is currently represented in the media contributes to the problem (Mitchell, 2001). Until we change our dominant narrative around sexual violence, and recognise the diverse circumstances in which it occurs, the words of women who are victimised will continue to be silenced, very few perpetrators will be held to account, and media reporting of sexual violence cases will continue to reflect the same old story. 


\section{Appendices}

Appendix A: List of newspaper articles

Aldridge, V. (1995, September 29). Using words to fight off a rapist. The Dominion, p. 9.

Clarkson, D. (2015, November 10). Rape in sand dunes alleged. The Press, p. 4.

Davison, I. (2015a, November 12). Riled MPs tell of past abuse. The New Zealand Herald, p. 9.

Davison, I. (2015b, December 18). Sex assault victim's bravery inspires move for reform. The New Zealand Herald, p. 8.

Gooch, W. (1995, April 20). Rape and gender. Taranaki Daily News, p. 6.

Gravett, J. (1995, June 29). Curfew for men needed. The Dominion, p. 8.

Humphreys, L. (2005a, February 4). Youth (15) held after rape in rest home. Taranaki Daily News, p. 1.

Humphreys, L. (2005b, April 19). Warning for women after nights gone wrong. Taranaki Daily News, p. 1.

Kidd, R., \& Ryan, S. (2015, May 1). Defendant challenges police expert. The New Zealand Herald, p. 10.

MacDonald, E. (1995, August 14). Daytime cemetery rape scares female students. The Evening Post, p. 15.

Mussen, J., \& Matthews, J. (1985, September 20). Letter to the Editor - Rape Reports. Otago Daily Times, p. 5.

Oldham, S. (2005, October 8). Tavern rape alleged. Otago Daily Times, p. 4.

Rae, S. (2005, October 24). Police seek witness. Otago Daily Times, p. 17.

Shadwell, T. (2015, August 15). Lawyer convicted on drugs charges. The Dominion Post, p. 3.

Smith, M. (2005, June 27). Police searching for rapist. The Southland Times, p. 2.

Weber, A. (2015, January 24). Sexually abused woman says victims should have right to be named. The New Zealand Herald, p. 26.

Williams, C. (2005, October 27). Woman alleges rape. Otago Daily Times, p. 13. 
Appendix B: List of newspaper articles with no author

1975

Women Run Risk Alone After Dark. (1975, April 22). The New Zealand Herald, p. 4.

Anti-rape Sprays 'Illegal'. (1975, September 18). Taranaki Daily News, p. 3.

Assault and Rape Victims May Have Been Trailed. (1975, September 12). The New Zealand Herald, p. 1.

Four Jailed For 'Vicious' Assault And Rape. (1975, July 5). The Evening Post, p. 10.

Girl's Cries To No Avail. (1975, June 18). The Evening Post, p. 1.

Jury finds youth not guilty of rape. (1975, May 2). The Press, p. 14.

Man gaoled for rape. (1975, June 21). The Press, p. 20.

News from the Supreme Court. (May 3, 1975). The Press, p. 7.

Prisoner Termed ‘Danger To Women’. (1975, October 30). Otago Daily Times, p. 9.

Rape case. (1975, June 23). Otago Daily Times, p. 4.

Rape charge. (1975, February 25). The New Zealand Herald, p. 4.

Rush on real, imagined rape. (1975, April 27). Sunday Star Times, p. 2.

Sex Attacks Warning To Women (1975, August 19). The New Zealand Herald, p. 8.

'Struggle shout, scream'... And know when to stop (1975, September 18). The Evening Post, p. 10.

Three-year prison term imposed for rape. (1975, June 14). The Press, p.20.

Vicious attack on elderly woman. (1975, March 15). The Press, p. 1.

Woman Raped At Knifepoint. (1975, July 25). The Southland Times, p. 1.

$\underline{1985}$

Arrest after fatal attack on elderly Chch woman. (1985, February 4). The Press, p. 1.

Help For Rape Centres. (1985, February 4). The New Zealand Herald, p. 11.

'Little old lady' who lived alone. (1985, February 4). The Press, p. 1.

Cash for Rape Crisis Centres. (1985, March 11). The New Zealand Herald, p. 4.

Rapist jailed 5 1⁄2 years. (1985, April 4). The Dominion, p. 5.

Defence says rape 'victim' prostitute. (1985, June 14). The Dominion, p. 8.

'I was rapist' taunt. (1985, June 19). The Evening Post, p. 1. 
Man convicted on rape charge. (1985, June 28). Otago Daily Times, p. 2.

Attack Was Savage, Brutal Says Judge. (1985, July 6). The New Zealand Herald, p. 8.

Search still on for gang rape site. (1985, July 23). The Dominion, p. 3.

Man Found Guilty Of Raping Woman in Car. (1985, August 2). The New Zealand Herald, p. 8.

Woman raped at knifepoint. (1985, August 22). The Dominion, p. 5.

Gaoled for four years for rape. (1985, October 25). Otago Daily Times, p. 2.

Attack prompts police warning. (1985, November 8). Otago Daily Times, p. 2.

$\underline{1995}$

Second rape reported. (1995, March 17). Otago Daily Times, p. 2.

Name suppression application denied: Eight years' jail for rape. (1995, May 6). Otago Daily Times, p. 12.

Jury fails to find verdict in sex trial. (1995, July 15). The New Zealand Herald, p. 2.

Curiosity turns to fear for serial rapist's victim. (1995, August 4). The Dominion, p. 7.

Reporting rape cases. (1995, August 8). The Dominion, p. 10.

Raped woman thought city was safe. (1995, September 8). Taranaki Daily News, p. 4.

Rapist used cord to drag woman. (1995, September 19). Taranaki Daily News, p. 2.

Sorry tale of small-town 'injustice'. (1995, September 25). The Evening Post, p. 8.

Coastal pair jailed for sex attack. (1995, October 21). Taranaki Daily News, p. 1.

Arrest after rape of elderly woman. (1995, December 2). The Press, p. 3.

$\underline{2005}$

Sex attack brings jail. (2005, April 29). The Southland Times, p. 3.

Rape claimant 'a hottie who sought out sex'. (2005, June 28). The Dominion Post, p. 4.

Man accused of rape and abduction says complainant a liar. (2005, June 29). Otago Daily Times, p. 35.

Victim of rape or haunted by memories? (2005, July 2). The Dominion Post, p. 5.

How cops netted city sex fiend. (2005, September 10). The Southland Times, p. 14.

How could jury believe a woman asks Iraqi. (2005, October 11). The Dominion Post, p. 4.

Iraqi refugee loses rape conviction appeal. (2005, October 18). Otago Daily Times, p. 16.

$\underline{2015}$

Rapist appeals conviction, sentence. (2015, March 7). Otago Daily Times, p. 32. 
Fifty years of feminism hasn't stripped away women's fear of men. (2015, March 14). The New Zealand Herald, p. 9.

Riverbank rapist, 17, pleads guilty. (2015, August 19). The Dominion Post, p. 4.

Letter to the editor. (2015, September 9). The New Zealand Herald, p. 24.

Inside the Rizalman fiasco. (2015, December 6). The New Zealand Herald, p. 16. 


\section{References}

Age Of Consent. (2017). New Zealand Age of Consent \& Statutory Rape Laws. Retrieved 14 February 2017, from: https://www.ageofconsent.net/world/new-zealand

Alice, L. (1999). Power, experience and process in feminist research. In C. Davidson \& M. Tolich (Eds.), Social Science Research in New Zealand: Many Paths to Understanding (pp. 62-68). Auckland: Pearson Education New Zealand.

Altheide, D. L. (1987). Ethnographic Content Analysis. Qualitative Sociology, 10(1), 65-77. Altheide, D.L. (1996). Qualitative Media Analysis. California: Sage Publications.

Bates, L. (2014, February 14). This is rape culture - and look at the damage it does. The Guardian. $\quad$ Retrieved April 2017, from: https://www.theguardian.com/lifeandstyle/womens-blog/2014/feb/14/rapeculture-damage-it-does-everyday-sexism

Bauchop, H. (1990). The Public Image of Rape in New Zealand: A case study of two newspapers, 1950 - 1970 (Honours Thesis, University of Otago, Dunedin, New Zealand).

Benedict, H. (1993). Virgin or Vamp: How the Press Covers Sex Crimes. New York: Oxford University Press.

Bennett, L. W. (2004). Gatekeeping and Press-Government Relations: A Multigated Model of News Construction. In L. L. Kaid (Ed.), Handbook of Political Communication Research (pp. 282-313). Mahwah, NJ: Lawrence Erlbaum.

Biddle, D. L. (2017, February 24). Kuggeleijn rape trial: Jury finds cricketer not guilty. Stuff. $\begin{array}{lll}\text { Retrieved } 23 \text { 2017, } & 23 \text { from: }\end{array}$ http://www.stuff.co.nz/national/crime/89757467/kuggeleijn-rape-trial-jury-findscricketer-not-guilty

Boczkowski, P. J. (2004). Digitizing the News : Innovation in Online Newspapers. Cambridge, MA: MIT Press.

Bogazianos, D. (2011). Methodological Essay. In 5 Grams: Crack Cocaine, Rap Music, and the War on Drugs. (pp. 149-154). New York: New York University Press.

Bohner, G. (2001). Writing about rape: Use of the passive voice and other distancing text features as an expression of perceived responsibility of the victim. British Journal of Social Psychology, 40(4), 515-529. 
Boyes, N. (2006, March 16). Ex-flatmate says Louise Nicholas 'wasn't saying no'. New Zealand Herald. Retrieved 21 2017, from: http://www.nzherald.co.nz/nz/news/article.cfm?c_id=1\&objectid=10372891

Boyle, K. (2005). Media and Violence: Gendering the Debates. London: Sage Publications.

Brownmiller, S. (1975). Against Our Will: Men, Women, and Rape. New York: Simon \& Schuster.

Bruns, A. (2008). Gatewatching, Not Gatekeeping: Collaborative Online News. Retrieved from: http://eprints.qut.edu.au/189/1/Bruns_Gatewatching.PDF

Bruns, A. (2011). Gatekeeping, Gatewatching, Real-Time Feedback: New Challenges for Journalism. Brazilian Journalism Research Journal, 7(2), 117-136.

Burt, M. R. (1980). Cultural Myths and Supports for Rape. Journal of Personality and Social Psychology, 38(2), 217-230.

Cameron, D. (1998). Introduction: Why is Language a Feminist Issue? In D. Cameron (Ed.), The Feminist Critique of Language: A Reader (pp. 1-20). New York: Routledge.

Caringella-MacDonald, S. (1998). The Relative Visibility of Rape Cases in National Popular Magazines. Violence Against Women, 4(1), 62-80.

Carter, C. (2002). When The 'Extraordinary' Becomes 'Ordinary': Everyday news of sexual violence. In S. Allan, G. Branston, \& C. Carter (Eds.), News, Gender and Power (pp. 219232). London: Routledge.

Cere, R., Jewkes, Y., \& Ugelvik, T. (2014). Media and Crime: A Comparative Analysis of Crime News in the UK, Norway and Italy. In S. Body-Gendrot, M. Hough, K. Kerezsi, R. Levy, \& S. Snacken (Eds.), The Routledge Handbook of European Criminology (pp. 1-21). London \& New York: Routledge.

Childress, R. (2016). Read all about it: A linguistic analysis of the media's construction of rape (Master's thesis, Georgetown University, Washington, DC). Retrieved February 13 2017, from: https://repository.library.georgetown.edu/handle/10822/1040755

Christchurch City Libraries. (2016). About findNZarticles. Retrieved 5 October 2016, from: http://my.christchurchcitylibraries.com/about-find-nzarticles/

Christie, N. (1986). The Ideal Victim. In E. A. Fattah (Ed.), From crime policy to victim policy: reorienting the justice system (pp. 17-30). Hampshire: Macmillan Press.

Clifford, K. (2016, November). Doing Media Criminology. Paper presented at the Australian and New Zealand Society of Criminology Conference, Hobart. 
Clifford, K., \& White, R. (forthcoming). Media and Crime. Melbourne: Oxford University Press. Cohen, B. C. (1963). The Press and Foreign Policy. Princeton, NJ: Princeton University Press. Cook, M. (2011a). Women's movement - Violence and Pornography. Te Ara Encyclopedia of New Zealand. Retrieved 9 February 2017, from: http://www.teara.govt.nz/en/womens-movement/page-10

Cook, M. (2011b). Women's movement - The mid-20th century. Te Ara Encyclopedia of New Zealand. Retrieved 23 March 2017, from: http://www.teara.govt.nz/en/video/27902/first-woman-to-serve-on-a-jury

Crimes Act 1961, New Zealand. Pub. L. No. 43, § 128, 389. Retrieved November 11 2016, from: http://www.nzlii.org/nz/legis/hist_act/ca19611961n43109/

Ditton, J., \& Duffy, J. (1983). Bias in the newspaper reporting of crime news. The British Journal of Criminology, 23(2), 159-165.

Dooney, L. (2017, March 7). Investigation launched over rape comments made by Wellington College students. Stuff. Retrieved April 11 2017, from: http://www.stuff.co.nz/national/education/90165634/investigation-launched-overrape-comments-made-on-facebook-by-wellington-college-students

Doyle, A. (2006). How Not to Think about Crime in the Media. Canadian Journal of Criminology and Criminal Justice, 48(6), 865-885.

Duncanson, C. (2008). Forces for Good? British Military Masculinities on Peace Support Operations. (Doctoral thesis, University of Edinburgh, Scotland). Retrieved April 18 2016, from: https://www.era.lib.ed.ac.uk/handle/1842/2752

Edwards, A., \& Heenan, M. (1994). Rape trials in Victoria: Gender, Socio-cultural Factors and Justice. The Australian and New Zealand Journal of Criminology, 27(3), 213-236.

Edwards, B. (2016). Journalism and democracy. In E. Johnson, G. Tiso, S. Illingworth, \& B. Bennett (Eds.), Don't Dream It's Over: Reimagining Journalism in Aotearoa New Zealand (pp. 55-65). Christchurch, New Zealand: Freerange Press.

England, K. V. L. (1994). Getting personal: Reflexivity, Positionality, and Feminist Research. The Professional Geographer, 46(1), 241-256.

Estrich, S. (1987). Real Rape: How the legal system victimises women who say no. Massachusetts: Harvard University Press.

Fanslow, J. L., \& Robinson, E. M. (2004). Violence against Women in New Zealand: Prevalence and health consequences. New Zealand Medical Journal, 117(1206). 
Fountaine, S. L. (2015). Who Makes the News? Global Media Monitoring Project National Report: New Zealand (pp. 1-16). Palmerston North, New Zealand: Massey University. Fowler, R. (1991). Language in the News: Discourse and Ideology in the Press. London: Routledge.

Franiuk, R., Seefelt, J. L., Cepress, S. L., \& Vandello, J. A. (2008). Prevalence and Effects of Rape Myths in Print Journalism: The Kobe Bryant Case. Violence Against Women, 14(3), 287-309.

Gaffey, J. (2016, November). Contemporary risk communication and experiential knowledge. Paper presented at the Australian and New Zealand Society of Criminology Conference, Hobart.

Gavey, N. (2005). Just Sex? The Cultural Scaffolding of Rape. East Sussex: Routledge.

Gill, R. (2007). Gender and the Media. Cambridge: Polity Press.

Greer, C. (2003). Sex Crime and the Media. Devon: Willan Publishing.

Greer, C. (2013). Crime and the media: understanding the connections. In Chris Hale, Keith Hayward, Azrini Wahidin, \& Emma Wincup (Eds.), Criminology (3rd ed., pp. 143-163). Oxford: Oxford University Press.

Greer, C., \& Reiner, R. (2015). Mediated Mayhem: Media, Crime and Criminal Justice. In M. Maguire, R. Morgan, \& R. Reiner (Eds.), The Oxford Handbook of Criminology (5th ed). Oxford: Oxford University Press.

Griffin, S. (1977). Rape: the all-American crime. In R. Chappell, R. Geis, \& G. Geis (Eds.), Forcible rape: the crime, the victim, and the offender (pp. 47-67). New York: Columbia University Press.

Griffin, S. (1986). Rape: The Politics of Consciousness. New York: Harper \& Row.

Hager, N. (2016). The crisis is all around us, and so are the solutions. In E. Johnson, G. Tiso, S. Illingworth, \& B. Bennett (Eds.), Don't Dream It's Over: Reimagining Journalism in Aotearoa New Zealand (pp. 186-194). Christchurch, New Zealand: Freerange Press.

Heath, L., Gordon, M. T., \& LeBailly, R. (1981). What Newspapers Tell Us (And Don't Tell Us) About Rape. Newspaper Research Journal, 2(4), 48-55.

Hermida, A. (2010). TWITTERING THE NEWS: The emergence of ambient journalism. Journalism Practice, 4(3), 297-308. 
Hesmondhalgh, D. (2006). Discourse analysis and content analysis. In M. Gillespie \& J. Toynbee (Eds.), Analysing Media Texts (pp. 122-156). Milton Keynes: Open University Press.

Hill, K. (Producer). (2016, August 31). Publishing and Journalism. [Audio podcast]. Retrieved $\begin{array}{llll}\text { September } & 62016 \text {, from: }\end{array}$ http://www.radionz.co.nz/national/programmes/saturday/audio/201813867/dunca n-grieve-and-barnaby-bennett-publishing-and-journalism

hooks, b. (1984). Feminist Theory: From Margin to Center. Cambridge, MA: South End Press. Hutchison, J. (2016). Four things we need to do to make digital journalism sustainable. In E. Johnson, G. Tiso, S. Illingworth, \& B. Bennett (Eds.), Don't Dream It's Over: Reimagining Journalism in Aotearoa New Zealand (pp. 332-339). Christchurch: Freerange Press.

Hutton, F., Wright, S., \& Saunders, E. (2013). Cultures of intoxication: Young women, alcohol, and harm reduction. Contemporary Drug Problems, 40(4), 451-480.

Hyman, P. (2000). Women in the CIB: Opportunities for and Barriers to the Recruitment, Progress, and Retention of Women in the Criminal Investigation Branch. Wellington, New Zealand: New Zealand Police.

Illingworth, S. (2016). A changing media: Crisis or opportunity? In E. Johnson, G. Tiso, S. Illingworth, \& B. Bennett (Eds.), Don't Dream It's Over: Reimagining Journalism in Aotearoa New Zealand (pp. 66-73). Christchurch, New Zealand: Freerange Press.

Jayaratne, T. E., \& Stewart, A. J. (1991). Quantitative and Qualitative Methods in Social Sciences: Current Feminist Issues and Practical Strategies. In M. M. Fonow \& J. A. Cook (Eds.), Beyond Methodology: Feminist Scholarship as Lived Research (pp. 85-106). Indiana: University Press.

Jewkes, Y. (2011). Media and Crime (2nd ed.). London: Sage Publications.

Jewkes, Y. (2015). Media and Crime (Rev. 3rd ed.). London: Sage Publications.

Jordan, J. (2001). True 'lies' and false 'truths' (Doctoral Thesis, Victoria University of Wellington, New Zealand).

Jordan, J. (2004). The Word of a Woman? Police, Rape, and Belief. New York: Palgrave Macmillan.

Jordan, J. (2012). Silencing rape, silencing women. In J. M. Brown \& S. L. Walklate (Eds.), Handbook on Sexual Violence (pp. 253-286). New York: Routledge. 
Jordan, J. (2013). From victim to survivor - and from survivor to victim: reconceptualising the survivor journey. Sexual Abuse in Australia and New Zealand, 5(2), 48-56.

Jordan, J. (2017, March 13). Patriarchal footprint still deeply embedded in society. Stuff. Retrieved April 12 2017, from: http://www.stuff.co.nz/dominionpost/comment/90323860/jan-jordan-patriarchal-footprint-still-deeply-embedded-insociety

Kahlor, L., \& Eastin, M. (2011). Television's Role in the Culture of Violence Toward Women: A Study of Television Viewing and the Cultivation of Rape Myth Acceptance in the United States. Journal of Broadcasting \& Electronic Media, 55(2), 215-231.

Keene, S. M. (2015). Risky residences: An exploratory study of sexual violence in university halls of residence (Master's thesis, Victoria University of Wellington, New Zealand).

Kelly, L. (1988). Surviving Sexual Violence. Minnesota: University of Minnesota Press.

Kingi, V., Jordan, J., Moeke-Maxwell, T., \& Fairbairn-Dunlop, P. (2009). Responding to Sexual Violence: Pathways to recovery. Wellington, New Zealand: Ministry of Women's Affairs.

Kingi, V., Mossman, E., \& Jordan, J. (2010). Challenging rape myths: Key findings from a New Zealand study. The Journal of Te Awatea Violence Research Centre, 8(1-2), 26-31.

Kitzinger, J. (2004). Media Coverage of Sexual Violence Against Women and Children. In Karen Ross \& Carolyn M. Byerly (Eds.), Women and Media: International Perspectives (pp. 13-38). Oxford: Blackwell Publishing.

Kitzinger, J. (2009). Rape in the media. In Rape: Challenging contemporary thinking (pp. 7498). Cullompton, Devon: Willan Publishing.

Lamb, S. (1991). Acts without agents: An Analysis of Linguistic Avoidance in Journal Articles on Men Who Batter Women. American Journal of Orthopsychiatry, 61(2), 250-257.

Lamb, S., \& Keon, S. (1995). Blaming The Perpetrator: Language that Distorts Reality in Newspaper Articles on Men Battering Women. Psychology of Women Quarterly, 19(2), 209-220.

LeGrand, C. E. (1973). Rape and Rape Laws: Sexism in Society and Law. California Law Review, 61(3), 919-941.

Leps, M.-C. (1992). Apprehending the Criminal: The Production of Deviance in NineteenthCentury Discourse. United States: Duke University Press. 
Lukin, A. (2016). 'He' vs 'she' in Australian media coverage: what the language of news tells us about gender imbalance. Retrieved 30 October 2016, from: http://theconversation.com/he-vs-she-in-australian-media-coverage-what-thelanguage-of-news-tells-us-about-gender-imbalance-67139

Lynch, E. (2015). Policy report prepared for Wellington Rape Crisis: Sexual violence representations in New Zealand news media (Honours Thesis, Victoria University of Wellington, New Zealand).

Mack, K. (1998). 'You should scrutinise her evidence with great care': Corroboration of women's testimony about sexual assault. In P. Easteal (Ed.), Balancing the scales: Rape, law reform and Australian culture (pp. 59-75). Sydney: The Federation Press.

Magilsen, A. (2015). The reality of rape: Why are we blaming our girls? (Honours Thesis, Victoria University of Wellington, New Zealand).

Marhia, N. (2008). Just Representation? Press reporting and the reality of rape (pp. 1-59). London: Eaves Lilith Project.

Meyers, M. (1997). News Coverage of Violence against Women: Engendering Blame. California: Sage Publications.

McChesney, M. (1985, October 9). Classroom Talks Bring Rape Out of the Closet. New Zealand Herald, p. 14.

McDonald, E. (2014). From Real Rape to Real Justice-Reflections on the Efficacy of More than 35 Years of Feminism, Activism and Law Reform. Victoria University of Wellington Law Review, 45, 487-508.

McDonald, E., \& Souness, R. (2011). From 'Real Rape' to Real Justice: The Reform Project. In E. McDonald \& Y. Tinsley (Eds.), From 'Real Rape' to Real Justice: Prosecuting Rape in New Zealand (pp. 31-84). Wellington: Victoria University Press.

Meyer, A. (2010). 'Too Drunk To Say No': Binge drinking, rape and the Daily Mail. Feminist Media Studies, 10(1), 19-34.

Ministry for Women. (2016). The Ministry's History. Retrieved 31 January 2017, from: http://women.govt.nz/about/new-zealand-women/history/ministry

Ministry of Women's Affairs. (2009). Restoring soul: effective interventions for adult victim/survivors of sexual violence. Wellington, New Zealand: Ministry of Women's Affairs. 
Mitchell, A., \& Holcomb, J. (2016). State of the News Media 2016. Retrieved 17 August 2016, from: http://www.journalism.org/2016/06/15/state-of-the-news-media-2016/

Mitchell, K. (2001). Rape in the news: media portrayals of rapists, victims and rape in New Zealand (Master's thesis, Victoria University of Wellington, New Zealand).

Moore, S. E. (2009). Cautionary tales: Drug-facilitated sexual assault in the British media. Crime Media Culture, 5(3), 305-320.

Morant, N. (1999). Social representations of gender in the media: Quantitative and qualitative content analysis. In Dorothy Miell \& Margaret Wetherall (Eds.), Doing Social Psychology (pp. 233-283). Sage Publications Ltd.

Mossman, E., Jordan, J., MacGibbon, L., Kingi, V., \& Moore, L. (2009a). Responding to Sexual Violence: A review of literature on good practice. Wellington, New Zealand: Ministry of Women's Affairs.

Mossman, E., MacGibbon, L., Kingi, V., \& Jordan, J. (2009b). Responding to Sexual Violence: Environmental scan of New Zealand agencies. Wellington, New Zealand: Ministry of Women's Affairs.

Murrizi, S. (2015). Media Construction of Campus Sexual Assault: A Case Study (Master's thesis, University of Ottawa, Canada).

Myers, M. A., \& LaFree, G. D. (1982). Sexual Assault and Its Prosecution: A Comparison with Other Crimes. Journal of Criminal Law and Criminology, 73(3), 1282-1305.

National Library of New Zealand. (2016). Index New Zealand, Collections, National Library of New Zealand. Retrieved 5 October 2016, from: https://natlib.govt.nz/collections/az/index-new-zealand-innz

Neale, L. (2015). Police Accountability for the Investigation and Prosecution of Sexual Offending: What the Roastbusters Investigation Revealed (Honours Thesis, Victoria University of Wellington, New Zealand).

New Zealand Family Violence Clearinghouse. (2016). Adult Sexual Violence (Data Summary No. 5) (pp. 1-17). New Zealand Family Violence Clearinghouse: Auckland, New Zealand.

New Zealand Law Commission. (2013). Defining 'news media' for the purposes of the law (The news media meets 'new media': Rights, responsibilities and regulations in the digital age No. 128) (pp. 77-105). New Zealand Law Commission: Wellington, New Zealand. 
Noaks, L., \& Wincup, E. (2004). Analysing Qualitative Data. In L. Noaks \& E. Wincup (Eds.), Criminological Research (pp. 121-136). London: Sage Publications Ltd.

Noelle-Neumann, E. (1993). The Spiral of Silence: Public Opinion - Our Social Skin. Chicago: University of Chicago Press.

O'Hara, S. (2012). Monsters, playboys, virgins and whores: Rape myths in the news media's coverage of sexual violence. Language and Literature, 21(3), 247-259.

O’Sullivan, T., Hartley, J., Saunders, D., Montgomery, M., \& Fiske, J. (1994). Key Concepts in Communication and Cultural Studies (2nd ed). London: Routledge.

Pfeffer, J., Zorbach, T., \& Carley, K. M. (2014). Understanding online firestorms: Negative word-of-mouth dynamics in social media networks. Journal of Marketing Communications, 20(1-2), 117-128.

Pratt, J. (2007). Penal populism: key ideas in criminology. London; New York: Routledge, Taylor \& Francis Group.

Rankine, J., Moewaka Barnes, A., McCreanor, T., Nairn, R., McManus, A.-L., Abel, S., Borell, B., \& Gregory, A. (2014). Content and source analysis of newspaper items about Maori issues: Silencing the 'natives' in Aotearoa? Pacific Journalism Review, 20(1), 213-233.

Rape Prevention Education. (2011a). Legal definitions. Retrieved 14 February 2017, from: http://rpe.co.nz/information/legal-definitions/

Rape Prevention Education. (2011b). Statistics. Retrieved 16 March 2017, from: http://rpe.co.nz/information/statistics/

Redshaw, V. P. (2006). Tact and Tenacity: New Zealand Women in Policing. Wellington: Grantham House Publishing.

Ripcikova, D. (2008). Gender in Newspaper Discourse: Representation of Women and Men in Hard News (Master's thesis, Masaryk University, Brno, Czech Republic).

Robinson, S. (2011). 'Journalism as process': The organizational implications of participatory online news. Journalism \& Communication Monographs, 13(3), 137-210.

Russell, D. E. (1975). The politics of rape: the victim's perspective. New York: Stein \& Day.

Ruth, S. (1984). Our Public Face: The Press on Homosexuality and Rape. Broadsheet, (122), 30-33.

Schlesinger, P., Dobash, R. E., Dobash, R. P., \& Weaver, C. K. (1992). Women Viewing Violence. London: BFI. 
Schwalbe, C. B., Silcock, B. W., \& Candello, E. (2015). Gatecheckers at the Visual News Stream: A new model for classic gatekeeping theory. Journalism Practice, 9(4), 465-483.

Scott Kuggeleijn rape trial: Alleged victim enjoyed the sex, cricketer tells court. (2017, February 21). New Zealand Herald. Retrieved from: http://www.nzherald.co.nz/nz/news/article.cfm?c_id=1\&objectid=11804670

Shadwell, T. (2014, August 13). Uni's rape advice: wear runners, carry whistle. Stuff. Retrieved March 6 2017, from: http://www.stuff.co.nz/life-style/life/10376703/Unis-rapeadvice-wear-runners-carry-whistle

Shapcott, D. (1988). The Face of the Rapist: Why men rape - the myths exposed. Auckland: Penguin Books.

Shariff, S., \& DeMartini, A. (2015). Defining the Legal Lines: eGirls and Intimate Images. In eGirls, eCitizens (pp. 281-306). University of Ottawa Press: Ottawa.

Singer, J. B. (2016). Transmission Creep: Media effects theories and journalism studies in a digital era. Journalism Studies, 1-18.

Smart, C. (1976). Women, Crime and Criminology: A Feminist Critique. London: Routledge \& Kegan Paul.

Smellie, P. (2016). The Great Media Free-For-All. The New Zealand Listener, 255(3976), 2027.

Soothill, K., \& Grover, C. (1994). Marital rape in the news. The Journal of Forensic Psychiatry, 5(3), 539-549.

Soothill, K. \& Walby, S. (1991). Sex crime in the news. London: Routledge.

Spender, D. (1985). Man Made Language (Second). United Kingdom: Routledge \& Kegan Paul.

Stanko, E. A. (1985). Intimate Intrusions: Women's Experience of Male Violence. London: Routledge \& Kegan Paul.

Stanley, L., \& Wise, S. (1993). Breaking Out Again: Feminist Ontology and Epistemology. London: Routledge.

Steward, I., \& Dennett, K. (2014, October 29). Roast Busters case: no charges to be laid. Stuff. $\begin{array}{llll}\text { Retrieved } & 21 & \text { February } & \text { from: }\end{array}$ http://www.stuff.co.nz/national/crime/10674764/Roast-Busters-case-No-chargesto-be-laid 
Stirling, L. (1987). Language and gender in Australian newspapers. In A. Pauwels (Ed.), Women and language in Australian and New Zealand society (pp. 108-128). Sydney: Australian Professional Publications.

Stroud, N. J., \& de Macedo Higgins, V. (2015). Content analysis. In D. Sloan \& S. Zhou (Eds.), Research methods in communication ( $3^{\text {rd }}$ ed., pp. 123-143). Northport, AL: Vision Press.

Sutherland, G., McCormack, A., Easteal, P., Holland, K., \& Pirkis, J. (2016). Media guidelines for the responsible reporting of violence against women: a review of evidence and issues. Australian Journalism Review, 38(1), 5-17.

Taslitz, A. E. (1999). Rape and the Culture of the Courtroom. New York: New York University Press.

Thakker, J. (2012). Public attitudes to sex offenders in New Zealand. Journal of Sexual Aggression, 18(2), 149-163.

Thakker, J., \& Durrant, R. (2006). News Coverage of Sexual Offending in New Zealand, 2003, 35(1), 28-35.

Tombs, E. A. (2017, March 3). Check Yourself, Wellington City Council. Salient, (1). Retrieved March 7 2017, from: http://salient.org.nz/2017/03/check-yourself-wellington-citycouncil/

Towle, M. (2017, March 13). Photos: Protest against rape culture at Parliament. Retrieved 27 March 2017, from: http://thewireless.co.nz/articles/photos-protest-against-rapeculture-at-parliament

Triggs, S., Mossman, E., Jordan, J., \& Kingi, V. (2009). Responding to Sexual Violence: Attrition in the New Zealand criminal justice system. Wellington, New Zealand: Ministry of Women's Affairs.

Ujevic, D. (2015). (Re)presentations of sexual violence against women: An analysis of media reports of rape (Master's thesis, University of Ottawa, Canada).

Weatherall, A. (2002). Gender, Language and Discourse. East Sussex: Routledge.

Wellington City Council. (2017). Check Yourself. Retrieved 6 March 2017, from: http://wellington.govt.nz/services/community-and-culture/communitysafety/safety-in-wellington/personal-safety/check-yourself

Wellington Rape Crisis. (2014). Information about rape and sexual abuse. Wellington: Wellington Rape Crisis. 
White, D. M. (1950). The 'Gate Keeper': A Case Study in the Selection of News. Journalism \& Mass Communication Quarterly, 27, 383-390.

Willig, C. (2008). Discourse Analysis. In Smith, J. (Ed.), Qualitative Psychology: a practical guide to reseach methods. London: Sage Publications.

Wood, N., \& Dickson, S. (2013). Reporting Sexual Violence in Aotearoa New Zealand (pp. 119). Wellington, New Zealand: Tauiwi caucus of TOAH-NNEST. Retrieved from: http://toah-nnest.org.nz/images/pdfs/ReportingSexualViolence.pdf

Wright Monod, S. (forthcoming). Chapter Four: Media in a Panic. In Making Sense of Moral Panics: A framework for research (pp. 45-64). London: Palgrave Macmillan.

Wright, S. (2016). 'Serious public mischief': Young women, alcohol and the New Zealand press. Continuum: Journal of Media and Cultural Studies, 30(6), 636-645. 